Vet Med

\title{
SF 765
}

$\$ 520$

1907

pt.l 


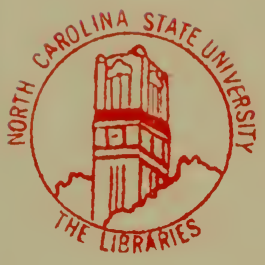







\title{
THE
}

\section{SURGICAL ANATOMY}

\author{
OF THE
}

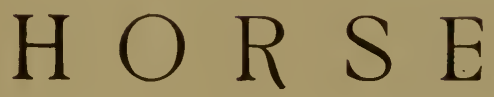

BY

JNO. T. SHARE-JONES, M.R.C.V.S.

LECTIRHK IN CHARGE OF THE DEPARTMENT OF VETHRINARY INITOMY IN

THE INIVERSITY OF I.IVFKPOOL; FORIERLY TVTOR IN SLKGFRY

ANI DHMONSTRATOR OF ANATOMY AT THE ROYAI.

VETERINARY COLLEGE, LONUON, ETC.

WII, BE COMPLETED IN FOTR PARTS

\section{PART I}

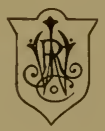

NRW YURK

IILI.I.A.I R. JIXKIXS C().

PLBI,ISHERS

$S_{51-853}$ Sixtil Airil:

1907 

TO

WILLIAM JOHNSTON, ESQUIRE

AND

PROFESSOR RUBERT BOYCE, F.R.S.

WHOSE EFFORTS SO LARGELY CONTRIBUTED

TO MAKING POSSIBLE THE TEACHING OF THE SUBJECT OF VETERINARY ANATOMY

IN A BRITISH UNIVERSITY, THIS WORK IS

HUMBLY DEDICATED BY

THE AUTHOR 



\section{PREFACE}

Some years ago, when Tutor in Surgery, it occurred to the author that, as a rule, students made very little real use of the subject of Anatomy in the diagnosis of surgical affections and in the practice of the surgical art.

Whilst conducting tutorial classes, however, it was elicited that this was by no means due to the students' deficient knowledge of the subject of Anatomy as a whole, but rather to the fact that Anatomy and Surgery were taught quite separately as subjects absolutely independent of one another. This led to a cogitation as to the true value of the subject of Anatomy to the student, with the result that whilst admitting its psychological value as a means of developing the faculty of observation the author is impelled to the conclusion that the subject is primarily and fundamentally utilitarian, and that the teaching of it should always be in association with the subject of Surgery, the necessary emphasis being laid on those parts concerned in the performance of operations. The student is thus from the beginning made aware of the connection which exists between the subjects, his interest is aroused, and he obtains material assistance throughout in the process of mental assimilation.

To endeavour to supply the connecting-link between these two important subjects is the aim of this work, in which are dealt with, therefore, only those parts of Anatomy concerned in the practice of Surgery. The author makes no apology for attempting such a work, for the numerous communications received from members of his profession, bearing on the subject, have led him to conclude that a work of this kind is an urgent necessity.

As a firm believer in the superiority of a pictorial over a verbal 
knowledge of Anatomy, an endeavour has been made to illustrate graphically wherever possible, and to reduce the written matter to a minimum. This, it is hoped, will commend itself alike to students and practitioners as being in accordance with modern methods of instruction, which tend towards economy of time and utility rather than the æsthetic side of specific education.

Indulgence is claimed when digression has occasionally been resorted to, and a little consecutive treatment given where it has been considered that such wnuld add to the utility of the work.

The writings of McFadyean, Chaveau, Möller, Dollar, Macqueen, Hunting, Quain, and others have been frequently consulted, to which the author wishes to express his indebtedness; and for facilities to carry out the necessary research work he begs to thank Vice-Chancellor Dale and the authorities of the University of Liverpool.

His colleagues, Mr. Henry Sumner, M.R.C.V.S., Mr. Stafford Jackson, M.R.C.V.S., and Dr. H. E. Annett, he has also to thank for numerous criticisms and valued suggestions, and also for several specimens for dissection, and lastly, Mr. J. Godber, M.R.C.V.S., for compiling the index and tables of muscles.

The tables of muscles and nerves and the brief synopses of the arteries are inserted as a means of reference only.

In submitting this work to the judgment of his fellow Veterinarians, the author does so fully conscious of its numerous imperfections. Nevertheless, he hopes it may prove to the busy practitioner a handy means of revising the Anatomy of the seats of the common operations, and to the student a ready aid in the application of his anatomical knowledge to the study and practice of Surgery. It is written with the sole object of contributing in a humble manner to the advancement of that profession of which the author is honoured to be a member.

The UnIVERSITY, LiVerpool.

fuly 1906. 


\section{CONTENTS}

\section{PART I-HEAD AND NECK}

CHAP.

I. SUPERFICIAL EXAMINATION

II. HEAD AND NECK IN SECTION

III. THE TEETH .

IV. THE TONGUE, SOFT PALATE, CESOPHAGUS AND SALIVARY

GLANDS . . . . . . . . . . . 45

V. THE LARYNX, TRACHEA AND GUTTURAL POUCHES . . $\quad 6_{3}$

VI. THE BONES-SINUSES OF THE SKULL . . . . . . . 85

VII. THE TEMPERO-MAXILLARY JOINT-THE LIGAMENTUM

NUCHÆ AND THE REGION OF THE ATLAS-POLL-EVIL 108

VIII. THE EYE AND EXTERNAL EAR . . . . . . . . 116

IX. THE SUPERIOR MAXILLARY DIVISION OF THE FIFTH NERVE-THE BLOOD AND LYMPH VESSELS • • . 128

MUSCLES OF THE HEAD AND NECK * * * * * . ${ }^{4} 47$

TABLE OF NERVES OF HEAD AND NECK . . . . . 158 



\section{ILLUSTRATIONS}

\section{COLOURED PLATES}

PLATE

III. Longitudinal Median Section of Head . . . . . . . 10

ViII. Transverse Vertical Section through the Base of the Neck . 22

XiII. Seat of Operation in CEsophagotomy . . . . . . . 50

XIV. Side of Face and Region of Parutid Gland (Superficial Dissection) 56

XVI. Seats of Operation in Tracheotomy . . . . . . . . . . 70

XiX. Longitudinal and Vertical Section, showing Interior of Right Guttural Pouch . . . . . . . . 80

XXXII. A. Seat of Neurectomy of Infra-orbital Nerve. B. Seat of

Operation of Hyovertobrotomy. C. Seat of Operation in Stenson's DUCT . . . . . . . . . . 128

\section{HALF-TONE PLATES}

I. AREA OF PARotid, etc. . . . . . . . . . . 2

II. Entrance to Nasal Chamber . . . . . . . . . . . . 4

IV. Transverse Section taken immediately below Orbits . . . 14

V. Inferior Portions of Frontal and Superior Maxillary Sinuses (viewed from above) . . . . . . . . . . . . 16

VI. Transverse Section across INferior Extremities of Zygomatic RIDGES . . . . . . . . . . 18

VII. Transverse Vertical Section through Atlas . . . . . . 20

IX. Incisor, Molar Teeth, etc. . . . . . . . . . . 26

X. The Roots of the Upper Molar Teeth . . . . . . . $3^{8}$

XI. INferior Maxilla With Roots of MOlars exposed (outer aspect) . 42 
PLATK

Xil. Transverse Section of Tongue.

XV. Longitudinal Section showing Anterior Portions of Nasal and Buccal Cavities . . . . . . . . . . . . 60

XVII. Longttudinal Section showing Left Wall of Larinx and Pharinx 72 XVIII. Transverse Vertical Section through Guttural Polch . $\quad 78$ XX. Floor of Left Guttural Pouch . . . . . . . . . . 82

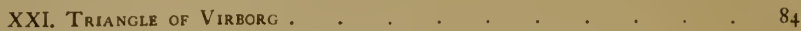
XXII. SKULL OF HORSE (viewed from front) . . . . . . . . . . . . . . 86 XXIII. SKull of HoRse (lateral vietu) . . . . . . . . . . . . . . 92 XXIV. The Facial Sinuses . . . . . . . . . . . . . . . . . 96 XXV. Interior of Facial Sinuses of Left Side . . . . . . . . . 98 XXVI. Trephined Openings into the Facial Sinuses . . . . . 102 XXVII. SEats of Operations on Sinuses of Skull . . . . . . . . 106 XXViII. A. Section of Upper Eyelid. B. Appendages of the Eye * . 116 XXIX. Transverse Vertical Sfiction across Muscles of Eieball . . 118 XXX. Outer Aspect of Orbit, showing Arteries and Muscles * . 120 XXXI. Arteries of External Ear . . . . . . . . . . . 124 XXXIII. A. Intravenous Injection. B. Phlebotomy with Fleams . . 140 


\section{HEAD AND NECK}

\section{CHAPTER I}

\section{SUPERFICIAL EXAMINATION}

ON making such an examination the eye should carefully survey the different areas, noting the most salient features, after which the parts should be manipulated and palpated with the hand. It is impossible to too thoroughly impress the reader with the great importance of such an examination, for it is only by constant practice of this nature that the ability to thoroughly and completely take in a mental picture of an operative area is acquired. Such ability is one of the essentials to the practice of successful surgery, for it enables the operator to anticipate difficulties, to avoid errors, and to perform his operation in a manner which is based upon a rational knowledge of the geography of his surroundings.

At the summit of the head will be seen a transversely elongated elevation, and upon palpation this will be found to be due to a subjacent osseous ridge. This ridge is the occipital or lambdoid crest. Running down from this crest is another crest, which is placed in the middle line, and which is not easily seen on account of the bulging mass of muscle on either side. This latter is the sagittal crest, and the muscle on either side is the temporal. From the inferior extremity of the sagittal crest a divergent ridge will be found on either side to extend obliquely downwards and outwards to the supra-orbital process of the frontal bone. The latter extends across the superior aspect of 
the orbit (of which it forms part of the roof) to meet and articulate with another osseous ridge which extends outwards from the extremity of the occipital crest, and then downwards to meet the supra-orbital process as stated. This process is the zygoma or the squamous temporal bone.

Near the root of the supra-orbital process palpation will reveal the presence of a foramen, also called the supra-orbital, which should be carefully located.

Below the divergent ridges, which are the continuations inferiorly of the sagittal crest, is a large area which narrows as we descend, and which terminates inferiorly in a projection on the middle line above the nostril. Throughout this area we find subcutaneous bone, the frontal bones underlying the skin of the upper part, and the nasal bones underlying the skin of the lower part, and the hard inferior extremity is formed by the peak of the last-mentioned bone. This area will be found to be resonant on percussion, for underneath it lie the frontal sinuses and nasal fossa, and this is the region where the operations of trephining into these chambers are performed. This point should be carefully remembered in connection with the diagnosis of empyema of the facial sinuses, when the resonance of the area over the sinuses is absent on percussion. In its stead we have a dull sound.

Taking a lateral view of the head, in almost the centre of the picture is placed the zygomatic ridge of the superior maxillary bone. This ridge stands out prominently, and is easily seen in the living subject; it terminates abruptly at its inferior extremity, and is continuous superiorly with a ridge on the malar bone, and this latter again with the zygomatic process of the squamous temporal bone. Superiorly placed to the ridge is the elongated elevation which corresponds to the belly of the levator labii superioris proprius muscle and the tendinous fibres of origin of the levator labii superioris alxque nasi. The levator labii superioris proprius muscle should be carefully 


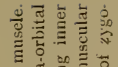

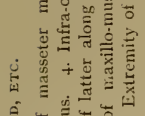

$$
\begin{aligned}
& \text { है }
\end{aligned}
$$

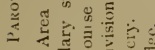

$$
\begin{aligned}
& \text { ப }
\end{aligned}
$$

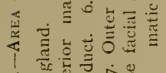

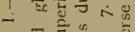

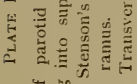

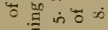

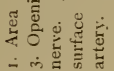

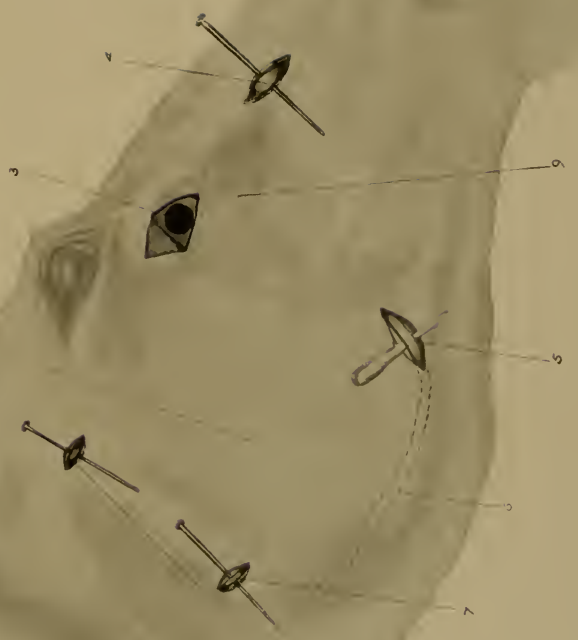



manipulated, since it is concerned in the performance of two operations to be hereafter described.

Below the zygomatic ridge is an almost flat area, the inferior three-fourths of which are found to be covered by muscle. This is the area of the inasseter; and its posterior, inferior, and anterior boundaries are indicated by a continuous curve which extends from immediately below the articular condyle of the inferior maxillary bone, round the angle of this bone, to terminate on the face near the anterior or lower extremity of the zygomatic ridge. The anterior arm of the curve, which runs almost vertically across the face, indicates the border of the masseter muscle, and also the course of Stenson's Duct with its accompanying vessels, the submaxillary artery and vein. As the vessels curve round the inferior border of the lower jaw, the artery is quite superficially placed, and since it rests immediately on the underlying bone, this is a convenient situation for the taking of the pulse.

The only point of surgical importance in connection with the masseteric area is the fact that on the external surface of the muscle there is formed an intricate network of nerves called the pes anserinus. To the formation of this plexus the seventh cranial nerve and the sub-zygomatic branch of the fifth cranial nerve contribute.

Above the zygomatic ridge is an elongated area, which extends from the rim of the orbit above, to the angle of the mouth below. This area is clothed by the thin facial muscles, amongst which ramify the terminal branches of the submaxillary artery and vein and of the infra-orbital branch of the superior maxillary division of the fifth nerve, together with the seventh cranial nerve. Along the line of division between the anterior and middle thirds of this area, but within the nasal chamber, runs the lachrymal duct in the osseous canal on the superior maxillary bone.

In a direct line with the inferior extremity of the zygomatic ridge, and at a distance of two inches in a superior direction from 
it, is placed the superior border of the infra-orbital foramen, which gives passage to the infra-orbital branch of the superior maxillary division of the fifth cranial nerve. The foramen, however, can only with difficulty be felt since it is covered by the levator labii superioris proprius muscle.

By taking the alar cartilage of the nostril between the thumb and index finger of one hand, and the outer lip of the nostril in the other, the interior of the nostril may be exposed. The line of demarcation between the skin and mucous membrane is distinctly seen if the termination of the skin be indicated by the line where the hairs cease to exist. On the floor of the chamber, and placed in the skin a little anteriorly to where the mucous membrane begins, is the inferior opening of the lachrymal duct. It is a small circular opening, and appears as though a small portion of skin had been excised. The false nostril should now be explored by passing the index and medius fingers along the antero-superior aspect of the nasal chamber.

If the tongue be now taken in the left hand and withdrawn from the right side of the cavity of the mouth, and while so held it is gently twisted, the animal will be compelled to keep its mouth open. This will be facilitated by insinuating two or three fingers of the right hand into the left interdental space. A good view of the interior of the mouth is thus obtained.

In the median line the franum lingux is visible, and on either side of it are placed the small elevations termed the barbs. It should be noticed that on the summit of each barb is a small circular aperture. This is the orifice of Wharton's Duct, the excretory duct of the submaxillary salivary gland. The right hand may safely be passed into the buccal cavity, and by such exploration the condition of the molar teeth ascertained.

The above method of dealing with the tongue should be adopted in the administration of a ball, which should be carried with the right 


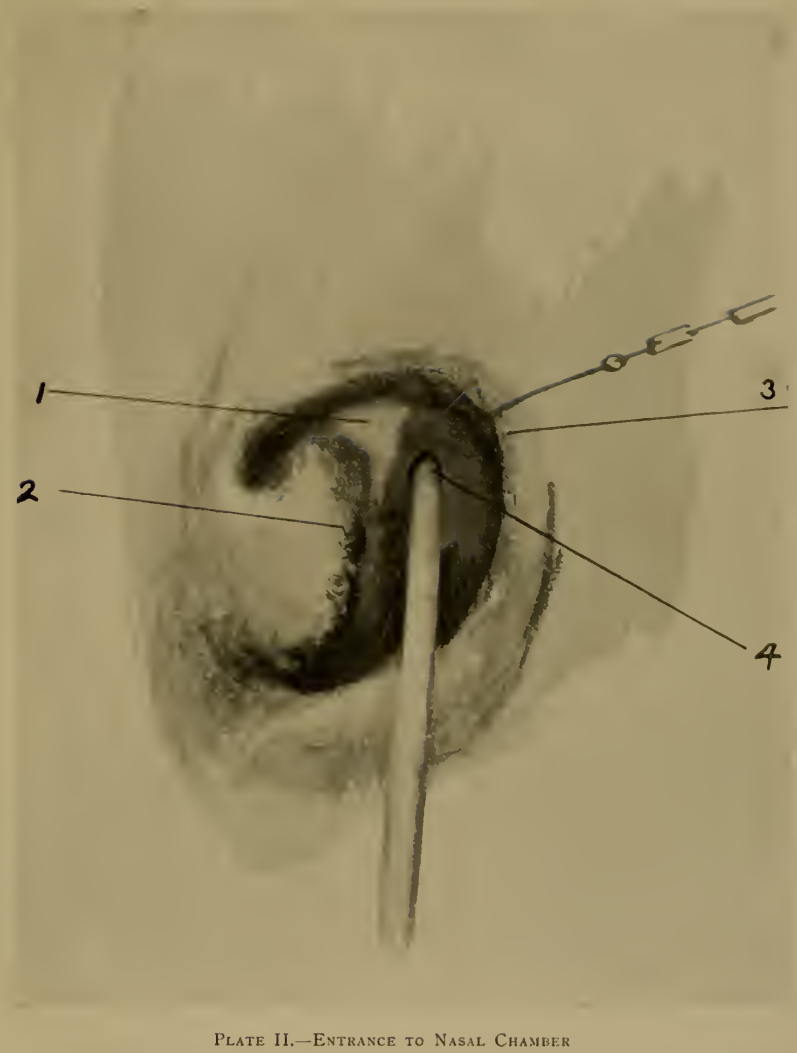

1. Nasal mucous membrane. 2. Inner lip of nostril with alar cartilage. 3. Outer lip of nostril drawn outwards. 4. Orifice of ductus ad nasum. 

hand over the dorsum of the tongue and dropped behind it, withdrawing the right hand simultaneously with the release of the tongue. The latter returns to its normal position, pressing the bolus backwards towards the pharyngeal orifice of the œsophagus, and the animal is stimulated to go through the voluntary act of deglutition.

The inter-maxillary space should now be examined, and the student should make himself quite familiar with the position and external form of the submaxillary lymphatic glands. Passing the hand backwards along the space, we come to the throat, where the cricoid (and in part the thyroid) cartilage of the larynx may be felt. Internal soreness of the larynx may very frequently be diagnosed by the application of slight pressure with the fingers and thumb to this part, and this is the area over which a counter-irritant should be applied in adopting such treatment for inflammatory affections of the larynx or pharynx. It is also the seat of operation for the removal of one of the arytenoid cartilages in the treatment of laryngismus paralyticus or "roaring." Considerable importance should therefore be attached to correctly locating the cartilages.

Attached to the posterior border of the vertical ramus is the parotid gland, the external surface of which is usually quite flat, and is simply covered by the skin, subcutaneous fascia, and the thin parotidoauricularis muscle, so that in affections where the gland is enlarged, there is an external indication in the form of a large convexity of this surface. It is necessary to examine both glands and to compare them one with the other, since some well-bred animals have normally very large parotids, which are somewhat indurated, and in such cases there would be a convexity of the parotid areas without necessarily implying any serious disease of the glands.

The area of the parotid is somewhat four-sided in shape, being bounded above by the root of the external ear, in front by the posterior border of the vertical ramus, behind by the wing of the atlas, and inferiorly by a straight, slightly marked, cord-like elevation of the skin, 
which corresponds to the inferior border of the gland. The anterior extremity of this border indicates the position where Stenson's Duct leaves the gland. The seat of operation in Hyovertobrotomy is in the area described.

The next step in the examination is to carefully locate the position of the temporo-maxillary joint. This may be done by following the posterior border of the vertical ramus upwards until the prominence formed by the external extremity of the condyle of the inferior maxilla is felt. The joint becomes more noticeable if the fingers be inserted in the interdental space, and the animal be thus caused to move the joint.

Curving round the posterior border of the vertical ramus, just below the condyle, is the transverse facial artery, one of the terminal branches of the superficial temporal division of the external carotid. The artery runs forwards, and the pulsation of the vessel may be easily felt. Accompanying this artery we have the seventh cranial nerve, otherwise the facial, together with the sub-zygomatic branch of the inferior maxillary division of the fifth cranial nerve.

At the junction of the middle and lower thirds of this border may be felt, by the application of pressure, the external division of the maxillo-muscular artery, and lower down the angle of the jaw is found to be very prominent in the horse.

The region of the poll should be examined, the seat of that troublesome affection "poll-evil." The anterior and external borders of the wing of the atlas stand out very prominently, and are easily felt in the living animal to form a well-marked curve, the convexity of which is directed downwards and forwards. These two edges are therefore continuous with one another. But the upper surface of the wing is clothed by muscle (the superior and inferior oblique muscles of the head). In ill-nourished animals behind the occipital crest may be felt the anterior extremity of the funicular division of the ligamentum nuchx. In well-nourished animals, however, there is a considerable quantity of fat in this region. 
The outline of the wing of the atlas should be noted with care, since it not infrequently occurs that a small portion of the bone is chipped off, is displaced, and ultimately leads to the formation of a sinus of the poll, i.e., "poll-evil." Familiarity therefore with the normal outline will materially assist in detecting displacement of even a small particle of bone.

The upper part of the lateral aspect of the neck is somewhat flattened, and is made up of muscular layers applied with their flat surfaces directed towards the lamellar portion of ligamentum nuchæ which is placed in the median line. The lower half, however, presents several points of surgical importance. First, the position and direction of the series of cervical vertebræ should be noticed, and it should be observed by comparison with a well-mounted skeleton that a line drawn in the direction of the vertebræ is much more oblique than one drawn in the direction of the middle line of the neck, since the bones run from the antero-superior to near the postero-inferior extremity of the neck. This should be remembered in dealing with cases of fracture of the cervical vertebræ or their processes. The animal should be made to turn its head alternately to the right and left, and this will bring the oblique and transverse processes of the vertebra into greater prominence.

Inferiorly to the thickened portion of the neck which corresponds to the position of the cervical vertebræ we observe a well-marked groove, which extends in the longitudinal direction from the upper extremity of the neck and terminates inferiorly between the shoulder and the front of the chest. This groove is the jugular furrow or channel, and is so named since it lodges the jugular vein. The furrow is bounded superiorly by the inferior border of the mastoido-humeralis muscle, and inferiorly by the upper edge of the sterno-maxillaris. It is of considerable surgical importance, since it is the seat of phlebotomy of the jugular vein, œsophagotomy, and other operations. The course of the jugular vein down the furrow may be made very evident by the application of 
pressure to the groove near the base of the neck. This arrests the flow of blood and causes the vein to become appreciably distended or " raised." The observer should make himself quite accustomed to the act of "raising" the vein, since it is not only necessary to do this in performing the operation of phlebotomy, but also in all cases of examination for soundness. In the latter connection the vein is raised to ascertain whether venesection has been performed on the animal, or to discover whether the vessel is pervious. If venesection has been previously performed there will be a dilatation at some part of the line indicating the course of the "raised" vein. This dilatation indicates the seat where the operation was performed.

The hand should now be passed over the trachea, and the regularity of the tracheal rings noted. Irregularity of this surface in the shape of a depression or prominence may be indicative of the previous performance of the operation of tracheotomy. In this manner also fracture of one or more of the tracheal rings due to accident may be diagnosed. Upon arriving at the upper extremity of the trachea a rounded elevation may be felt which indicates the position of the thyroid body.

The inclination of the asophagus to the left side near the root of the neck may be observed during the passage of a bolus of food along the tube. 


\section{CHAPTER II}

\section{HEAD AND NECK IN SECTION}

A Longitudinal sagittal section of the head is represented in Plate III. The plate was executed from a fresh specimen.

Assuming the head held with its long axis placed horizontally as in the plate, the anterior extremity shows the upper and lower lips in section and also the right middle incisor teeth in the upper and lower jaws respectively, the upper one being carried by the right pre-maxillary bone and the lower by the inferior maxillary bone. The inner surface of the right pre-maxilla is shown and a section through the body of the inferior maxilla. On the inner surface of the first-named bone is an antero-posterior groove, which with a similar groove on the corresponding bone of the opposite side forms the incisor foramen when the two bones come into apposition.

The anterior two-thirds of the section is divided into two parts by the hard and soft palates. The portion above this line of division represents the right nasal chamber, the boundaries of which are seen to be as follows: Superiorly are the frontal and nasal bones, inferiorly the palatine portion of the palatine bone, and the palatine plates of the superior maxillary and pre-maxillary bones-these bones form what is known as the "floor" of the chamber.

Anteriorly the chamber communicates with the exterior by the anterior nares, whilst posteriorly the right lateral mass of the ethmoid bone is seen to project freely into its upper portion, and below this we 
have the posterior nares, placing the nasal chamber and the cavity of the pharynx into direct communication with one another.

The outer wall is formed by the nasal and superior maxillary bones, and the inner wall (which has been removed from the specimen) separates the chamber from that of the left side. This wall is formed by the septum nasi, which for part of its extent is osseous and for the remainder cartilaginous in structure. The posterior part of this partition is formed by the perpendicular plate of the ethmoid and its inferior portion by the vomer, which rests on the line of articulation between the two halves of the hard palate. But much the greater portion of the septum is formed by the septal cartilage, which rests in the cleft of the vomer, and which is attached posteriorly to the anterior extremity of the ethmoidal perpendicular plate.

To the outer wall are attached the superior and inferior turbinated bones. The former is attached to the nasal bone, and is hence frequently referred to as the nasal turbinated bone. The latter is attached to the superior maxillary bone, being therefore referred to as the maxillary turbinated bone.

Above the superior turbinated bone is an elongated narrow space which is placed between this bone and the roof of the chamber. This space is the superior or anterior meatus. Two other somewhat similar spaces will be noticed to run longitudinally along the nasal wall. One of these is placed between the two turbinal bones, and the other between the inferior turbinal bone and the floor of the nasal chamber. These spaces are called the middle meatus and the inferior or posterior meatus respectively.

It should be noted that the communication between the sinuses of the head and the exterior is by way of the middle meatus. The frontal and sphenoidal sinuses communicate with the superior maxillary sinus, and the latter opens into the posterior extremity of the middle meatus by a narrow, curved, slit-like aperture which is not visible in the plate. To bring this opening into the sinus into view, a forcible separation of the 


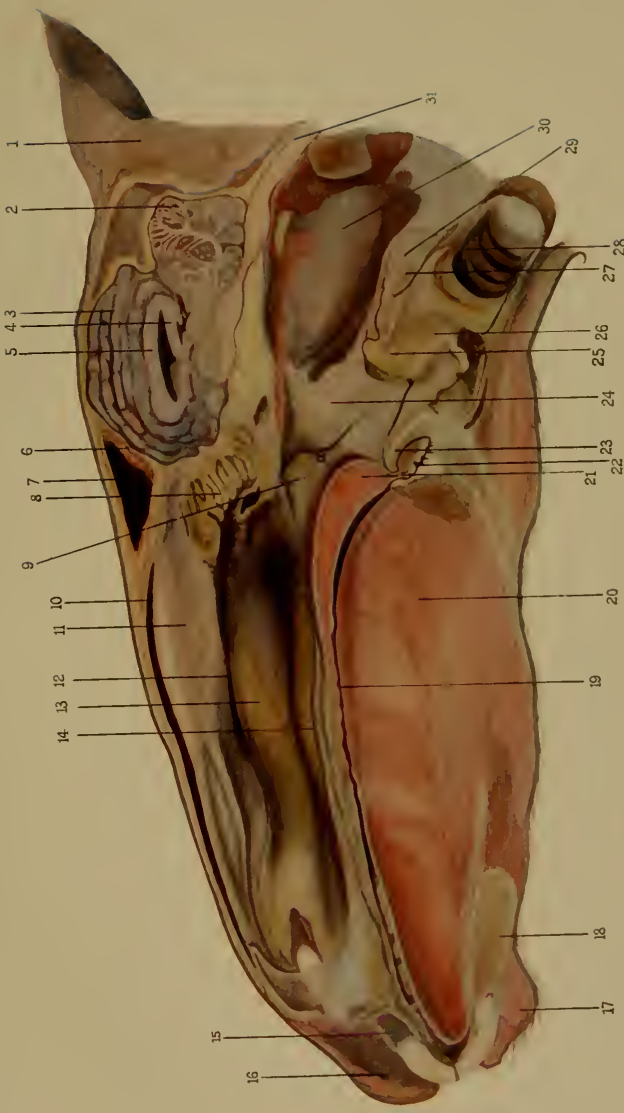

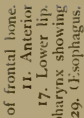

y

대를

플

ํํㄹ 5

ป气

0. 0 ते

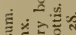

डु

च

㧱苛 包, 边

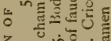
z. ํㅜㅇ

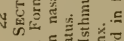
z+口牙 鱼 ए

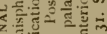
更地

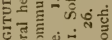

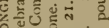
원

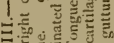

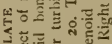
过范 g 造 हैं

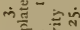
.

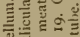
产产的 ษั้ iं $\dot{x}$ है เं है. है 롤ㄹ⿺ㄹ . - 

two turbinated bones near their posterior extremity is necessary, and it will thus be gathered that any surgical attempt to communicate with the sinuses through the nostrils by way of this natural opening would be attended with considerable difficulty.

The Schneiderian Membrane (frequently called the pituitary membrane) is the mucous lining of the nasal chamber. In the posterior fourth of the cavity this membrane is of a slightly yellowish colour. This is the portion to which the olfactory nerve is distributed, and it is therefore the area of the sense of smell. The remainder of the membrane is much more vascular in appearance, and is lined by columnar ciliated epithelium, which is found throughout the air passages generally. In the olfactory portion of the membrane we also find columnar epithelium; but the cells are not ciliated, and between them are placed the peculiar spindle-shaped cells which contain the end organs of the sense of smell.

The filaments of the olfactory nerve enter the nasal chamber through the perforations in the cribriform plate of the ethmoid bone. These perforations thus form in the mascerated and dry skull a communication between the cranial and nasal cavities.

Below the palate is the cavity of the mouth. The examination of the roof of this chamber will reveal the presence of a number of curved parallel ridges. The concavity of the curves is directed backwards, and as we proceed in the posterior direction the ridges approximate more closely to one another. Two sets of ridges will be noticed, one on either side a median raphe, from which the ridges curve outwards. In the plate, therefore, only the sections of the extremities of the series of ridges covering the right half of the palate are represented.

Running along the palate, one on either side and placed underneath the ridges which have just been described, and near their outer extremities, we have the palatine arteries. Each of these vessels is the continuation of the internal maxillary artery of the same side. It commences where the latter splits up in the maxillary hiatus, and the 
division of the internal maxillary artery which we are now considering takes its course through the palatine canal, which it leaves at the inferior palatine foramen. It then courses along the palatine groove, and at the level of the corner incisor tooth it curves inwards towards the median line, and meets and inosculates with the corresponding vessel of the opposite side. The vessel which results from this inosculation passes forwards through the incisor foramen to supply the upper lip.

It is important to note the position of these vessels, since the palatine artery is not infrequently injured. Such injury might be due to accident whilst performing the operation of scarification in the treatment of lampas, or to the presence of sharp foreign bodies, such as bits of glass in the food, etc. But whatever the cause, hamorrhage is more easily arrested if the artery is completely cut through, since the longitudinal fibres in the arterial wall withdraw the severed end of the vessel into the surrounding tissues, and the latter being here quite tense they exert considerable pressure on the wall of the vessel, with the result that the lumen of the latter is thus closed. If the artery is only partially severed it is therefore best to complete the section. If the hæmorrhage should not be effectively arrested by this method, more pressure should be placed upon the vessel by plugging the mouth and bandaging round the upper and lower jaws to keep the mouth closed.

The chamber of the mouth when closed is almost wholly taken up in accommodating the tongue. The superior surface of this organ is quite free, and so is the inferior surface for from four to five inches from the tip, when the mucous membrane of the inferior aspect of the tongue passes on to the floor of the mouth, forming the fold called the frænum linguæ. On either side of the frænum is seen the papilla, which is called the barb.

The tongue itself gradually increases in thickness from its tip backwards for about three-quarters of its length, and then during its posterior fourth its thickness decreases.

Hanging behind the backwardly descending portion of the tongue 
we have the pendulous palate. From the position of the pendulous palate and its relation to the epiglottis, it will be seen that, excepting during the act of deglutition, the buccal cavity is effectively shut off from that of the pharynx, thus rendering the process of respiring through the mouth a most difficult one in the horse.

Passing backwards from the inferior part of the nasal chamber we have the right division of the posterior nares. It places the inferior meatus into direct communication with the pharynx, and excepting during deglutition, it is quite patent. A reference to the plate will show that a curved line with the concavity downwards would indicate the contiuuity of this meatus with the rima glottidis through the pharynx.

While the act of deglutition is being carried out, however, there is a marked alteration in the relationship of the structures of this region to one another. The dorsum of the tongue is arched by the stylo-glossi muscles, and the soft palate is raised and stretched by the levator and tensor palati muscles. Thus the opening of the posterior nares is shut off and the dorsum of the tongue is rendered an inclined plane down which the bolus of food passes until it is grasped by the constrictor muscles of the pharynx. The genio-hyoid, the anterior belly of the digastricus, and the mylo-hyoid muscles cause the whole larynx to rise, the epiglottis is drawn downwards and the rima glottidis is closed, so that the plane formed by the dorsum of the tongue is now in a straight line with the cosophageal opening from the pharynx, the line having a slight inclination downwards and backwards.

It is of most urgent importance to note the relationship to one another of the various structures of this region, and from what has been said the advisability of allowing the animal to voluntarily perform the act of deglutition during the passage of the probang, or the administration of a bolus, etc. is apparent.

In the same plate the right outer wall of the membranous vestibule, the pharynx, is shown. This chamber is regularly cylindrical in form, 
with the axis of the cylinder directed upwards and forwards from the opening of the glottis inferiorly to the posterior nares superiorly.

Near the nasal entrance to the pharynx is the curved slit-like aperture, which represents the inferior opening of the right eustachian tube. The opening is protected by a valve-like plate of cartilaginous structure, the free edge of which is directed towards the nasal chamber. This opening places the pharynx into communication with the right middle ear, and also with the right guttural pouch, and its position should be carefully noted inasmuch as one of the methods adopted for the removal of purulent matter from the pouch is by way of the eustachian tube. The aperture is large enough to accommodate the little finger without much difficulty.

On the floor of the pharynx we have the opening of the glottis. This is a gaping orifice placed in the centre of the floor. It is bounded in front by the epiglottis, which is seen in section, and which projects forwards and upwards into the pharynx, towards which its convex surface is directed, its concave surface being opposed to the pendulous palate. Behind the opening we have the arytenoid cartilages, the inner surface of the right cartilage being represented in the plate. The cut edges of the cricoid and thyroid cartilages are shown, and the right side of the interior of the larynx. Very faintly marked we see the upper free border of the right vocal cord, and posteroinferiorly the interior of the beginning of the trachea.

In front of the aperture of the glottis and at a slightly lower level we have the isthmus of the fauces, by which the pharynx communicates with the mouth; but this aperture is practically closed by the pendulous palate, which extends in a posterior direction right down to the base of the epiglottis.

Behind the rima glottidis and at a slightly higher level is the entrance to the asophagus, and this again, excepting during the passage of food, is practically closed.

The posterior wall of the pharynx presents two bulgings. These are 


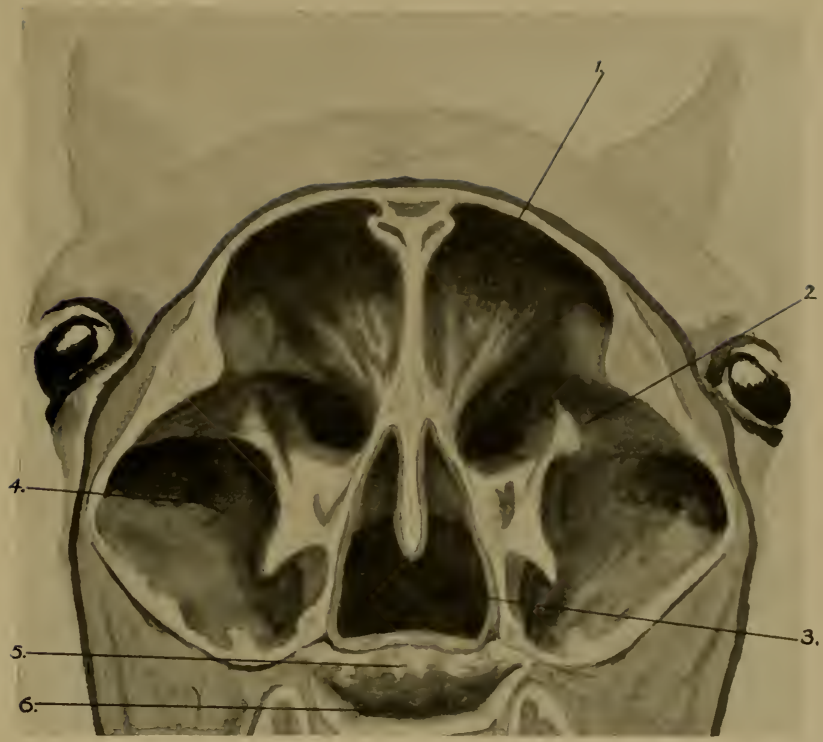

Plate IV.-Transverse Section taken immediateily helow Orbits

I. Frontal sinus. 2. Communication between frontal and superior maxillary sinuses. 3. Posterior nares. +. Superior maxillary sinus, 5. Soft palate. 6. Isthmus of the fauces. 

placed one on either side of the middle line above the entrance to the asophagus. These bulgings are caused by the pressure on the pharyngeal wall, of the anterior diverticula of the guttural pouches. The inner wall of one of the pouches, namely, the right, is distinctly shown in the plate, since in this case the operator whilst making the section was fortunate enough to strike the median line, and so preserved the walls of the pouches intact. It will be observed that the pouch is elongated from before backwards, and that it also presents a posterior diverticulum which extends downwards, ${ }^{\circ}$ backwards and outwards towards the angle of the inferior maxillary bone.

Above the pharynx part of the perpendicular plate of the ethmoid bone is visible, as are also some of the ethmoidal cells, which are attached to the anterior aspect of the horizontal or cribriform plate of the ethmoid. At a still higher level the opening of the right frontal sinus is placed. The septum between the two sinuses was present after the section was made, but has been removed in order that the interior of the sinus may be brought into view.

Running downwards and forwards (in the ordinary position of the head downwards and backwards) from the body of the frontal bone, we have the reflected plate of that bone which bounds the frontal sinus, and which is articulated inferiorly to the horizontal plate of the ethmoid. This reflected plate is the partition which separates the frontal sinus from the cranial cavity, and it forms a very acute angle with the body of the bone to which it is attached, the apex of the angle being directed upwards, and thus it is that the frontal sinus ascends some distance above and in front of the lower boundary of the cranial cavity.

The inner aspect of the right cerebral hemisphere is observed since the falx cerebri has been removed, while the corpus callosum which united the two hemispheres is seen to have been cut through. Extending downwards and forwards from the posterior extremity of the corpus callosum is the fornix.

Posteriorly in the cranial cavity we notice a section through the 
medulla oblongata, which is easily recognised at a glance by the arborisation of the white matter in this part of the brain. Running inwardly between the cerebrum and the medulla oblongata is the ossific tentorium. This is the bracket-like piece of bone which dips into the cranial cavity from the deep aspect of the interparietal bone. It gives attachment to the tentorium cerebelli and the falx cerebri, the former being the process of the dura mater which projects downwards and forwards, and separates the cerebral and cerebellar divisions of the brain. Its inferior border arches over the crura cerebri. The latter is the process of the dura mater which separates the two cerebral hemispheres. It is attached superiorly to the parietal and frontal sutures and anteriorly to the crista galli process of the ethmoid. Along its superior border runs the superior longitudinal venous sinus, whilst along its inferior boundary, which bridges over the corpus callosum, is placed the inferior longitudinal sinus.

Above the guttural pouch the anterior straight muscles of the head run to their insertion into the tubercles on the inferior aspect of the base of the cranium at the junction between the body of the occipital bone and that of the post-sphenoid.

The rod-like base of the cranium is cut through longitudinally, and is represented in section. Near the anterior extremity of this base is seen part of the sphenoidal sinus, the visible part being that hollowed out of the right anterior half of the body of the pre-sphenoid. Projecting into the cranial cavity from its anterior extremity is the crista galli process of the ethmoid, the superior portion of which is that part giving attachment to the falx cerebri, and in the dried skull this part may be seen on looking through the foramen magnum as a sharp edge separating the two olfactory fossæ.

The inferior portion of the crista galli process is articulated to the plate-like piece of bone projecting from the anterior end of the body of the pre-sphenoid, and which is called the rostrum. 


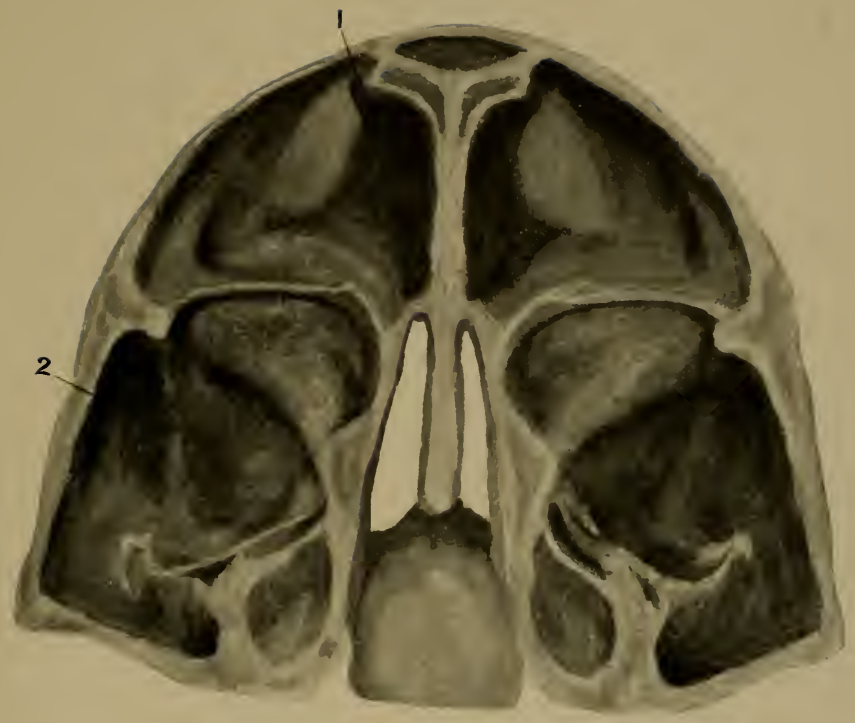

Plate V.-Inferior Portions of Frontal and Supfrior Maxillary Sinuses (Vicwed from abovi)

I. Frontal sinus. 2. Superior maxillary sinus. 



\section{Transverse Sections}

Plate IV. (facing page 14 ) represents the section across the head immediately in front of or below the orbits. A reference to it will show the intercommunication which exists between the frontal and superior maxillary sinuses, and also between the two divisions of the last-named sinus over the osseous ridges which project into the spaces.

The outline of the opening of the posterior nares is here somewhat triangular, and the isthmus of the fauces is elongated in its transverse direction, being very narrow from above to below. The section passes through the inferior maxillary bone behind the last molar tooth, and near the angle of the jaw.

The appearance presented by the lower part of the sinuses as looked at from above is given in Plate V. (facing page $\mathrm{I} 6$ ).

A very interesting section is that represented in Plate VI. (facing page I8), which is taken immediately at the anterior extremity of the zygomatic ridge of the superior maxillary bone. This section passes through the inferior maxillary sinus a little anterior to the mid-point between its superior (or posterior) and inferior (or anterior) extremities, and the interior of each sinus is visible from the front or below. Looking into it we see the plate of bone which separates the two divisions of each sinus. The inferior maxillary sinus here approaches the quadrilateral in outline, and the nasal chambers are completely separated from one another by the septum nasi, which is accommodated inferiorly in the cleft formed by the vomer bone.

In the nasal chamber are the two turbinated bones, the anterior or superior of which is seen arising from its attachment to the nasal bone, whilst the posterior or inferior turbinated bone arises from the nasal aspect of the superior maxillary bone on a level with the middle of the inferior maxillary sinus.

A vertical transverse section through the left guttural pouch is 
represented in Plate XVIII. Inside the pouch are seen elevations caused by the styloid cornu of the hyoid bone, and also by the eustachian tube. On the outer side of the pouch is placed the occipito-styloid muscle, the inner surface of which is covered by the membranous wall of the pouch. The thickness of the muscle is evident, as also is its relation to the superposed parotid gland.

The probe is passed through the counter opening made in Hyovertobrotomy for the purpose of draining the pouch, and it enters the pouch at its posterior diverticulum, which, when the pouch is distended with purulent or other inflammatory products, becomes pressed towards the angle of the inferior maxillary bone.

In Plate VII. (facing page 20) we have a representation of a vertical transverse section of the neck taken through the posterior third of the atlas. A reference to this plate is of utility in studying the seat of "poll-evil." Immediately under the skin is a considerable quantity of adipose tissue, in which is embedded the funicular division of the ligamentum nuchæ.

Below the ligament is a considerable mass of muscular tissue made up chiefly of the rectus capitis posticus major and minor muscles. The depth of muscular tissue is here about two inches, whilst clothing the lateral aspect of the atlas we have a layer of muscular tissue which is about equal in thickness to that placed on the superior aspect of the bone, and which is made up chiefly of the obliquus capitis inferioris muscle.

It will thus be seen that the structures usually involved in a sinus of the poll are fatty, ligamentous, muscular and possibly osseous tissue, and it will also be noticed that in an average sized animal where the opening is at the highest point of the neck, the depth to which the sinus may be probed in the vertical direction for operative purposes without any danger of piercing an intervertebral joint is at least two inches, and this depth increases as we proceed in a posterior direction down the neck.

The atlas is cut through near its posterior extrenity, so that the posterior foramen in the wing is represented by a notch, the posterior 


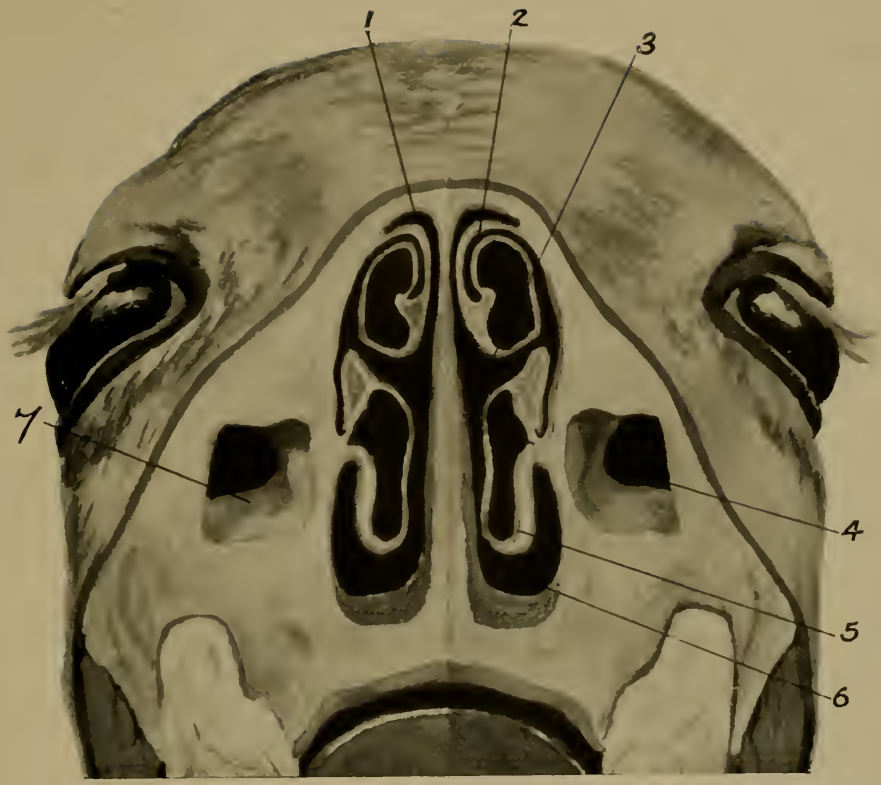

Plate Vi.-Transverse Section across INferior Extremities of Zygonatic Ridges

I. Anterior meatus. 2. Anterior turbinated bone, 3. Middle meatus. 4. Inferior maxillary sinus. 5. Posterior turbinated bone. 6. Posterior meatus. 7. Ridge between the two divisions of the inferior maxillary sinus. 

boundary of the foramen having been removed. In the notch is placed the retrograde or anastomotic branch of the occipital artery, which after passing through the foramen inosculates with the terminal branch of the vertebral artery. Inferiorly to the atlas are the prevertebral muscles (the rectus capitis anticus and the longus colli) which separate the bone from the superior surface of the asophagus. The latter is here quite in the median line, and superposed to the trachea, and the corrugated appearance of its lining membrane is quite evident.

Externally to the esophagus is the carotid artery, on the superior aspect of which is placed the common nervous trunk formed by the pneumogastric nerve and the cervical cord of the sympathetic. Inferiorly and here slightiy to the inner side of the artery is the inferior (recurrent) laryngeal branch of the pneumogastric.

The jugular vein is placed about half an inch externally to the carotid artery, for this is the situation where the vein is approaching the artery after having pierced the parotid gland, and coursed along its outer surface near its postero-inferior angle.

The superior surface of the trachea is flattened, and in outline the lumen of the tube approaches the elliptical.

On the inferior surface of the trachea the sterno-thyro-hyoideus, and the subscapulo-hyoideus, or pre-tracheal muscles, are situate, and they will be observed to form quite a thin broad sheet.

Plate VIII. (facing page 22 ) represents a transverse vertical section taken across the base of the neck. The section passes through the seventh cervical vertebra, which is seen almost in the centre of the plate, and which is readily recognised by the height of its superior spinous process.

Extending upwards from the tip of the process are the two sheet-like or lamellar portions of the ligamentum nuchæ. These are closely applied to one another, and their width (i.e., the distance from the funicular portion to the vertebral column) is very much greater than near the upper extremity of the neck. Above the lamellar portion of 
the ligament is the funicular division, and superposed to this again is a quantity of fatty tissue which is interposed between the ligament and the skin.

Lying on the articular processes of the vertebra are the semispinales muscles, one on either side, and in section these somewhat approach the quadrangular. On the superior face of this muscle, and running in the triangular space which is bounded by it inferiorly, the ligamentum nuchæ inwardly, and the lower border of the complexus superiorly, is the superior cervical artery with its accompanying vein.

Above the vertebra there are four muscles with their flat surfaces directed towards the ligamentum nuchæ, and in section therefore they appear very much elongated. That next the ligament is the complexus, and it is much the most bulky of these muscles. It occupies practically the whole of the space between the semispinales muscles and the funicular portion of the ligament. Externally to the complexus is the splenius, the outline of which in section appears irregular on account of the muscle being much thicker in its upper than in its lower portion. Between the upper or thicker portion and the skin is the cervical division of the trapezius muscle, which spreads out in the form of a very thin sheet upwardly from this muscle over the outer surface of the cervical portion of the rhomboideus muscle. The latter appears as a thick band, which is wedged in between the trapezius outwardly, and the funicular portion of the nuchæ with the upper edges of the complexus and splenius muscles inwardly. The trachelo-mastoid muscle is situate above the semispinales and between the inferior borders of the complexus and splenius.

In the downward direction the trapezius spreads over the upper portion of the outer aspect of the levator anguli scapulæ. This muscle is related inwardly to the lower portion of the outer aspect of the splenius, to the intertransversales muscles of the neck, and to the upper edge of the scalenus muscle, whilst outwardly it is related towards its inferior portion to the superior part of the mastoido-humeralis. 


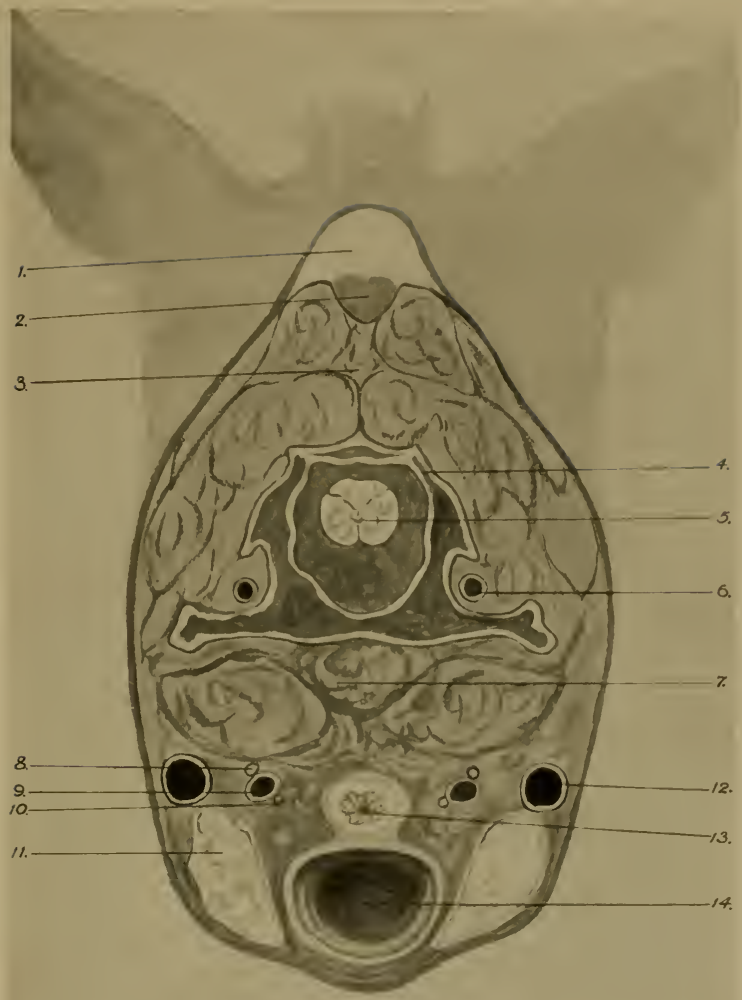

Plate Vil.-Transverse Vertical Section throvgh atlas

1. Adipose tissue. 2. Ligamentum nucha. 3. Muscles above atlas, 4. Arch of atlas. 5. Spinal cord. 6. Retrograde branch of occipital artery. 7. Pre-vertebral muscles. 8. Vagus nerve. 9. Carotid artery. 10. Recurrent laryngeal nerve. 11. Submaxillary gland. 12. Jugular vein. 13. Esophagus. 14. Trachea. 

On the outer aspect of the levator anguli scapulæ is the spinal accessory nerve, which is cut through as it is ascending from the deep face of the mastoido-humeralis (along which it has descended the neck) to the trapezius muscle where the nerve terminates.

The vertebral artery is severed as it passes forwards to run across the inferior aspect of the transverse process of this particular vertebra, and in this connection it may be mentioned that this transverse process is not pierced by a vertebral foramen. Accompanying the artery is the vertebral vein, whilst covering the artery and vein is the scalenus muscle, which spreads out inferiorly over the longus colli and œ6ophagus on the left side, whilst on the right side it touches the trachea. Outwardly this muscle is related from above downwards to the inferior border of the levator anguli scapulx, to the thin strap-like subscapulo-hyoideus muscle, and below this to the mastoido-humeralis. On the inferior border of the subscapulo-hyoideus is placed the inferior cervical artery, which is related inwardly to the scalenus and outwardly to the mastoido-humeralis.

The longus colli muscle is represented by a thick band which runs along the inferior aspect of the vertebral centra. In this part of the neck it is related inferiorly to the trachea, and on the left side to the æesophagus also, but as we ascend the neck, as has been already stated, the asophagus ascends to the upper aspect of the trachea and insinuates itself between the muscle and the windpipe.

It is important to note the position of the asophagus in this section, in connection with the performance of the operation of asophagotomy. To reach the œsophagus from the exterior, it will be seen that it is necessary to incise the skin and panniculus slightly above the ridge indicated by the raised jugular vein. The fingers should then be passed over the vein, breaking down the loose connective tissue. By raising the thin inferior border of the scalenus muscle, which spreads over the asophagus, the latter is exposed. 
Under the longus colli is the trachea, inferiorly to which are the sterno-thyro-hyoideus, sterno-maxillaris and panniculus muscles. The last-named muscle leaves the outer aspect of the sterno-maxillaris, and spreads upwards over the jugular vein.

Wedged in between the vein and the trachea at this point is the carotid artery, which is at a slightly higher level than the vein. On the superior aspect of the artery is the vagus nerve, which on the left side is related superiorly to the asophagus, and on the right to the inferior border of the scalenus muscle.

On the inferior aspect of the carotid, and between it and the sterno-thyro-hyoideus muscle is the recurrent laryngeal branch of the vagus. 


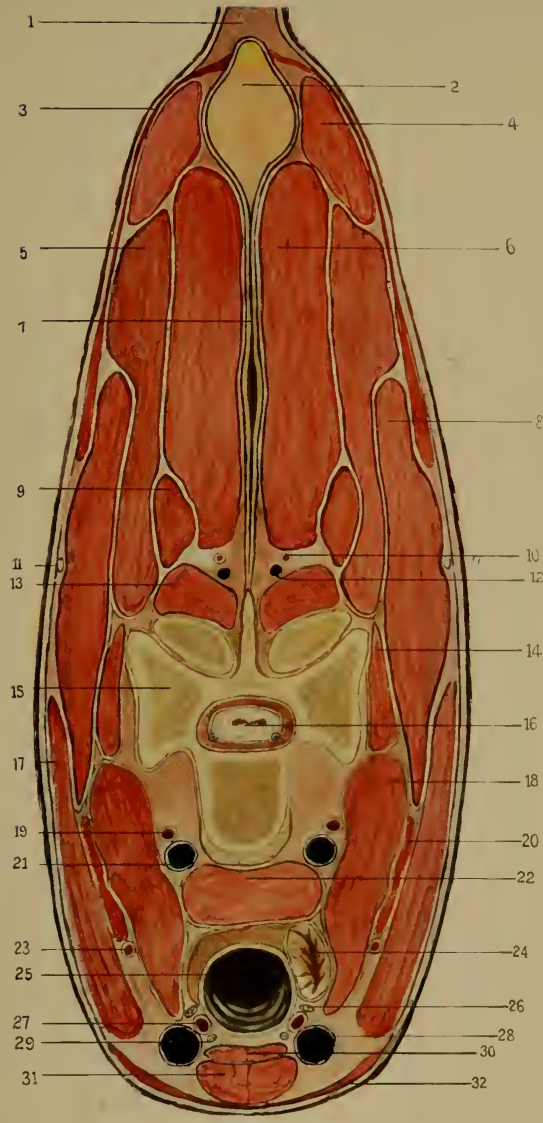

Plate IIII.-Transverse

Vertical Section

THROUGH BASE OF NECK

(VIEIED FROM FRONT).

I. Fatty tissue.

2. Funieular divisuon of ligamentum nuchae.

3. Trapezius musele.

4. Rhomboideus muscle,

5. Splenius.

6. Complexus.

7. Lamellar division of ligamentum nuchae.

8. Levator anguli scapule.

9. Trachelo-mastordeus.

10. Superior cervical artery.

II. Spinal accessury nerve.

12. Superior cervical vein.

13. Semispinalis muscle.

14. Intertransversales colli.

15. Seventh cervical vertelora.

16. Spinal cord.

17. Mastoido-humeralis.

18. Scalenus.

19. Vertebral artery.

20. Subscapulo-hyoideus muscle.

21. Vertelural vein.

22. Longus colli.

23. Inferior cervical artery.

24. Esophagus.

25. Trachea.

26. I'neumogastric nerve.

27. Carotid artery.

28. Jugular vein.

29. Inferior laryngeal (recurrent) nerve.

30. Sterno-thyro-hyoideii muscles.

31. Sterno-maxillaris.

32. Panniculus. 


\section{CHAPTER III}

\section{THE TEETH}

\section{Structure of the Teeth}

A тоотн is made up of two parts, one of which is firmly implanted in the socket or fossa, technically called the alveolus, in the bone which carries the tooth. This part is called the root. The other portion is exposed and its base is surrounded by the gum. The surface of this portion, which is subjected to wear on account of the friction during mastication, is called the table of the crown. The constricted portion of the tooth which separates these two parts is the neck.

The extremity of the fang shows a small perforation opening into a cavity which extends for some distance up the middle of the tooth. This is the pulp cavity, and into it a small protoplasmic mass extends from which the tooth obtains its nutrient supply. This mass is the dental pulp, and it contains minute blood-vessels and nerves. The table of the crown being the part subjected to wear, undergoes considerable variations in form and appearance.

Three substances essentially enter in the composition of all teeth, namely, dentine, enamel, and cement.

The dentine is the yellowish-white, bone-like material which makes up the greater part of the tooth, and surrounds the pulp cavity. Microscopically it presents a number of wavy tubules, which radiate outwardly from the cavity. Each tubule is surrounded near the cavity by a delicate layer of hardened material, and into the tubule passes a fine 
prolongation of the protoplasmic contents of the central excavation. The tubules are too small to admit blood-vessels or nerves. Chemically, dentine is composed of 28 per cent. organic matter, the remainder being inorganic. The latter is made up principally of phosphate of calcium.

The enamel is the shiny white layer which extends over the exposed portion of tooth, and which is seated upon the underlying dentine. At the tables of some teeth, the enamel dips into the tooth to a varying depth. It is destitute of blood-vessels, and is made up of a peculiarly arranged series of prisms. Its inorganic constituents make up 96.5 per cent. of the whole, and it is the densest structure in the body.

The cement is simply connective tissue converted into bone and it is spread over parts of the exterior of the tooth. It differs from true bone inasmuch as its lacunæ have no definite arrangement, but seem to be scattered indiscriminately, and moreover, they are much fewer in number.

\section{Development of Teeth}

The first stage in the development of a tooth is the appearance in a groove in one of the maxillary bones of a little closed sac, which is called the dental follicle. The membranous wall of the follicle encloses a papilla which is at a later stage termed the dental pulp, and from which the dentine is secreted. The enamel is developed from a special layer of epithelium which covers the upper aspect of the pulp, and which is called the enamel organ. As the dentine is formed from the superficial cells of the pulp it becomes deposited between the latter and the follicular wall.

From the superficial cells the tubular processes of the dentine are thrown out, but the inter-tubular substance is secreted by the deeper layer of cells. This latter substance contains the earthy salts.

The cells which form the enamel are at first cylindrical in shape, but they become transformed into the prisms of which the enamel is made up as already stated, and the enamel thus becomes deposited as a layer covering the dentine. 
The wall of the dental cavity or sac ultimately becomes the periosteum of the tooth, developed from its deep layer after the manner of bone formation, and deposited on the enamel or dentine.

The next step is the rupture of the outer wall of the follicle, and when the tooth becomes sufficiently hardened by the deposition of salts in the different layers, the pressure from below caused by the increase in size of the fangs, assisted by the pressure from without by the frequent application of the upper and lower gums to one another, causes the eruption of the tooth.

The walls of the alveoli are completed by the ossification of the septa which originally separated the follicles from one another. Although the tooth may now be able to carry out its functions, growth continues, new layers of dentine being constantly deposited on the old layers from the dental pulp, with the result that the pulp cavity and also the pulp gradually diminish in size and ultimately disappear.

For a more detailed account of the development of the teeth, a text-book on Embryology should be consulted.

\section{Temporary and Permanent Teeth}

Two sets of teeth are developed, namely, temporary or milk teeth, and permanent or persistent teeth.

In each jaw of the adult male there are developed twelve molars, six incisors, two canines, and occasionally one or two of the socalled wolf's teeth. In the temporary dentition, however, there are six incisors and only six molars-the first three on either side. A peculiar feature in connection with the teeth is that as the table of the tooth becomes worn out by friction, the alveolar cavity becomes gradually filled up, so that the tooth becomes slowly pushed out from its socket. This goes on throughout life, and thus we have, at successive periods of the animal's existence, at first the crown, next the neck, and lastly the fang actually in wear. Although in an aged animal the incisors appear to be very long owing to the increase in length of their visible portion, 
the actual length of the tooth has diminished on account of the diminution in length of the tang.

The maximum length is attained when the animal is about five years old.

\section{The INCISORS}

These are in three pairs, termed respectively the centrals, middles, and corners. They are named incisors because they are adapted for cutting. Each is made up of a crown, which is compressed from before to behind, and a fang, the upper portion of which is somewhat threesided. A little lower down the fang becomes circular, whilst near the apex it is in the form of an ellipse, the long axis of which lies in an antero-posterior direction. These differences in shape of the tooth at various situations are used as an indication of the age of the animal, since the outline of the free wearing surface will vary according to the part of the tooth which is in use.

The table of the crown presents a marked depression called the infundibulum. This was formerly used as an indication of the animal's age, since its disappearance from the tooth was supposed to occur constantly at definite periods during the life of the animal. This theory is negatived by the fact that considerable variations are met with in the depth of the cavity.

The enamel covers the exposed portion of the incisor and also in part the fang. It also dips into and lines the infundibulum. Thus when the table has been slightly worn two rings of enamel are visible on its surface, namely, an outer ring by which the whole surface is surrounded, and an inner ring surrounding the infundibulum.

The cement is deposited in a layer, which presents considerable variations in thickness, over the enamel.

\section{Distinction between Temporary and Permanent Incisors}

Temporary teeth are much smaller and whiter. They possess a welldefined neck, the anterior aspect of the crown presents a faint striation, 

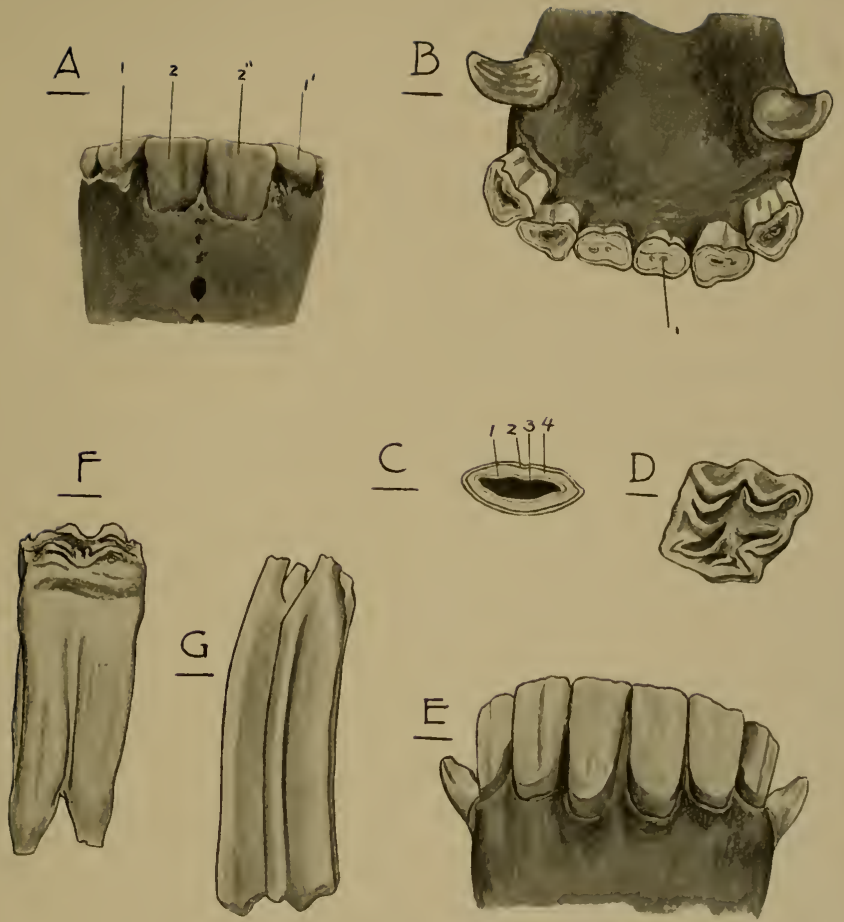

Plate IX.

A. Incisors of lower jaw at three years; 1,1 ', Temporary incisors; 2, 2", Permanent incisors. $B$. Tables of incisors of aged horse showing dental star $\mathrm{I} . \quad C$. Table of young permanent incisor; 1 , Inner ring of enamel; 2, Outer ring of enamel; 3, Infundibulum; 4, Dentine. D. Table of molar tooth showing arrangement of enamel ridges. $E$. Anterior surfaces of aged incisors (lower jaw). F. Molar of lower jaw (outer aspect). G. Molar of upper jaw (outer aspect). 

and the infundibulum is present at first, but it is very shallow and consequently soon disappears as the tooth is worn.

Permanent teeth, on the other hand, are much larger, and on the anterior surface of the crown there is present a well-marked vertical groove. The tooth tapers gradually from the crown to the fang, so that there is no well-defined constriction or neck. The infundibulum is wide and deep, and surrounded by a fairly thick layer of enamel.

\section{The Molars}

In the permanent dentition there are twelve of these in each jaw, six on either side. The two rows in the superior maxillary bones are more widely separated from one another than are those in the inferior maxilla. Moreover, the tabular surfaces of the former are directed obliquely downwards and outwards, whilst those of the latter take an oblique direction, which is upwards and inwards. The inner edge of the lower molars is therefore higher than the outer, and the outer edge of the upper molars extends to a much lower level than the inner edge.

Each molar presents a free exposed portion and a portion concealed in the alveolus.

The molars of the upper jaw are all fixed in alveoli, which are situate in the superior maxillary bones. The free portion of each of these molars presents four surfaces and an inclined base which represents the table. The surfaces are almost equal to one another in breadth, so that a transverse section of the tooth would be approximately square in outline.

The outer surface shows two parallel and longitudinal grooves, which are continued on to the concealed portion of the tooth, and of which the anterior is much the deeper. The inner surface presents only one such groove, which is very shallow, but which also runs longitudinally.

A transverse section of one of the lower molars would be oblong in outline, as the outer and inner surfaces are much broader than the 
remaining ones; moreover, these teeth are easily distinguished from those of the upper jaw, inasmuch as they present only one longitudinal groove on their outer aspect, and that is faintly marked.

The number of fangs varies. Each of the end molars in both jaws possesses three fangs, whilst the remaining molars in the superior maxilla possess four, and those in the inferior maxillary bones only two fangs. These fangs are only formed when the remainder of the tooth is completely developed, and the filling up of the alveolus has commenced, the crown being in wear.

In the unworn tooth, the table presents a very undulated appearance, but the outer layer of enamel covers everywhere the underlying dentine, and lines the two fossx or infundibula, which extend to a considerable depth into the tooth. As the tooth becomes worn therefore an external ring of enamel is present, enclosing the internal rings. Owing to the irregularity in outline of the tooth these rings are likewise very irregular. The enamel, being the densest of the three substances of which the tooth is composed, wears much more slowly than the dentine and cement, with the result that the rings of enamel stand out prominently above the cement and dentine as thin, hard, irregular ridges. The arrangement of the rings is thus easily noted, and it has been very aptly compared with the Gothic "B" with a small appendage.

In the teeth of the lower jaw no dentine is visible between the inner portion of the outer ring of enamel, and the corresponding portions of the rings of the infundibula, since these layers towards the inner side of the tooth are continuous with one another.

The roots of some of the molars project into the maxillary sinuses, where they are covered by a thin layer of bone. This is an important surgical point, which will be referred to later in describing the removal of diseased molars.

Four teeth are frequently present which are placed one in front of each first molar. These are the so-called wolf's teeth. Each is developed in the same dental groove as the corresponding row of molars, 
and is probably due to the displacement of a supernumerary dental germ in the groove. Their exposed portion presents considerable variation in shape. Usually they are somewhat tubercular, but occasionally one is observed with a crown which resembles in shape that of a small molar.

\section{Canine Teeth}

There are four of these, two in each jaw, and they are frequently referred to as tusks or fangs. They are characteristic of the male, but in rare and exceptional cases they are met with in the female.

The tusks of the upper jaw are much more posteriorly placed than are those of the lower. In the former the alveoli are situate immediately in front of the projecting anterior extremity of the superior maxilla, whilst those in the inferior maxilla are found almost immediately behind the alveoli for the corner incisors. The outer surface of the exposed part of the tusk is convex transversely, and presents a faint longitudinal striation. This surface is separated from the inner by two well-defined edges. The inner surface presents a small rounded elevation, and on either side of this, and separating it from the edges, is a slight depression or groove. The fang of the tusk is curved, and presents a large pulp cavity, which, as in the case of the incisors, becomes filled up as the animal advances in years. But the exposed portion presents no infundibulum, and does not change its appearance except that it becomes more yellowish in colour. That this is the only change is due to the fact that the teeth, owing to the difference in position in the two jaws, do not come into apposition with one another. There is, therefore, no friction, and in consequence no change in the teeth due to wear of their exposed surfaces. The canine teeth are not replaceable.

The Teeth as an Evidence of Age

Although the time of eruption of the teeth is subject to considerable variation, depending upon the habits and uses of the animal, the nature 
of the food, etc., the examination of the teeth remains nevertheless up to a certain period of life one of the most potent methods we possess of determining the age. The times given below are of course only approximate, but they may be reasonably accepted as being the most constant.

When the horse is one year old all the temporary incisors are present, and each jaw also carries six temporary molars, three on either side. In addition a fourth molar is found, which has made its appearance through the gum, but is not so well developed as the remaining three. This is the first permanent molar.

At two years old the animal's mouth presents some little difficulty. The incisors are showing signs of wear. The cup-like cavities on their tables have disappeared, and the tables themselves are flat, and present a faint striation. It is most important to be on one's guard in distinguishing between these and permanent incisors. At this age the molars form the better guide, for an additional permanent molar has made its appearance, so that we now have five present, three of which are temporary and two permanent.

The middle temporary incisors are cast, and the first pair of permanent incisors burst through the gums at two years and six montlis.

When the horse attains the age of three the first and second (in position counting from the front but numbers three and four in age) permanent molars cut through the gums, pushing before them the first and second temporary teeth beneath which they have developed. These, of course, are not yet the height of numbers four and five. The supplementary molars or wolf's teeth are most frequently cast simultaneously with the shedding of these two temporary molars. The first pair of permanent incisors are now well up, and their tables are level with those of the adjacent teeth.

The second pair of permanent incisors (the laterals) appear through the gums at three years and six months, and their tables are on a level with those of the first permanent pair when the horse attains the age of four. 
At four years and six months the corner permanent incisors are cut, and when these teeth are well up, and the inner and outer edges of their tables are level, the horse is five years old.

The last two permanent molars (numbers three and six in position) in each jaw are cut between the ages of four and five.

At six the corner incisors are exhibiting evidence of wear. The infundibula of the two middle incisors may have entirely disappeared. This disappearance was formerly looked upon as constant at this age, but for the reasons before stated such is not the case, and some trace of them is frequently found to remain, although the depressions are much more shallow than are those in the lateral or corner incisors. At this age also a new feature presents itself on the tabular surface of the central incisors in the form of a blackish or brownish line which runs transversely between the disappearing infundibulum and the anterior edge of the tooth. This is the first appearance of what is known as the dental star, and it indicates the fact that so much of the tooth has been worn away as to bring the upper extremity of the pulp cavity filled with dentine into appearance on the table.

A similar change occurs in the infundibula of the lateral incisors at the age of seven, the infundibula being either missing or much more shallow, and at this age the dental star appears in these teeth. The first appearance of the dental star is not noticeable excepting under careful observation. When the horse is seven years old it is much better marked in the central incisors, and at eight there should be no difficulty in seeing it.

Its position also seems to change between the years of six and eight. At first it is, as already stated, quite close to the anterior edge of the tooth, but as the animal advances in age the star recedes from the edge and approaches nearer the centre of the table.

From the age of eight onwards very little definite evidence can be obtained, but still certain further changes occur which assist in arriving at an approximate estimate. 
When the incisors are young they stand upright in the alveoli, but as the age advances, the long axis of the exposed portion of the tooth forms a progressively increasing angle with an imaginary line drawn longitudinally through the middle of the horizontal ramus. Thus at the age of ten the angle formed at six is slightly increased. At fifteen the increase is very perceptible, whilst at twenty the two imaginary lines are almost in a straight line with one another.

Again, at the age of ten the crown of the tooth is still in wear. From this age, until the age of twenty, the central portion is being worn, whilst after twenty the fang on!y is utilised. The outline of the upper surface of the exposed portion also varies, therefore, according to that portion of the tooth which is actually in wear.

The foregoing remarks apply chiefly to the teeth of the inferior maxilla. The infundibula are later in disappearing from the incisors of the upper jaw, the old theory (which, however, does not hold for reasons already stated) being that they disappeared in the upper jaw from the centrals at nine, the laterals at ten, and the corners at eleven.

It is particularly important to study well the outline of the table, since the change in outline would be definite evidence of an old tooth in cases where the infundibula are unusually deep, and the appearance of which consequently persists.

\section{"Bishopped" TEeth}

This is the term which is applied to old teeth upon which artificial marks have been made to imitate those found normally on young teeth. The marks are supposed to imitate those of the infundibula. First a little excavation is made with a sharp tool, which excavation is supposed to represent the cavity of the infundibulum. The depth of this cavity is then coloured by means of a hot, pointed iron, and occasionally intensity is given to the colour by the application of nitrate of silver.

When teeth are suspected of having been "bishopped," the observer 
should look carefully for the central rings of enamel, which, it will be remembered, surround the infundibular cavity. However artistically the imitation of the infundibular depression may have been carried out, there is no known artifice by which even an expert can effectively replace the ring of enamel which has disappeared through friction.

Another device to give an old tooth a youthful appearance is to shorten the crown and then bishop. In cases of "bishopped" and "trimmed" teeth, evidence of the use of the rasp or file may frequently be found if carefully sought for in the form of roughened markings on the enamelled surface of the tooth.

\section{IrREgUlar Edges of Molars}

One of the most common forms of irregularity is found in connection with the edges of the molars, the outer edge of the upper row and the inner edge of the lower being the edges affected.

It was a common belief that serious injuries to the buccal wall were frequent results of such irregularities, but the consensus of opinion at present is opposed to this view, and is inclined to the belief that wounding by irregular molars is extremely rare.

An animal with such teeth, however, does not feed well, and for this reason it is advisable that a level edge should be obtained by means of the rasp.

\section{Overgrown Teeth}

It frequently happens that one or more molars or incisors appear to be much longer than the remaining teeth. This is due to the fact that the visible portion of the tooth is much longer. The length of the whole tooth is not greater than that of those around it, but it appears longer on account of its having been pushed a little further out of its socket.

The increased length of the exposed portion may be due to the absence of the opposing tooth either through accident or extraction. 
This is most frequently the cause, although in some cases the alveolus may fill up and the tooth be pushed out from its socket more quickly than the remaining teeth. In the natural course the filling up of the several alveoli proceeds at a uniform rate.

It is usual in such cases to give the row of teeth an even bearing by clipping off the overgrown part. For this purpose an instrument called a "tooth-shears" is used. It will be evident that the further in the mouth the affected tooth is placed, the more difficult does the operation become. In fact, when further back than the third molar, the operation is one which presents considerable difficulty.

\section{Shear Mouth}

This is the term which is applied to the condition wherein there is such irregularity in the wear of the teeth, that the tabular surfaces present a very much exaggerated degree of inclination. The outer edge of the upper molars continues to grow to such an extent that it frequently injures the gums of the lower jaw. Similarly the inner edge of the lower row may reach and lacerate the palate.

In addition to the liability to injury of the parts named, there is marked want of ability to effectively masticate the food.

The condition depends to a great extent upon the conformation of the lower jaw, those cases in which the two rami approximate too closely to one another being specially predisposed to the affection.

Occasionally only one or two teeth are affected, but usually the condition affects all the molars. In the latter cases very little can be done, especially if the cases are advanced. In those cases where the condition is limited to one or two teeth, excision of the faulty tooth or teeth by means of a tooth-shears is practised. The tooth-shears is a very heavy instrument, and care must be taken whilst using it not to split the remaining portion of the tooth, or to fracture the edge of the alveolus. 
Good results sometimes follow also the removal of the sharp edge by means of the rasp.

\section{Step Mouth}

When the height of neighbouring teeth varies suddenly, a long and a short tooth alternating with one another, the condition is what is known as "step mouth."

This condition may be due to extraction, or loss of the opposing teeth, but when these are present it is usually attributed to a variation in the degree of hardness of the teeth, the softer ones being worn away much the more quickly, and hence the variation in length.

Treatment of such cases depends considerably upon the extent of the condition. When many teeth are affected very little can be done, but if limited to two or three teeth the extremities of the long teeth may be removed with the tooth-shears.

In all the foregoing cases soft food is indicated, since the work to be performed by the molars is thus considerably diminished.

\section{Split Tooth}

The splitting of a tooth is frequently the source of much trouble. Particles of food material become insinuated in the fissure or fissures so formed, which irritate the lining membrane of the alveolus, and set up periostitis.

The exact cause of the injury is unknown, but it is probably due to the presence of hard and resistant substances in the food, such as pieces of stone, or iron, and the tooth is split by the animal's endeavours to crush them.

The symptom which presents itself is that the animal "quids" its food and on this account the veterinary surgeon is consulted. At first sight nothing appears to be wrong with the teeth, but more careful examination will reveal the presence of a crack or fissure.

In such cases the only treatment is extraction. It usually happens 
that when the forceps are applied to the tooth, one part of the latter gives way and may easily be extracted.

After the removal of the tooth the alveolus should be plugged, otherwise an irregularity will arise in the subsequent overgrowth of the corresponding molar in the opposed row.

\section{Alveolar Fistula}

As its name implies, this is a sinus, one of the openings of which conducts into an alveolus. The external opening of the fistula is usually on the outer side, between the molars and the cheek. In the lower jaw it may be placed anywhere along the outer surface of the anterior half or may be two-thirds of the horizontal ramus.

The tubular cavity may extend in any direction from the alveolus with which it is connected. Thus the external opening may be placed some distance anteriorly or posteriorly to the affected alveolus, or it may be placed directly opposite to it.

Again, in this affection the horse is usually brought to the veterinary surgeon on account of inability to masticate the food and " quidding."

To ascertain the whereabouts of the opening of the fistula the fingers should be passed along the outer side of the teeth, the palmar aspect being directed towards the gums. Occasionally the fistula is situate between two teeth.

The fistulix of alveoli in the lower jaw are not so difficult to diagnose, since in these cases there is generally a wound which is visible on the exterior.

Regarding the treatment in such cases a probe should be passed through the external opening of the fistula, and by careful manipulation of this instrument the direction of the cavity ascertained. Continuing the examination still further in this manner we are enabled to detect the particular alveolus from which the fistula originates. In this connection an important point to be remembered is that the tooth itself may be 
perfectly sound, the diseased condition being confined to the alveolus.

The fistula should be then injected with antiseptics, and in all cases it is advisable to extract the tooth.

\section{Dental Caries}

This is the name given to the necrotic process which leads to the destruction of the teeth. The dentine and cement are the parts which are the most quickly destroyed, the enamel remaining comparatively intact. The disease is not by any means common in the horse, and some observers even go so far as to state that it does not occur at all in this animal. Such, however, is not the case. The disease is very commonly met with in dogs. According to Kitt, "the caries, as observed in the teeth of animals, is of the dry and chronic kind."

With regard to the exact seat and origin of the disease, there is considerable difference of opinion. Some observers maintain that it commences in the dentine, whilst others are equaliy definite in their assertions that the cement substance is the part of the tooth which forms the starting-point of the disease. But this is not a matter which greatly concerns us here, since it will suffice for our purposes to know that whether the disease actually commences in the dentine or the cement, both become quickly affected, and the subsequent progress of the disease is gradual.

Caries of the tables of the molars is very rare. The part which is most commonly affected is the interdental surface. It is supposed that as the teeth are thrust out from the alveoli, the interdental spaces gradually increase in size. The gums shrink slightly, and particles of food material make their way into the spaces between the teeth, where they become permanently fixed.

The decay of the teeth is generally attributed to the decomposition of this food material, which has thus become insinuated between them. Caries of the interdental surface extends very slowly, so that 
it takes a considerable time to extend through the substance of the crown and attack the pulp.

It will be easily seen that the above theory of the origin of the disease is not applicable in those cases where the disease is confined to the tables of the teeth; and as yet no adequate explanation of the origin in such cases has been forthcoming. Contrary to what has been said regarding the progress of the disease affecting the interdental surfaces, when the tabular surfaces are attacked the disease extends rapidly.

Caries of the fang is extremely rare. When this disease exists in the fangs of the upper molars there is generally an indication on the exterior of the facial region. There may be a chronic and offensive discharge from the nostrils. The bones covering the teeth project, and the affection is said to lead to empyema of the facial sinuses.

In commencing cases of caries the treatment consists in scraping the affected area, very thoroughly disinfecting, and subsequently stopping the cavity which has thus been scraped out. For this purpose dental instruments used in human practice should be employed. In advanced cases the affected teeth should be extracted.

\section{Removal of Molar Teeth}

As already stated teeth are extracted when they are split, or when their crowns or fangs are diseased.

It will be gathered from our brief description of the development that, especially in the case of molar teeth, extraction presents much less difficulty in old animals than in young, on account of the tooth being pushed out of the socket nearer and nearer the surface of the gum by the filling up of the alveolus. In fact, in very old animals the teeth have been pushed up so far out of the alveoli, that they stand quite loosely as shells embedded in the gums, and may frequently be removed with the fingers without difficulty. In young animals the 


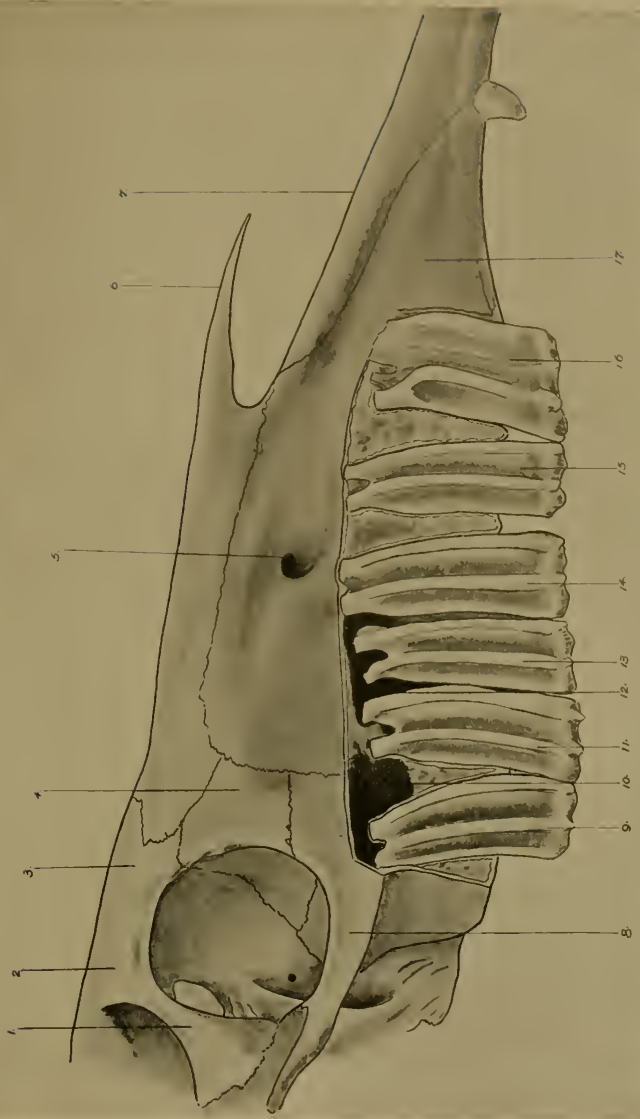

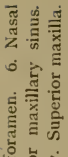

홍

를

ड़े जี

혼

$\subseteq$.

的至葛

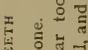

$H \doteq$

쟁

은

先的

跑 +5

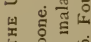

$+\stackrel{\circ}{\circ}$

岁 焉

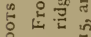

\& $\dot{2}$

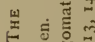

更

$\therefore$ त

出 $\frac{2}{2}$

至

럴

를 을

$\overrightarrow{\vec{r}}$ :

त

is

हुँ

한

푤

능

¿됴

芯壳

क范 

case is far different, and the operation of extraction is classified amongst the most difficult with which we have to contend.

There are two recognised methods of removing molars, namely, by extraction, with specially constructed forceps, and repulsion, or punching the tooth out of its alveolus by means of a mallet and small punch.

\section{Extraction By Forceps}

Owing to the amount of force which is necessary, the forceps employed are very strong and weighty, which renders great care necessary in their use. Some operators even use a fulcrum, and the tooth is removed by a process of leverage.

The animal should be cast, and a mouth gag inserted. If the tooth is loose in the socket, it is not necessary to anæsthetise. The tongue should be taken by an assistant, and withdrawn from the side of the mouth opposite to that where the diseased tooth is placed. The operator should then pass his left hand into the mouth between the upper and lower rows of molars, the palmar aspect of the fingers being directed towards the tables of the teeth of the row which contains the tooth to be removed. Having passed the diseased tooth he should rest the tips of his fingers on the table of the tooth behind it.

The open forceps should now be taken in the right hand, and passed along the row of teeth. It will be guided on to the proper tooth by the fingers of the left hand. The left hand is then withdrawn from the mouth, and the handles of the forceps should be grasped tightly with both hands.

It should now be the object of the operator to loosen the tooth in the alveolus by endeavouring to rotate it to and fro on its long axis. If a fulcrum is used, it should be laid on the surface of the second molar next the opening of the mouth counting from the diseased tooth. The handles of the forceps are now pressed towards 
the incisors of the same jaw, and if sufficient care has been taken in rotating the tooth, extraction is easy.

\section{Repulsion of TEeTH}

A second method of removal is by punching out the tooth, and is termed "repulsion." This method is adopted in the removal of fangs where the crowns have broken away, or in the removal of teeth where the presence of odontomata, etc., renders extraction by forceps unusually difficult.

In connection with the removal of molar teeth by this method a careful study of the direction which the root of each tooth takes is necessary. The root of the last molar in the upper jaw when the skull is considered with its long axis disposed horizontally, projects in a direction which is much more obliquely upwards and backwards than is the case with the roots of the remaining molars.

This root forms a projection, the inner aspect of which is entirely in the outer compartment of the superior maxillary sinus, where it is covered by a thin osseous plate.

The root of the fifth molar forms inwardly an elevation which is only in part visible in this sinus. The remainder of this root, together with the elevation formed inwardly by the whole of the root of the fourth molar and also part of that formed by the root of the third molar, is visible in the outer compartment of the inferior maxillary sinus.

It is evident, therefore, that to be able to apply a punch to the root of the sixth or fifth molars, the operation of trephining into the superior maxillary sinus should be performed. In this case the seat adopted should not be that which is selected when the object is to drain the sinus, because the object is not, as in the latter case, to make the opening as near as possible to the septum separating the superior and inferior maxillary sinuses, but to arrive at a seat which will be immediately over the extremity of the root of the molar which it is desired to remove.

The root of the sixth molar runs upwards and backwards to within 
half an inch of the rim of the orbit, and a like distance above or in front of the zygomatic ridge. If a spot be selected which is .75 of an inch above the ridge, and equidistant from the orbital rim, and this spot be taken as the centre of the opening to be trephined, when this part of the operation is completed a punch may readily be applied over the root of the sixth molar. The trephined opening is thus entirely in the malar bone. The root however is not exposed, since it is covered by the thin osseous plate to which reference has already been made. This plate should be removed with the mallet and chisel, removing only a small portion at a time, but completing the operation so that the whole of the root is free.

The operator himself should have one hand in the mouth and applied to the crown of the affected tooth, or if the crown be absent, the hand should be placed near the alveolus. With the other hand the punch is held in position. A mallet or hammer is then taken by an assistant and two or three hard, sharp taps given to the punch. Particular care must be taken to hold the punch with its long axis in a direct line with that of the tooth. The tooth is thus driven into the mouth, and is seized and removed by the hand of the operator which is in that cavity.

When the desired effect is not attained by this method, the tooth is frequently split by means of a chisel, and the fragments carefully removed.

Care must be taken, in making the cutaneous incision, not to injure the orbital branch of the superior dental artery. This branch is given off by the superior dental near the maxillary hiatus, and before the latter vessel enters the superior dental canal. It creeps over the outer part of the floor of the orbit to reach the face, down which it runs quite close to the seat of operation, to anastomose with the terminal branch of the angular division of the submaxillary artery. If when the flap of skin has been reflected the artery is visible, it may easily be pushed forwards clear of the operating area. 
Whilst working in the sinus, it will be observed that we are also in close proximity to the osseous superior dental canal, and this should be avoided, particularly during the use of the chisel, otherwise injury to the important structures running though the canal, which include the sensory superior dental portion of the superior maxillary division of the fifth nerve, is a very liable complication.

The root of the fifth upper molar takes a direction which more nearly approaches the vertical than does that of the sixth. In this case the centre of the trephine is fixed at a point which is 1.25 inch anteriorly to that selected in the previous case, and an inch above or in front of the zygomatic ridge.

The root of the fourth upper molar, as already mentioned, forms a prominence which is entirely in the inferior maxillary sinus, and the piece of bone removed is similar to that removed for the evacuation of the contents of the sinus. (See Facial Sinuses.)

The anterior limit of the inferior maxillary sinus would be indicated by a vertical line dirawn three-quarters of an inch in front of the extremity of the zygomatic ridge. Now the root of the third molar is indicated by an elevation which for the greater part is visible in this sinus.

If therefore the centre of the trephined opening be taken at a point which is half an inch in front of the extremity of the ridge, and 1.5 inch above it, the opening will lie over the extremity of the root. The openings in this and the next case are of great importance in order that we may keep clear of the infra-orbital nerve, where it appears on the face through the foramen of the same name.

The circular opening for the removal of the second molar should be an inch further forwards, but in line with that made in the removal of the third, whilst that for the first molar should, on account of the great antero-posterior dimension of this tooth, and the compartively short root which it possesses, be made one inch and a half anteriorly to that for the second molar, and half an inch nearer the tables of the teeth. 


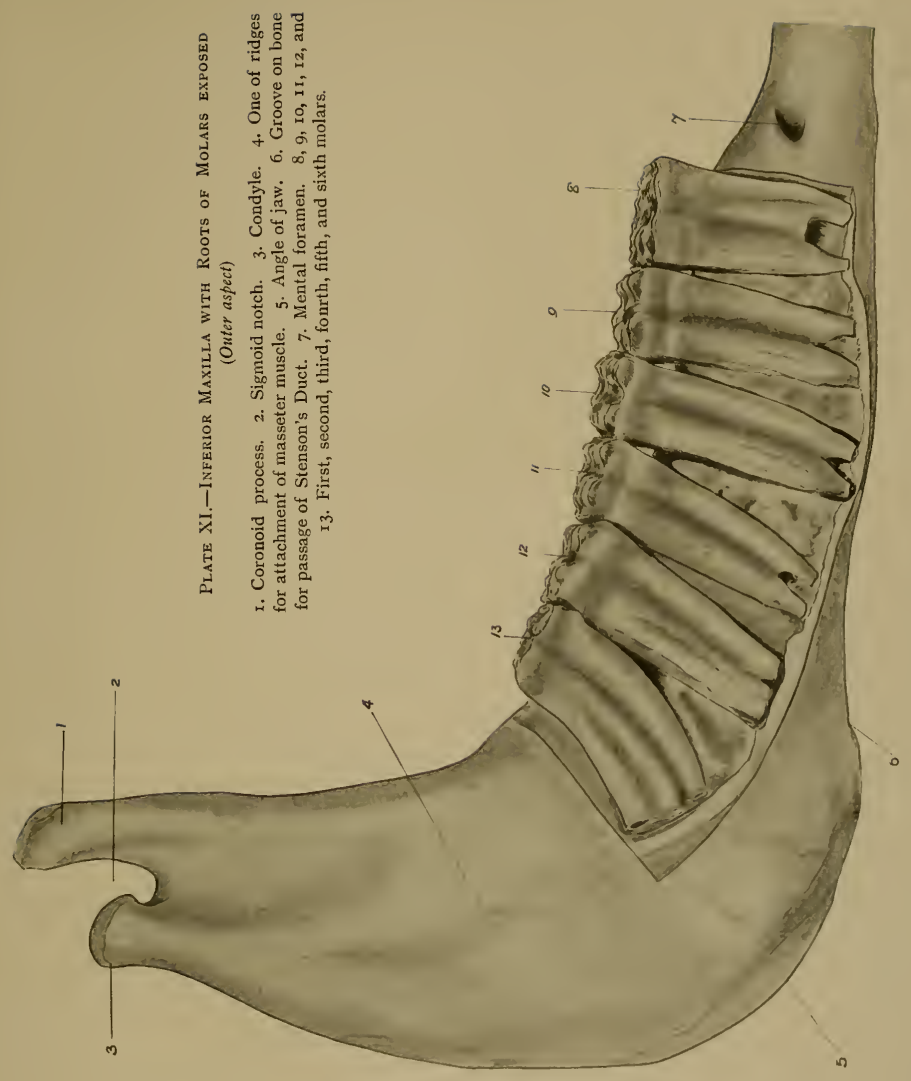



In trephining for the removal of the second molar the operator must be on his guard against injuring the angular artery and vein. These are frequently of considerable size, and they pass slightly behind and below the seat of operation indicated.

With regard to the amount of muscular tissue to be removed or incised, the operations on the sixth and fifth molars present no difficulty, since we have in the former case only the thin aponeurotic origin of the levator labii superioris alæque nasi muscle. In the latter case we have the upper extremity of the levator labii superioris proprius. This extremity is very thin, and consequently in the two cases mentioned very little hæmorrhage from muscle need be expected. But in dealing with the third and fourth molars, the levator labii superioris proprius is much thicker. It is, however, easily displaced in the forward direction, and this is a method of procedure which is to be preferred to the making of an incision through the muscle.

The areas for operation on the first and second molars are covered by the muscular portion of the levator labii superioris alæque nasi. This muscle is spread out over the seats, and moreover is not easily displaced on account of its extensive aponeurotic attachment to the bones. It must therefore be incised. The operation is carried out with a minimum amount of hæmorrhage, if, after the flap of skin has been reflected, the incision in the muscle is made downwards and forwards, taking the direction in which the muscle fibres run.

Plate XI. represents the direction taken by the roots of the molars of the lower jaw. As in the case of the corresponding tooth in the upper jaw, the root of the sixth molar projects obliquely backwards, and of course in this case downwards. The seat of operation is situate two inches upwards and forwards from the most prominent point of the angle of the inferior maxilla.

It will be remembered from our superficial examination of this part that this area is clothed by the masseter muscle. This muscle has 
therefore to be incised. After the reflection of the cutaneous flap, twigs from the pes anserinus which ramify on the outer aspect of the muscle, are to be avoided whilst making the deeper incision.

The centre of the trephine should be brought one inch and a halr further forwards and half an inch downwards in operating on the fifth lower molar, and in this case also it is necessary to make an incision in the masseter muscle.

The operation on the fourth molar probably presents much the greatest difficulty. The seat in this case is one inch forwards and a quarter of an inch downwards from that in the previous case. We are here in close proximity to the submaxillary artery and vein, and the accompanying duct of the parotid gland. To keep clear of these the pulsation of the artery is felt, and remembering that the artery is the most anterior of these structures we know that in operating well in front of the artery we are clear of the vein and duct.

But at a point which is usually about half an inch above our seat, the submaxillary artery gives off its inferior labial branch, which, in this position of the head, runs forwards and to a slight extent obliquely upwards, to pass beneath the depressor labii inferioris muscle. This vessel is easily avoided if our measurement be carefully taken from the inferior border of the lower jaw, from which the distance to the seat of operation is one inch and a quarter. Regarding the first three molars of the lower jaw little difficulty is experienced in this respect since the seat of operation in each case is placed about three-quarters of an inch above the edge of the inferior maxilla, and a distance of one inch and a half separates the centre of the trephined opening from that of the root of the adjacent tooth.

The foregoing measurements were taken from the skull of a fiveyear-old animal, fifteen hands high. From this age onwards, the seat of operation will approach progressively nearer the alveolar edges of the maxillary bones. 


\section{CHAPTER IV}

\section{THE TONGUE, SOFT PALATE, CESOPHAGUS AND SALIVARY GLANDS}

\section{THE TONGUE}

THE tongue rests in a kind of sling formed by the two mylo-hyoid muscles, which are attached to the deep faces of the horizontal rami and meet one another in a median fibrous raphe.

In the horse the tongue is in shape somewhat like a three-sided pyramid. Its posterior or fixed portion is attached by muscles to the hyoid and inferior maxillary bones, and these muscles also enter into the formation of the tongue itself.

The whole of the tongue is invested by a continuation of the mucous membrane of the mouth, and if the free portion of the organ be raised. the frænum linguæ will be visible in the median line. This is simply a folding of the buccal mucous membrane as it passes on to the tongue. Similar folds are found where the membrane passes from the root of the tongue on to the soft palate, and these folds constitute what are known as the anterior pillars of the fauces.

The small conical filiform papillæ are found to be scattered over the tongue. The fungiform papillæ are placed along the dorsum and sides, whilst the circumvallate papilla, of which there may be two or three, are found on the dorsum. These last-named papillæ have flattened summits, and each is surrounded by a well-defined furrow, in which are placed the gustatory bodies or end organs of taste. These bodies derive 
their nerve-supply from the glosso-pharyngeal nerve. Gustarory bodies are also present on the organs of Mayer or the papillx foliatx. There are two of these, one on either side, and they are placed immediately in front of the anterior pillars of the fauces. They are elliptical in shape and the long axis of the ellipse measures about half an inch.

The structure of the tongue is best studied from a transverse section, a representation of which is given in Plate XII.

Such a section reveals the fact that the tongue is mainly made up of muscular tissue. A median septum divides the organ into two symmetrical halves. Closely applied to the upper three-fourths of this septum is a large flat muscle, which is the genio-hyo-glossus, and below this the septum has applied to it the genio-hyoid muscle. Externally to the genio-hyo-glossus is a small muscle termed the middle hyo-glossus, and this is covered by a large muscle to which the name great hyoglossus is given.

All the foregoing structures are encased laterally and inferiorly by the mylo-hyoid muscle, and superiorly by the continuation on to the organ of the mucous membrane of the mouth.

\section{Amputation of the Tongue}

In the operation of amputation of the tongue in this region it is thus seen that the greatest care is necessary whilst severing the outer fourth of the organ on each side, since this contains the lingual and hypo-glossal nerves and the lingual artery. If the knife is used, this portion should be cut through in layers, first the mylo-hyoid muscle, then the lingual and twelfth nerves, and then very carefully through the great hyoglossus muscle, when the lingual artery will be exposed. This should be seized and ligatured, and the remaining portion of the tongue may be quickly severed.

Frequently this operation is performed with the écraseur, in which 


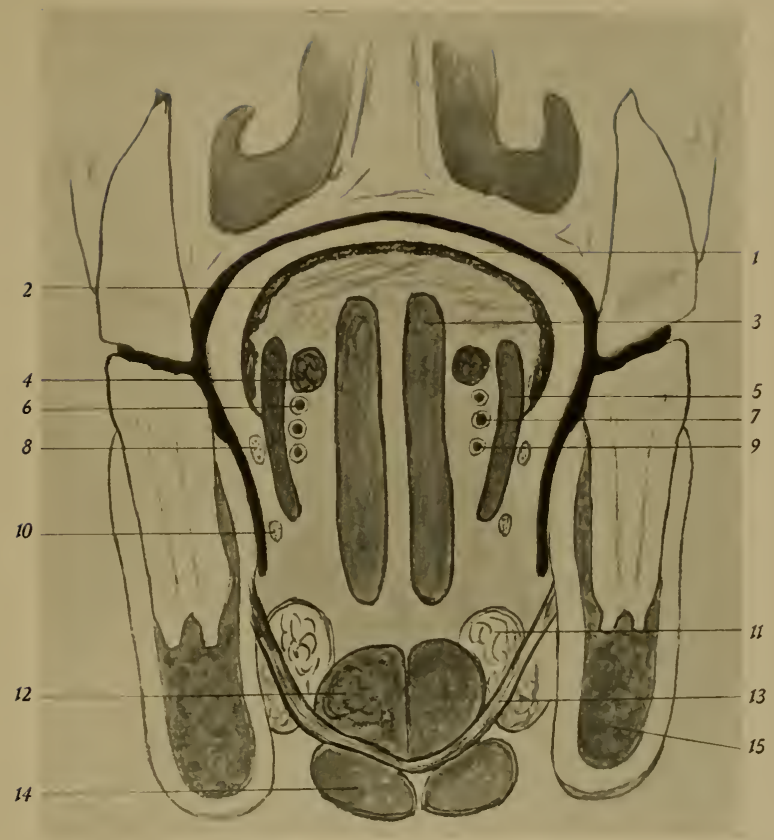

Plate Xil.-Transierse Section of Tongue

1. Superior maxilla. 2. Dorsum of tongue. 3. Genio-glossus. +. Middle hyo-glossus. 5. Great hyo-glossus. 7. Lingual artery. 6 and 9. Its venæ comites. 8. Lingual nerve. 10. Hypoglossal nerve. 11. Sublingual gland. 12. Genio-hyoid. 13. Mylo-hyoid. 14. Digastricus (inferior belly). 15. Vertical ramus with molar tooth. 

case it is usual to notch the organ on either side at the level of the seat of section. When using this instrument there is less hæmorrhage from the small muscular vessels, but the operator should proceed carefully when approaching the lingual artery, since even when this method of amputation is adopted, it is frequently necessary to ligature the vessel, as it is not always effectively closed by the process of crushing with the écraseur.

The above is a description of the operation when amputation is performed near the root of the tongue. In operating nearer the tip of the organ we have also to cut through the stylo-glossus muscle, which is applied to the outer surface of the great hyo-glossus. In this situation the lingual and hypo-glossal nerves run along the superior and inferior borders respectively of the stylo-glossus muscle. The lingual artery is placed on the deep face of the great hyo-glossus muscle and between it and the middle hyo-glossus.

\section{THE SOFT PALATE}

This may be looked upon as a continuation posteriorly of the hard or osseous palate. It is disposed after the manner of a valve which, excepting during the act of deglutition, completely shuts off the cavity of the mouth from that of the pharynx. It takes a direction which is obliquely downwards and backwards, extending from the hard palate to the base of the epiglottis.

Its anterior or inferior face looks downwards and forwards towards the cavity of the mouth, whilst its posterior or superior face forms the anterior boundary of the pharynx. Its anterior border is firmly attached to the posterior edge of those parts of the palatine bones which enter into the formation of the hard palate, but its posterior border is free, and closely embraces the base of the epiglottis.

The lateral borders of the soft palate are attached to the walls of the 
pharynx and mouth, along the line of demarcation between these two chambers.

The anterior face is covered by a continuation of the mucous membrane of the hard palate, and this surface presents a number of longitudinal and transverse folds or ridges. Upon close inspection there are also here visible numerous minute orifices, which are the apertures of the ducts of small glands which are placed in the sub-mucous layer.

The posterior surface is covered by a continuation of the mucous membrane of the nasal chamber, and at the posterior or free border of the valve the mucous nembranes enter into continuity with one another. The mucous membrane of this surface is also thrown into ridges, but these are more regular than are those of the anterior surface, and are disposed in a longitudinal manner only.

In structure the partition consists of:

I. Two layers of mucous membrane;

2. A fibrous aponeurosis;

3. Muscies ;

4. Vessels and nerves.

1. The mucous membranes have already been described.

2. The fibrous aponeurosis forms a powerful framework to the structure. It is attached anteriorly to the palatine bones, and extends in a posterior and downward direction for about onehalf the length of the soft palate, where it becomes continuous with the palato-pharyngeii muscles, the anterior attachment to which it affords.

3. Muscles.-The palato-pharyngeus muscle. This may be exposed by removing the mucous and glandular layers covering the anterior face of the soft palate, when its continuity with the fibrous aponeurosis will be made apparent. In the middle line its fibres will be noticed to be intermixed with those of the corresponding muscle of the opposite side. The muscle extends upwards and backwards along the wall of the pharynx, 
beneath the mucous membrane, to become inserted into the thyroid cartilage.

The Azygos-uvula. There are two of these small muscles which run longitudinally in the soft palate, from its free to its attached border.

The Levator-palati. This is a long delicate muscle which arises from the styloid process of the petrous temporal bone. It runs along the wall of the pharynx beneath the mucous membrane, and is inserted with the palato-pharyngeus.

The Tensor-palati. This is more powerful than the preceding muscle with which it arises. Its tendon plays round the hamular process of the pterygoid bone, and then curves inwardly to be inserted into the fibrous aponeurosis. The action of each of the last two muscles is indicated by the name.

4. The Vessels and Nerves. The soft palate has a free nerve and blood-supply, the latter coming from the staphyine and pharyngeal arteries and the former from the superior maxillary division of the fifth nerve, and from Meckel's ganglion. The staphyline nerve, which is chiefly derived from this sensory division of the fifth, is capable of sensory and motor functions, owing to the motor fibres which it receives from Meckel's ganglion, which has a motor-supply from the seventh nerve.

During the act of deglutition the soft palate is raised and made tense by the contraction of the levator and tensor palati muscles, so that the isthmus of the fauces is not merely an aperture, but becomes an elongated tube, the roof of which is formed by the anterior face of the palate, and the floor by the root of the tongue. 


\section{Staphylotomy}

Owing to the length and the manner of disposition of the soft palate in the horse, manual exploration of the parts behind it, i.e., the pharynx, guttural pouches, eustachian tubes, etc., by way of the mouth, is rendered much more difficult than in most other animals. To facilitate the passage of the hand into the pharynx through the isthmus of the fauces in making such an examination, McKillip recommends the longitudinal slitting of the soft palate-an operation to which the name "Staphylotomy" is given.

In performing this operation the animal is cast, and the jaws are widely separated by means of a mouth speculum. The tongue is then drawn well out of the mouth and held firmly. With the other hand a knife is carefully carried through the isthmus to the posterior or free border of the soft palate, when the curved cutting edge of the blade is turned towards the latter, and the palate is slit along the middle line from its free border to its attachment in to the palatine bones, during the process of withdrawing the hand.

In this manner the roof of the isthmus is slit throughout its length, which permits of the free and easy introduction of the hand into the pharyngeal chamber.

\section{THE OESOPHAGUS}

This is a long and somewhat cylindrical membranous tube which extends from the pharynx to the stomach. When not in use its lumen becomes almost entirely obliterated, and its pharyngeal orifice is so small that it will scarcely admit a finger-tip. This orifice is seen to be placed on the floor of the pharyngeal chamber above and slightly posterior to the glottis, and its mucous lining in the undilated condition of the tube is seen to be very corrugated.

It descends behind the trachea to the middle of the neck and then 


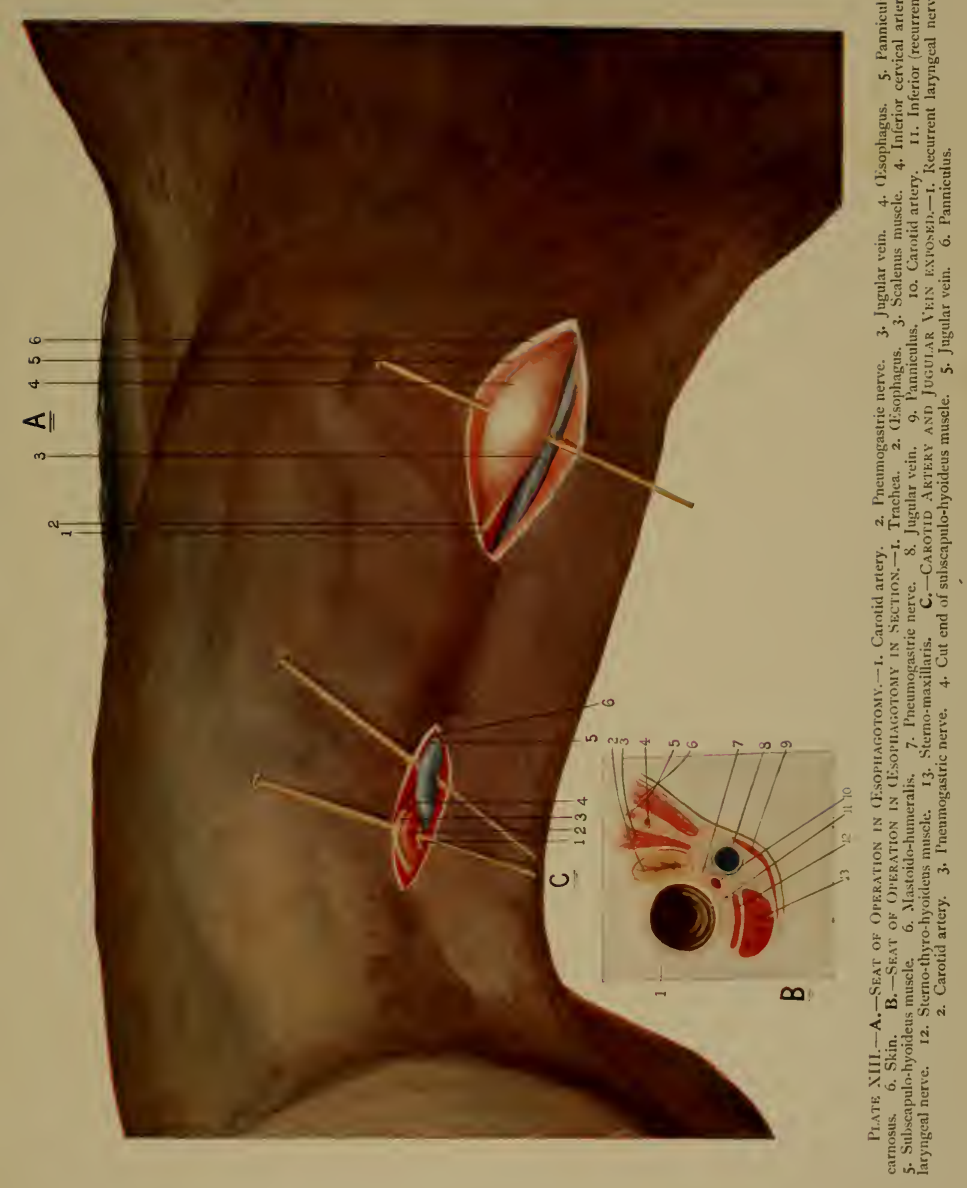



inclines towards the left side of the windpipe, entering the thorax across the inner aspect of the first rib of the left side. It then regains the upper aspect of the trachea, crosses the base of the heart, and passes through the foramen sinistrum of the diaphragm. Almost immediately upon entering the abdominal cavity it passes through the notch in the upper edge of the lobulus quadratus of the liver, and then opens into the stomach.

The first part of the œsophagus runs along a groove formed by the inferior surface of the guttural pouches. These, therefore, form its first superior relations. Inferiorly this part is related to the arytenoid and cricoid cartilages, but there are interposed between it and these structures, the posterior crico-arytenoideii and the arytenoideus muscles.

In the upper half of its course down the neck it is related to the trachea in front or below, and to the longus colli muscle above or behind, whilst laterally it is related to the carotid artery, the pneumogastric and sympathetic nerve trunk, and the inferior (recurrent) laryngeal nerve.

In the lower cervical region it is placed between the left outer surface of the trachea inwardly, and the inner surface of the left inferior scalenus muscle, and also the jugular vein outwardly.

Its relations in the thorax are not of very great surgical importance, but the opening into the stomach is most peculiar, and should be noted both in connection with the physiological difficulty experienced by the horse in the act of vomiting, and also in connection with the passage of the probang. The fibres surrounding the orifice, as McFadyean describes, are in two sets, namely, a circular set and a set arranged after the manner of a horse-shoe, whilst some of the fibres of the anterior limb of the horse-shoe are derived from the circular fibres. The orifice is thus kept in a state of contraction, and regurgitation from the stomach is frustrated.

The mucous coat of the esophagus is quite loosely attached to the outer or muscular coat. 


\section{Choking}

It is rather important to remember that the asophagus appears to be constricted at certain places, either on account of the pressure of the surrounding structures upon it, or on account of a flexuous disposition of the asophagus itself. Thus we find constrictions at its commencement, as it passes into the chest between the first pair of ribs, and also where it passes through the foramen sinistrum of the diaphragm. The importance of this point is in connection with the treatment of choking, for it will be seen that choking from an arrested obstacle is most likely to occur at one of the three positions named.

If the obstruction should occur at the entrance to the osophagus, it will be evident from Plate III. (longitudinal section) that its removal with the hand is not a difficult operation, particularly if staphylotomy be first performed, since the hand may be easily placed in the pharynx. In fact, this is the process which should be adopted, the ordinary mouth gag being used. 'The occipito-atlantal joint is fully extended, the tongue is taken in the left hand and the right hand passed into the mouth. The knuckles should be kept quite close to the hard palate. On arriving at the soft palate (providing the latter be not first slit), this is pressed gently backwards, and the operator's hand narrowed as much as possible to pass through the isthmus of the fauces. Whilst this is being done the epiglottis is pressed over the opening of the larynx, and care is taken not to insinuate the finger-tips into this opening, otherwise violent coughing will ensue.

Having grasped the obstacle, still greater care should be taken in withdrawing it, and it is frequently advisable to work it into the palm by means of the fingers, the knuckles meanwhile applying pressure to the epiglottis. Should the obstacle be placed at either of the other situations named, the anatomical difficulties, in the way of either external manipulation or of operating from the external cervical region, 
render these courses almost impossible, and the only course of treatment which remains is the passage of the probang.

\section{Passage of the Probang}

In passing this instrument a careful reference to the plate representing the longitudinal section of the parts will show that the safe course is to keep close to the roof of the mouth, and that the first difficulty is met with at the entrance to the asophagus. Noting that, excepting when the animal is in the act of swallowing, the glottis is open, and there is a danger of the probang entering the trachea instead of the asophagus, it is therefore best not to attempt to force the passage of the instrument just at this stage, but to wait until the animal, of its own accord, performs the act of deglutition, when the probang will pass naturally into the csophagus and the glottis will be closed.

That it is in the asophagus will be evident by the fact that it will glide smoothly away from the operator, and not slip suddenly from his grasp, as it would do if it were in the trachea, since the walls of the latter are rigid and its lumen always patent.

Upon reaching the obstacle gradual pressure should be applied in forcing it down the tube, deliberating particularly at the entrance to the stomach on account of the peculiar arrangement of the fibres here already referred to.

The obstruction may be placed in the cervical portion of the cesophagus.

In this case its position is easily determined by the fact that it causes a swelling which, if the aesophagus is not ruptured, is well defined. If the asophagus is ruptured, however, the swelling is diffused and extends downwards over the side, and even the under aspect of the trachea, and upwards over the mastoido-humeralis muscle. Moreover, the swelling is emphysematous.

Failing other methods of removal, e.g., manipulation, passage of probang, etc., the operation of cesophagotomy may be performed. 


\section{(Esophagotomy}

This is the operation of making an opening into the asophagus from without.

The seat of operation depends upon the position of the obstruction, for the cutaneous incision should be made immediately over the latter and preferably on the left side of the neck. (See Plate XIII. A and B).

Having incised the skin and panniculus muscle great care should be taken to avoid injury to the jugular vein, and also the carotid artery and the nerves which accompany it. The cesophagus feels like a strip of soft muscle with a thickener core internally.

It should be liberated from the surrounding structures by breaking down the prolongation between them of the deep cervical fascia. Having done this the opening into the asophagus may now be made by means of a longitudinal incision, the length of which depends upon the size of the obstruction, it should be long enough to admit of the removal of the latter. The closure of the wound in the asophageal wall is the most important part of the whole operation. The wall of the essophagus should be sutured in layers. In the mucous layer, Lembert's Interrupted Sutures should be inserted. The slit edges of this layer should not be brought into apposition, but should curve into the lumen of the esophagus, and the sutures should only be passed through the external half of the thickness of the layer sutured.

The muscular and cutaneous layers are sutured separately.

\section{THE SALIVARY GLANDS}

The Parotid Gland.-This is the largest of the salivary glands, and it is placed below the base of the conchal cartilage of the ear, occupying the area which is bounded posteriorly by the edge of the wing of the atlas and anteriorly by the posterior border of the vertical ramus of the inferior maxilla. 
The gland is flattened, is elongated in the vertical direction, and it presents for purposes of description two surfaces and four borders. The outer surface is almost flat, and is partially covered by the thin parotido-auricularis muscle, which descends vertically from its attachment into the base of the conchal cartilage above, to be attached inferiorly to the outer surface of the gland. Over this surface the panniculus also spreads in the form of a thin sheet. Upwards and forwards across this aspect of the gland the auricular branch from the second cervical nerve passes, whilst the cervical branch of the seventh cranial nerve crosses the gland downwards and backwards to gain the jugular furrow. The posterior auricular vein also descends through the gland. This vein, together with the auricular branch of the second cervical nerve, must be avoided in performing the operation of hyovertobrotomy, since they run slightly anterior to the position where the cutaneous incision of this operation is made.

The inferior portion of this surface of the gland is traversed downwards and backwards to its postero-inferior angle by a furrow along which the jugular vein runs, after the latter vessel has pierced the gland from within outwards.

The deep face of the gland is moulded on to the structures which lie beneath it, and in consequence is very irregular. It lies over the guttural pouch, the stylo-hyoid muscle, the upper belly of the digastricus, the upper insertion of the mastoido-humeralis, and the obliquus capitis superioris muscles, the styloid process of the occipital bone and the styloid cornu of the hyoid bone, the occipito-styloid muscle, the submaxillary salivary gland, the tendon of the sternomaxillaris muscle, the external carotid artery with its terminal branches, and the seventh cranial nerve.

The anterior border is firmly attached to the posterior border of the vertical ramus. Between this border and the ramus, the sub-zygomatic branch of the fifth cranial nerve and the seventh nerve emerge to run forwards on the external surface of the masseter muscle, where they form 
the pes anserinus. These nerves pass between the gland and the bone immediately below the condyle of the inferior maxilla, and here also the transverse facial artery with its accompanying vein passes. Much nearer the inferior extremity of this border the outer terminal division of the maxillo-muscular artery makes its appearance, and runs forwards embedded in the masseter muscle. The transverse facial artery is much more superficially placed than is this division of the maxillomuscular.

The posterior border of the gland is curved, with the concavity of the curve directed upwards and backwards. It is loosely attached to the outer border of the wing of the atlas.

The superior border is also curved, and encircles the base of the conchal cartilage.

The inferior border is almost straight, and along it runs the submaxillary vein, which takes a course backwards to unite with the jugular vein, just before the latter vessel leaves the gland at its postero-inferior angle.

The parotid gland derives its blood-supply from the collateral twigs of the vessels which it covers, namely, the external carotid artery and its terminal branches. The nerve-supply of the gland comes from the seventh, and the inferior maxillary division of the fifth nerve.

\section{Diseases of the Parotid Gland}

External Injury.-Owing to the superficial position of this gland it is very liable to external injury, such as wounds, bruises, etc. Such injuries are most serious when affecting the posterior half or an area of about two inches above its inferior border, since in these positions the vessels and nerves already described are very frequently involved in the injury. Towards the centre of the gland there is much less risk, for the jugular vein is here deeply seated within the substance of the gland. 


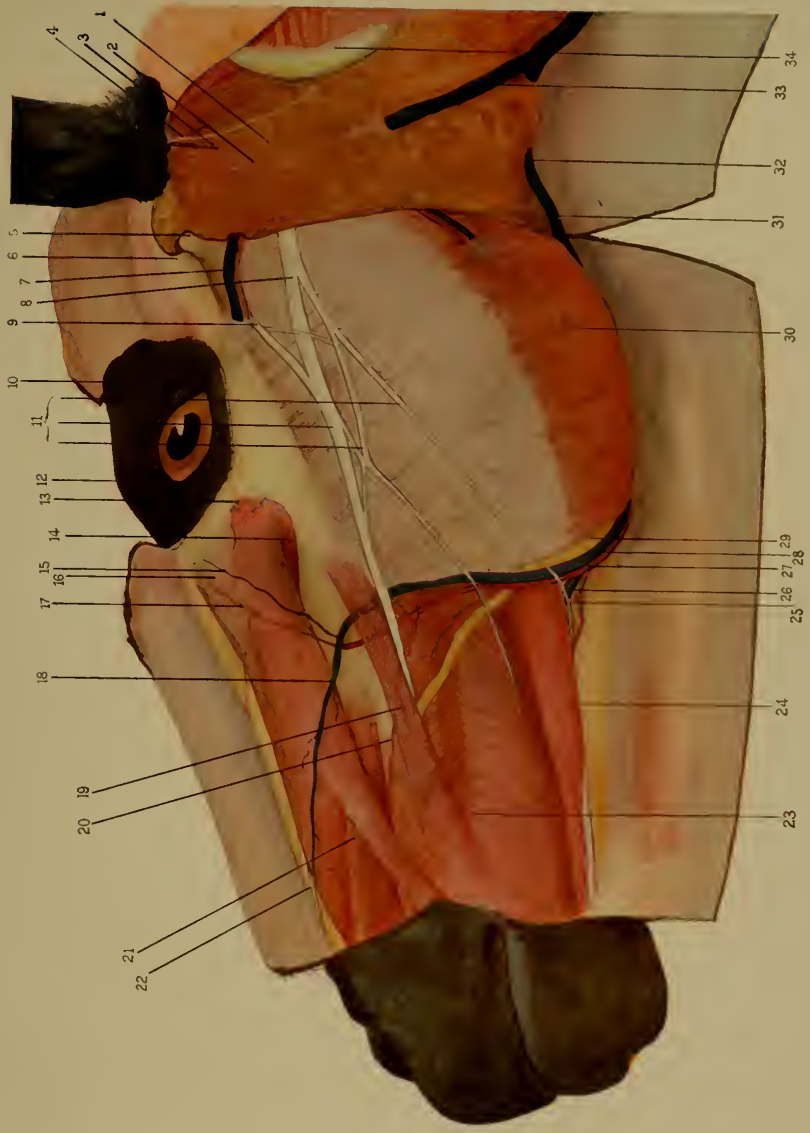

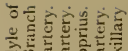

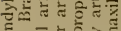

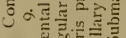

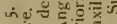

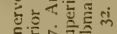
늘

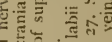
둘

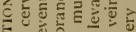

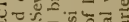
w 出 bั

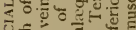
든 존 중

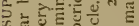
व

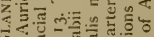
$0+$ 플

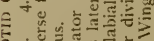

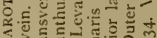
इ E

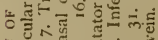
zับ

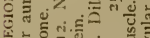

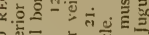

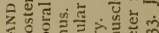

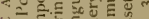

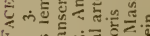
L क हैंत्र

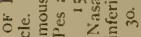
है

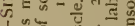
1 次

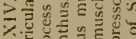

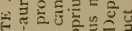
政

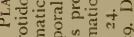
है है है능 हो रิसे हैं 을 ปे:

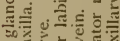

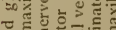

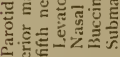
a e 
Wounds or injuries to the gland require immediate treatment, and in order that a salivary fistula may not follow as a sequel, the wounds should be cleansed and at once closed, and every endeavour made to procure healing by first intention.

Parotitis.-This is the name given to inflammation of the parotid. It may be due to access of foreign bodies through external injury, or the irritants may reach the gland through the Duct of Stenson. This latter is probably the most common method of infection.

The inflammatory affection quickly leads to abscess formation and necrosis of large areas of the tissue of the gland. In the earlier stages the gland is much enlarged, hot, and painful to the touch; and in order to enlarge the area for the accommodation of the gland, and ease the pressure upon it by the wing of the atlas and the posterior border of the vertical ramus, the animal inclines its head towards the non-affected side.

There is little resistance to the outward burrowing of the purulent matter, with the result that fluctuation is easily detected, and the point where the abscess is to be opened readily indicated. Should the abscess not be surgically opened it usually bursts outwardly. It is owing to the fact that there is such slight resistance to the outward extension of the abscess, and also to the fact that the animal is naturally inclined to hold its head in the manner indicated, that pressure upon the posterior border of the vertical ramus and the structures which wind round it, is so limited as to cause paralysis of the facial muscles, resulting from pressure upon the seventh cranial nerve, to be an exceptionally rare complication.

When the abscess points in the region of the large blood vessels, the course of the latter is to be carefully studied, and the cutaneous incision should be made parallel to the direction of the vessel which is nearest the seat of operation.

If the disease extends to the chronic stage little can be done, and the only operation indicated is the extirpation of the gland, an 
operation which is attended by great difficulties, particularly during the separation of the gland from the subjacent structures.

\section{The Duct of Stenson}

This is the excretory duct of the parotid gland. It leaves the gland at its antero-inferior angle, being formed at the inferior portion of the anterior border by the union of three or four of the largest "ductlets" which drain the gland.

The duct first takes a course inwardly across the inferior aspect of the tendon of insertion of the sterno-maxillaris muscle, and then passes forwards round the digastricus muscle, to become related to the inner face of the internal pterygoid.

It passes along the maxillary space in company with the submaxillary vein beneath which the duct is placed. With this vein and the submaxillary artery, it next curves round the inferior border of the horizontal ramus of the inferior maxillary bone to reach the face, the duct being the most posterior of the three structures, and the artery being placed in front of the vein.

The three structures named ascend along the anterior border of the masseter muscle, and throughout this part of their course they lic immediately upon the outer aspect of the horizontal ramus. The three structures maintain the same relationship to one another until they reach the inferior border of the depressor labii inferioris muscle, where the artery gives off its inferior labial branch. The corresponding branch of the vein is received by the latter slightly above the point where the inferior labial artery is given off.

The duct now passes obliquely upwards and forwards beneath the artery and vein, and, running obliquely across the outer aspect of the depressor labii inferioris muscle, it reaches the buccinator. Passing beneath the zygomaticus, it pierces the buccinator from 
without inwards, to open into the cavity of the mouth opposite the third upper molar tooth.

In structure the duct is made up of an internal mucous lining and an outer layer of connective tissue, with elastic fibres arranged both circularly and longitudinally.

If it should be necessary to functionally destroy the parotid gland this may be done by applying a ligature to the duct. The best seat to pick up the duct is just where it is curving round the lower jaw. Plate XXXII. shows this seat dissected, and on reference to it the position of the duct with regard to the accompanying vein and artery will be evident.

After making a cutaneous incision in the position indicated careful dissection is necessary to free the duct from the surrounding structures, to which it is somewhat firmly adherent.

It is not uncommon to find salivary calculi in the duct, due to precipitation of the salts of the saliva. These calculi are best left alone unless there is a suspicion that the lumen of the duct is completely obstructed, and if such be the case it becomes necessary to abstract the calculus.

The seat is usually quite close to the lower jaw. There is no difficulty in cutting down on to, and removing the calculus. The difficulty lies in effectively closing the wound, and preventing the formation of a salivary fistula as a complication.

It will be noted that the structures cut through in making an incision into the duct are skin and skin muscle, fascia, and the wall of the duct. These should be sutured in separate layers in closing the wound, several fine sutures being inserted in the wall of the duct. Adhesive strapping should then be applied to support the sutures, and the food given should be moist. Dry food is to be strictly avoided, owing to the amount of salivation which their mastication excites, and the jaws should be kept as still as possible.

If a salivary fistula should form as a complication consequent on the 
above operation, or from some other cause, such as external injury, it will be easily diagnosed by the ejection of saliva, which takes place at every movement of the jaw. Should the fistula be on the side of the face the position is very favourable for treatment. An incision should be made along the line of direction of the duct and over the seat of the fistula. Having thus exposed the duct the edges of the rent aperture should be pared and the opening closed in the manner described above for the removal of a salivary calculus.

\section{The Submaxillary Gland}

This gland is much more deeply seated than the parotid, and in consequence is much less liable to injury from without. It lies to the side of the larynx in the inter-maxillary space, and outwardly it is protected by the ramus of the inferior maxilla. It is smaller than the parotid, and in shape it is somewhat crescentic, with its concave border directed upwards and forwards.

The gland is loosely attached superiorly beneath the wing of the atlas, and it extends downwards and forwards to the inter-maxillary space between the internal pterygoid and the thyro-hyoid muscles. Its anterior border is thin, and margined in its superior portion by the upper belly of the digastricus muscle and inferiorly to this by the Duct of Wharton, which is the excretory duct of the gland.

The nerve-supply to this gland is derived from the carotid plexus, whilst its blood-supply comes from small twigs given off by the external carotid and submaxillary arteries.

\section{RANULA}

This term is applied to an acute inflammation of the submaxillary gland and its excretory duct. It is commonly met with in cattle and occasionally also in horses. There is considerable swelling of the gland and the duct, the orifice of the latter being frequently occluded by 


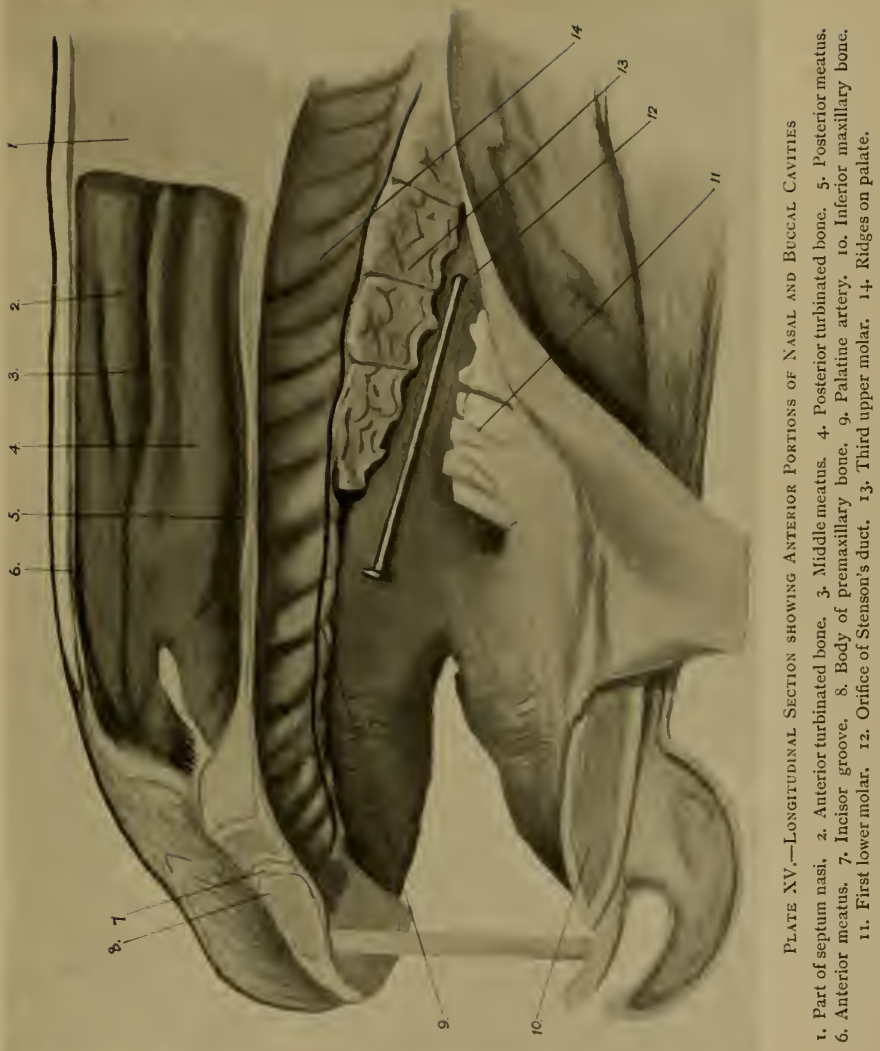



inflammatory material. Upon examination of the interior of the buccal cavity a large elevation is seen on the floor of the mouth near the frænum linguæ.

Owing to the close proximity of the gland to the pharyngeal wall, as the gland enlarges it presses the wall of the pharynx inwardly and marked dyspnoxa results.

The condition is usually relieved by pinching up with the forceps a small portion of the buccal mucous membrane near the barb, and removing it with the scissors.

\section{The Duct of Wharton}

This is the excretory duct of the submaxillary gland. It is formed along the anterior border of the gland by the union of ducts of the numerous lobules of which the gland is composed. The duct leaves the gland at its anterior extremity, and here the submaxillary artery crosses it outwardly. It next runs along the deep face of the mylo-hyoid muscle, and between this muscle and the hyo-glossus and stylo-glossus. It passes between the genio-glossus muscle and the sublingual gland, and it ultimately communicates with the mouth on the summit of the barb, which is a little papilla flattened superiorly and placed near the frænum lingux.

The wall of Wharton's Duct is not so strong as is that of the Duct of Stenson. It is devoid of circular elastic fibres, and its outer connective tissue coat is much thinner.

\section{The Sublingual Gland}

This is smaller than the submaxillary gland. It is also elongated, flattened from side to side, and it extends from opposite the fifth molar tooth, forwards to the symphysis of the inferior maxilla. Its position is indicated in the cavity of the mouth by an elevation of the buccal mucous membrane, which elevation is situate to the side of the frxnum 
lingux. The uplifting of the mucous membrane is caused by the underlying gland, and it is called the sublingual ridge. The gland is related outwardly to the mylo-hyoid and inwardly to the stylo-glossus and genio-hyoideus muscles. Its inner face is also crossed by Wharton's Duct and the lingual nerve. The gland is of the compound racemose type.

\section{The Ducts of Rivinius}

These are the excretory ducts of the sublingual gland. They number from fifteen to twenty for each gland. Their openings into the cavity of the mouth are found on the summits of little tubercles arranged in two rows, which are placed one on each sublingual ridge. 


\section{CHAPTER V}

\section{THE LARYNX, TRACHEA AND GUTTURAL POUCHES}

\section{THE LARYNX}

THIs is the upper portion of the tube which places the lungs in communication with the pharynx. This tube is naturally divided into three portions, namely, the larynx, the bronchi or inferior portion, and a connecting part called the trachea or windpipe.

In addition to being a part of this respiratory tube, the larynx is also the organ of voice. In order that it may perform the double function, it is of complicated structure, being made up of a groundwork of cartilages which are connected with one another by membranes and ligaments. A number of small muscles assist in attaching the cartilages to one another, but these also bring about the various movements of the cartilages which are necessary in the production of vocal sounds.

The Cartilages. - These are five in number, and are named respectively, the Thyroid, Epiglottis, Arytenoids (of which there are two), and the Cricoid.

The Thyroid Cartilage. - The thyroid cartilage is made up of a body which is placed anteriorly, and two lateral plates which project backwards from the body, one on either side. The body is in the form of a constricted rod, to the superior surface of which the base of the epiglottis is attached by elastic fibres. Its inferior surface is clothed by the insertion of the subscapulo-hyoideii muscles, whilst 
to its extremities the lateral plates or wings are attached by their antero-superior angles.

Each wing possesses two surfaces, four edges, and four angles. The inner surface is concave, and bounds the interior of the laryngeal tube, whilst the outer surface is slightly convex. The supero-posterior angle presents an upwardly projecting process called the superior cornu, near the root of which the wing is pierced by a foramen, through which the superior laryngeal branch of the pneumogastric nerve enters the larynx.

The postero-inferior angle is also drawn out into a process which terminates in an acute angle, where it is articulated to the cricoid cartilage.

The thyro-hyoid membrane connects the superior edge with the styloid cornu of the hyoid bone, and to the inferior edge the cricothyroid muscle is attached.

The Epiglottis.-The epiglottis is soft and flexible, and overhangs the opening into the larynx, which it closes by being bent over it during the passage of the bolus of food backwards from the isthmus of the fauces to the entrance to the asophagus. In outline it resembles an ovate leaf, and excepting during deglutition its apex is directed forwards. In the horse a small muscle is attached to its anterior surface near the base. This is the hyo-epiglottideus muscle, which arises from the superior face of the body of the hyoid bone, and which assists the cartilage to resume its "respiratory" position after the voluntary act of deglutition has been accomplished.

The borders of the cartilage are curved, and slightly serrated, and to them are attached inferiorly folds of mucous membrane, which run horizontally backwards to the arytenoid cartilages.

The Cricoid.-The cricoid cartilage is in the form of a ring, which has a greater depth posteriorly than in front, and which is attached to the superior extremity of the trachea.

The Arytenoid Cartilages.-The arytenoid cartilages in shape are not unlike three-sided pyramids. The inner surface is directed towards the interior of the larynx, the posterior surface gives attachment to the 
arytenoideus muscle, and to the outer surface the thyro-arytenoideus muscle is attached. The base presents a small shallow facet for articulation with the cricoid. The apices project upwards and backwards, and correspond to the cornicula laryngis of man.

The above cartilages are attached to one another in a manner which permits of a great degree of moveınent and flexibility.

The vocal cord is the upper edge of the thyro-arytenoid ligament, which runs from the anterior edge at the base of the arytenoid cartilage, to the back of the body of the thyroid, and the necessary tension and parallelism of the edges of the cord for the production of sound, are brought about by the movements of the arytenoid cartilages upon the cricoid. The articulation between these cartilages is of great importance, and will be concerned in an operation to be described hereafter, in which one of the arytenoid cartilages is excised. The concave facet, already mentioned, on the base of the arytenoid cartilage accommodates a convex articular surface on the upper aspect of the cricoid. The joint is of the diarthrodial variety, and possesses a small capsular ligament which is lined by a synovial membrane.

Muscles of the Larynx.-The muscles of the larynx are in two groups, extrinsic and intrinsic.

The extrinsic group includes the sterno-thyro-ihyoideus and the hyoepiglottideus muscles. The attachment and action of the latter have already been given.

The sterno-thyro-hyoideus muscle arises from the cariniform catilage of the sternum. It is a long ribbon-like muscle, which extends up the neck along the inferior surface of the trachea, being closely applied in the middle line to its fellow of the opposite side.

In the upper part of the neck the muscle divides into two portions, one of which continues its course along the trachea to be inserted into the body of the hyoid bone, whilst the outer division runs to its insertion into the thyroid cartilage.

The intrinsic group is made up of four pairs and one single muscle. 
The first pair are the crico-thyroid muscles. These muscles are placed one on either side the larynx. Each arises from the lateral aspect of the cricoid cartilage, and the fibres extend obliquely upwards and backwards to be inserted into the inferior edge of the wing of the thyroid cartilage. The action of the crico-thyroid muscles is to pull the thyroid cartilage downwards and so tighten the vocal cords.

The thyro-arytenoideus muscle is also paired, and it runs from the anterior portion of the deep face of the thyroid cartilage to the outer aspect of the base of the arytenoid. It acts in antagonism to the crico-thyroid by diminishing the tension of the vocal cords.

The lateral crico-arytenoideii muscles are placed beneath the wings of the thyroid cartilage. Each is therefore deeply seated to the corresponding thyro-arytenoid muscle. The fibres of these muscles run from the upper edge of the cricoid to the external tubercles and outer surfaces of the arytenoid cartilages. When these muscles contract the vocal cords are approximated more closely to one another by the twisting of the arytenoid cartilages inwardly on their bases.

The posterior crico-arytenoideii muscles run from the back of the cricoid to the external angles of the arytenoid cartilages. During contraction of these muscles the arytenoid cartilages are twisted on their bases in the outward direction, and so the vocal cords are more widely separated from one another.

The arytenoideus muscle.-This is usually referred to as a single unpaired muscle. Strictly, however, there are two muscles which meet in a median fibrous raphe. From this raphe each muscle runs downwards and outwards, to be inserted into the posterior aspect of the arytenoid cartilage of its own side. When these little muscles contract the arytenoid cartilages are drawn closer together, and so the edges of the cords are approximated and made parallel.

Mucous Membrane of the Larynx:-The mucous membrane which lines the pharynx envelops the opening into the larynx and then passes through the opening into the laryngeal chamber. It then covers the 
posterior aspect of the epiglottis and the anterior surface of the arytenoid cartilages. It is deflected into the ventricles of the larynx, and next passes over the vocal cords to gain the deep face of the cricoid cartilage, from whence it becomes continuous with the mucous membrane which lines the trachea.

Superior Laryngeal Nerve.-This is a branch of the pneumogastric nerve which is given off from the latter a little below the origin of the pharyngeal nerve. It passes beneath the external carotid artery to gain the wall of the pharynx. It then runs on to the outer surface of the thyroid cartilage in front of the thyro-pharyngeus muscle. It gains the interior of the larynx by passing through the foramen which has already been mentioned as being placed near the base of the superior cornu.

On the deep face of the thyroid cartilage this nerve splits up into three sets of branches; the anterior set pass to the epiglottis and the mucous membrane at the base of the tongue. The middle set are distributed to the mucous membrane lining the lateral walls of the larynx, whilst the posterior set pass backwards to supply the mucous covering of the arytenoid cartilages and a small portion of the beginning of the œsophagus.

The intricate ramifications of this nerve endow the mucous membrane of the larynx with a very high degree of sensibility.

Near its origin this nerve gives off a motor branch which runs to supply the crico-pharyngeus and crico-thyroid muscles. This branch is frequently referred to as the external laryngeal nerve.

The Inferior Laryngeal or Recurrent Laryngeal Nerve.-The right and left recurrent laryngeal nerves differ as regards the seat of their origin. Each is given off from the vagus; but whereas that on the right side arises at the entrance to the chest and is reflected round the arterial trunk, which on this side is common to the dorsal and superior cervical arteries, the recurrent nerve on the left side is given of within the chest and is reflected round the root of the posterior aorta. 
The left nirve passes between the aorta and the left bronchus, in which situation it is related to the bronchial lymphatic glands, and receives communicating filaments from the cardiac nerve. The left nerve then runs forwards along the inferior aspect of the trachea and passes out of the chest between the first pair of ribs.

During its course up the neck each nerve is closely related to the corresponding common carotid artery, along the inferior aspect of which vessel the nerve runs. The inferior laryngeal nerve supplies all the intrinsic muscles of the larynx with the exception of the cricothyroid.

\section{Some Diseases of the LARYNX}

Laryngismus Paralyticus.-This is an affection of the larynx, otherwise known as hemiplegia, or more commonly "roaring." It is characterised by marked dyspnoza, and by an extraordinarily audible respiratory sound which is heard during the inspiratory movements, and which becomes more appreciable as the rapidity of the respirations is increased, as, for instance, after a sharp gallop.

It is an affection of uncertain cause. Post-mortem examination has revealed the fact that in advanced cases all the intrinsic muscles on the left side of the larynx, with the solitary exception of the crico-thyroid, are usually found to have undergone a considerable degree of atrophy. That all the muscles so affected should be supplied by the left inferior (recurrent) laryngeal nerve, whilst the crico-thyroid is not supplied by that nerve, has led us to naturally conclude that "roaring" is most probably due to some injury leading to paralysis of this particular nerve.

Now the intrinsic muscles on the right side of the larynx are not usually affected, and since the right nerve exactly resembles the left in the course which it takes up the neck from the entrance to the chest to its distribution in the larynx, and also in the relationship which it bears to its surrounding structures throughout this part of its course, several theories explanatory of the causation of "roaring" have been advanced, 
attributing the affection to anatomical relationships of the additional length of the left nerve which is found within the chest. Thus some writers have endeavoured to connect the disease with certain pathological conditions of the heart or great vessels on account of the close proximity of the nerve to these structures. Enlargement and induration of the bronchial lymphatic glands have also been cited as a cause. From an anatomical point of view it will be easily understood that enlargement of these glands would exert considerable pressure upon the nerve as the latter passes forwards between the aorta and left bronchus. The question, however, remains in obscurity, and the cause is not definitely known.

In a larynx the subject of this affection there is relaxation of the left vocal cord, and during inspiration the left arytenoid cartilage falls forwards and downwards towards the rima glottidis. The passage of air through this part of the respiratory tube which has become structurally so disarranged, leads to the production of the sound heard in "roaring."

No form of known treatment is effective in curing the paralysed nerve and restoring the atrophied muscles to their pristine condition, but there are methods of relieving the difficulty which the animal experiences during respiration, and these methods are also effective in causing a cessation of the abnormal sound which was heard.

The two principal methods of treatment are the performance ot the operation of arytenectomy (excision of the affected arytenoid cartilage) or of tracheotomy, which latter provides for the direct admittance of air into the trachea. These operations will be described hereafter.

Chronic Laryngitis. - This is usually due to injury by some sharp substance taken in by the mouth. The anatomical position of the larynx renders it to a great extent immune from external injury, since it is protected by the vertical portions of the rami of the inferior maxillary bone. The acute inflammation which follows the injury becomes chronic and leads to extensive proliferation in the connective tissue 
near the cartilages. Another condition which might result is the formation of an abscess.

Tumours.-Tumour-like growths are not infrequently found in the larynx, the exact nature of which has not been determined.

\section{Operations on the LAKYNX}

Accurate diagnosis of affections of the larynx is attended by considerable difficulty. The framework of the organ being made up of somewhat rigid cartilage, internal growths produce little if any change in the external appearance of the part.

In most cases there is respiratory difficulty, and frequently also interference with deglutition.

In the horse the use of the laryngoscope is not very satisfactory, on account of the great length of the cavity of the mouth. The hand may, however, be placed in the pharynix and the presence of abnormal growths ascertained if these should be placed near the pharyngeal opening, i.e., near the base of the epiglottis or apices of the arytenoid cartilages.

In suspected cases by far the most satisfactory method is to open into the larynx-an operation which is by no means difficult.

\section{LARYNGOTOMY}

This is the term applied to the operation of opening into the larynx. The animal should be cast, placed upon its back, and the occipito-atlantal joint fully extended. This will increase the distance between the body of the thyroid cartilage and the cricoid, and permit of a more extensive view of the interior of the chamber when the incision into it has been made.

The parts should now be palpated-the location being determined, first of the uppermost two or three tracheal rings, then the cricoid cartilage, and lastly the pomum adami or body of the thyroid. This 

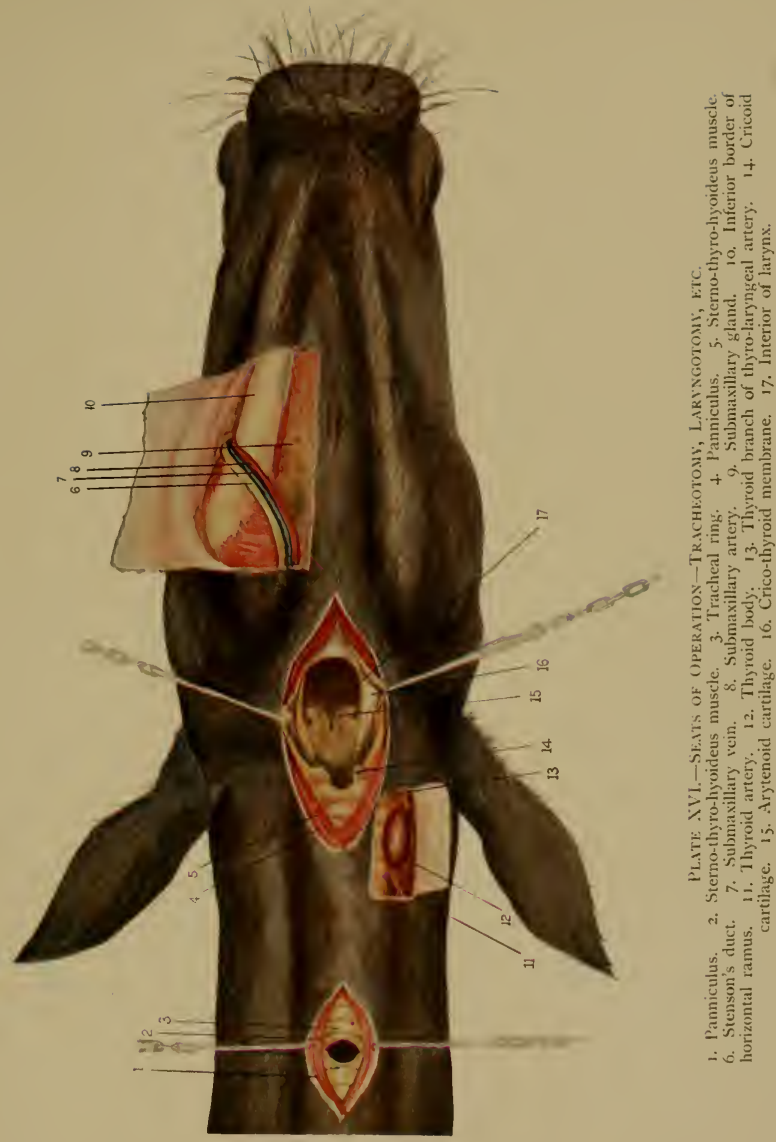

area should undergo careful preparatory treatment in the way of shaving and cleansing.

A cutaneous incision is made in the median line, and should extend from the body of the thyroid to the second tracheal ring.

The incision should next be carried through the thin layer of panniculus, and subsequently, if sufficient care be taken to strike the median line, when the lips of the wound are separated, the delicate septum between the two inner divisions of the sterno-thyro-hycideii muscles may be seen. These muscles are made very tense owing to the manner in which the head has been disposed.

The part should now be carefully sponged and the operation continued by making an incision along the septum referred to. Little, if any, hæmorrhage arises from the last-named step.

The scalpel should next be held with but a short portion (e.g., half an inch) of the blade exposed, and plunged into the cricothyroid membrane; and having done this, the membrane should be slit from the thyroid to the cricoid cartilages.

All that now remains is to turn the cutting edge of the knife towards the cricoid cartilage, and cut through the latter by applying steady pressure. By separating the edges of the wound thus made a good view of the interior of the larynx is obtained.

Care must be taken not to injure the thyro-laryngeal branch of the carotid artery. The laryngeal division of this vessel runs upwards to the larynx a short distance to the outer side of the seat of operation, whilst its thyroid branch takes a retrograde direction to enter the upper or anterior face of the gland.

The posterior extremity of the submaxillary gland lies to the outer side of the anterior extremity of the incision, and to the outer side of this again lie the excretory duct of the parotid, namely, the Duct of Stenson, and the submaxillary artery with its accompanying vein.

The edges of the wound should be hooked back and fixed whilst the examination of the interior of the larynx is being carried out. 
Tumours or other growths may thus be excised, a dry sponge being freely used to absorb and remove any hamorrhage and prevent its escape down the trachea. Extreme precaution in this direction must be taken during the removal of purulent or other such accumulations in the larynx.

If, after examination, it is found that the condition necessitates a prolonged operation, it is usual to insert a tracheotomy tube in order that the respirations may not be interfered with, and through which the administration of anæsthetics may be continued. It may also be necessary to extend the wound by cutting through one or two rings of the trachea.

In such cases the operation wound is prevented from closing for several days, in order that the interior of the chamber may be examined and dressed frequently, and any complications which may arise at the seat, attended to.

\section{ARYTENECTOMY}

This is the operation which has already been referred to as one of the methods of relieving dyspnœa in cases of "roaring." By the term is meant the excision of the arytenoid cartilage.

The animal is secured, placed on its back, and the occipito-atlantal joint fully extended, as in the operation previously described. A tracheotomy tube should be inserted and the operation of laryngotomy performed, the first two tracheal rings being included in the incision.

The apex of the left cartilage (the one usually removed) is seized with a long pair of rat-tooth forceps and with a sharp knife, or preferably a pair of scissors, an incision is made through the lining membrane as it passes from the surface of one arytenoid cartilage to that of the other. This incision should then be carried along the base of the cartilage, the cartilage being frequently twisted on its base in order that its outline may be traced and followed.

The course of the incision is next bent at right angles, and takes 


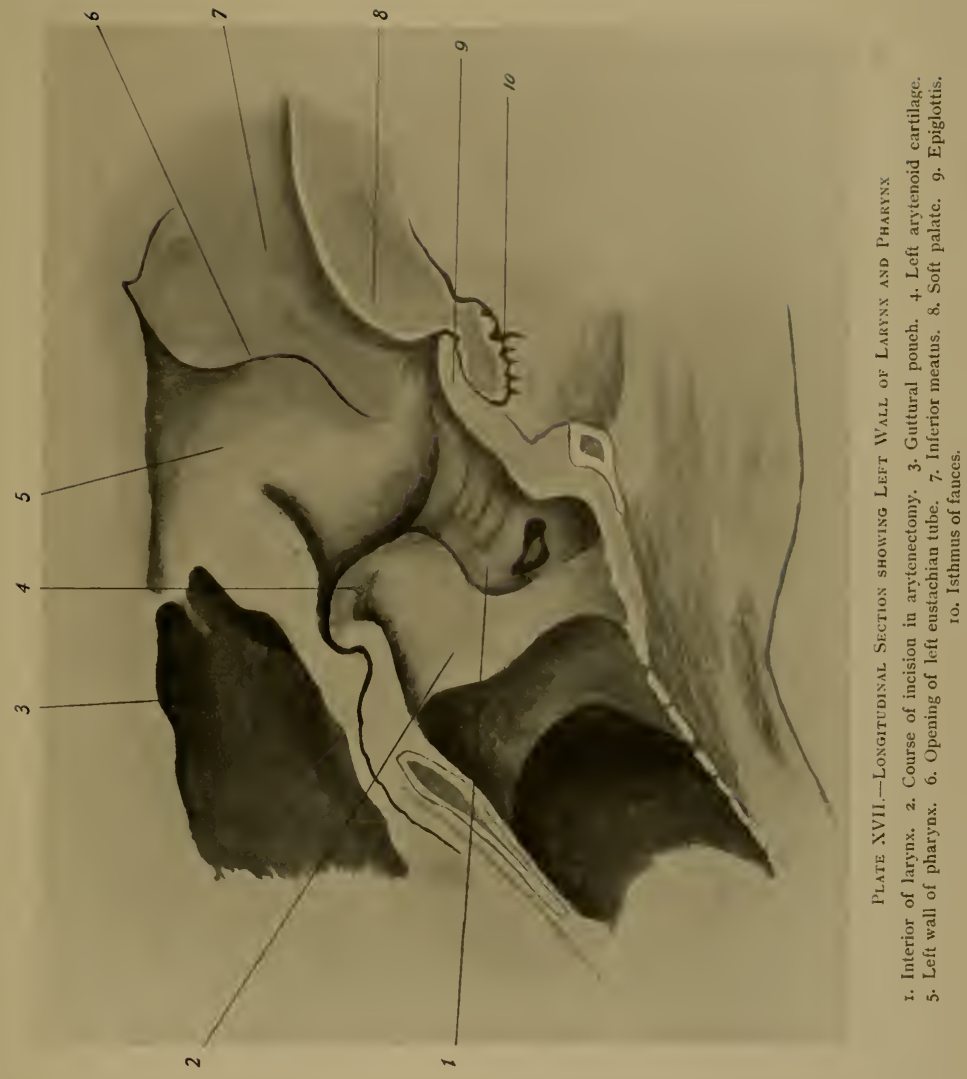



an upward direction, that part of the membrane being slit which connects the arytenoid cartilage with the base of the epiglottis, again following the outline of the cartilage. This part of the incision cuts through the left vocal cord.

The cartilage is now freed from the membrane, and the joint which its base forms with the upper aspect of the "bezel" of the cricoid should be carefully located and disarticulated.

The outer edge of the arytenoid is now seized and drawn gently towards the operator whilst he dissects the cartilage free from the structure which lies behind it, namely, the arytenoideus muscle. During this part of the operation the terminal branch of the laryngeal division of the thyro-laryngeal artery is severed, and the hæmorrhage from it must be immediately arrested by compression with a pair of artery forceps. This process of dissection having been completed, the cartilage is free and may be removed.

The consecutive treatment is as in laryngotomy.

\section{THE TRACHEA}

The trachea is the middle or connecting piece of the respiratory tube. It is flexible and elastic, and is made up of a series of cartilaginous rings, which however are not complete. A transverse section represents the outline of the tube as being almost cylindrical, but not perfectly so since it is slightly compressed from above to below.

The rings are incomplete superiorly, and on this aspect of the trachea the osophagus, for the greater part in the cervical region, rests. The anterior, or inferior, face is blended with the lateral surfaces, and these are regularly rounded. These surfaces are crossed transversely by a series of grooves which correspond to the intervals between the cartilaginous rings, the intervals between the cartilages being filied up by an elastic membrane.

The trachea commences at the cricoid cartilage of the larynx and 
descends below the longus colli muscle to the entrance to the chest, where it presents a slight bend, and passes into the thorax between the two first ribs. In the chest it is placed between the layers of the anterior mediastinum, and continues its course backwards until it arrives at the heart, above the left auricle of which it is placed to the right of the posterior aorta. Here it divides into the right and left bronchi.

In the neck it is related superiorly to the asophagus and longus colli muscle, and inferiorly it is clothed by the sterno-thyro-hyoideii muscles. Its lateral aspect is crossed obliquely upwards and forwards by the sterno-maxillaris muscle and downwards and forwards by the subscapulo-hyoideus. Its left side is also related in the inferior portion of the neck to the osophagus, which here leaves the middle line and deviates towards the side of the trachea.

The scalenii muscles clothe its lateral aspects near the root of the neck.

In the chest the inferior cervical ganglia of the sympathetic lie on its lateral surfaces, which are also crossed by the dorsal and superior cervical arteries on the left side, and on the right side by the common trunk of these vessels. These surfaces are also crossed by the veterbral arteries.

Above the thoracic portion is the œsophagus and also the longus colli muscle. Inferiorly the trachea crosses the angle formed by the anterior and posterior divisions of the aorta, where it lies over the anterior vena cava. Immediately in front of its bifurcation it is crossed obliquely downwards on its right side by the great azygos vein and frequently also by the thoracic duct, and the œsophagus here takes a downward course between the trachea and the posterior aorta.

The somewhat elliptical outline of the trachea will be apparent if a transverse section be made, and such a section will also reveal the presence of the trachealis muscle which consists of fibres running 
transversely and cutting off the upper portion of the circumference of the ellipse.

The first four rings of the trachea are related laterally to the thyroid body, and the thyro-laryngeal artery runs forwards and upwards between this structure and the trachea.

In connection with operations on the trachea it should be remembered that the carotid artery crosses the tube obliquely upwards and forwards, being below the trachea near the entrance to the chest, and taking a more obliquely upward course than the trachea, reaches its upper surface and at its termination, where it splits up into external and internal carotids and occipital arteries, it is placed above the cricoid cartilage.

The common carotid is accompanied by the cord common to the cervical portion of the sympathetic and the vagus nerves. This cord lies above the artery, and running along the inferior aspect of the artery is the recurrent laryngeal nerve. The jugular vein in the upper part of the neck follows the upper border of the sterno-maxillaris muscle and is here separated from the carotid by the subscapulo-hyoideus, but in the lower part of the neck the vein, like the carotid artery, is related to the trachea.

\section{TRACHEOTOMY}

It is frequently necessary to perform the operation of tracheotomy, thus providing a new respiratory opening for the relief of difficult or obstructed respiration, which may be either temporary or permanent. If the operation is for temporary relief, and the case is very urgent, failing the insertion of a tube a slit is simply made through the skin and through one or two tracheal rings, but if the difficulty is a permanent one the relief provided must likewise be permanent, and in these cases a tracheotomy tube is inserted to maintain the opening in the trachea patent.

In deciding the seat which should be adopted for the operation the 
manner in which the animal carries its head should be taken into consideration as it is generally advisable to conceal the tube from view as much as possible, and yet insert it in such a position that there will be no hindrance to the inward and outward passage of the respired air. An advantage in adopting a seat high up the neck is that, should complications subsequently arise which necessitate the re-insertion of the tube at a different seat, a considerable area would be at the operator's disposal. Such a complication is not by any means uncommon, for it is a matter of frequent occurrence that the lumen of the trachea becomes almost completely blocked at the position where the tube is inserted, on account of the accumulation of granulation tissue, the result of irritation by the tube. Many and various have been the designs of tubes which have been claimed to prevent the growth of this tissue.

Having selected the seat, the animal should be placed in stocks, a longitudinal incision should be made along the median line about two inches in length through the skin and panniculus, and the edges of the wound well separated. It is then possible and advisable to separate the flat pre-tracheal muscles by dissection, since it is not necessary to incise any muscular tissue other than the panniculus, and consequently there should be very little hæmorrhage. The incision is made along the median delicate raphe separating the sterno-thyro-hyoideii muscles. Having done this the trachea is brought into view.

A transverse incision is now made between two of the cartilaginous rings, and with a narrow-bladed scalpel a half-moon shaped piece should be excised from each of the adjacent rings. About three-fourths of the breadth of each ring should be taken, so that neither of the two rings is completely severed. IVhilst excising the pieces of cartilage they should be firmly seized with a pair of rat-tooth forceps, otherwise there is a danger that when separation is complete, they might slip away from the operator and pass down the trachea. A circular hole is thus made which is large enough to admit the ordinary sized tube.

This operation is a simple one, and there is very little danger 
attached to its performance provided due care and dexterity are shown during the insertion of the tube. That part directed towards the lungs should be inserted first.

By a reference to Plate XVI. it will be seen that there are no important vessels or nerves near the usual seat, consequently the operator's attention can be wholly directed to the prevention of hæmorrhage from the cutaneous and muscular vessels, and the removal of the sections of cartilage. The operation is best performed whilst the animal is in the standing position, and since it is not very painful and the time taken is quite brief (only a few minutes) only local anæsthesia is necessary.

When it is necessary to adopt a seat near the root of the neck, the ugular vein and carotid artery should be located in order that injury to them may be avoided.

Similarly, when for some pathological or other reason it is necessary to select a seat in the upper part of the neck, it will be well to remember that occasionally in horses, there is present the isthmus connecting the two thyroid bodies across the inferior face of the trachea, as is found in man. This, if present, will be avoided if the seat of operation selected is below the fourth tracheal ring.

\section{THE GUTTURAL POUCHES}

There are two of these, placed one on either side the median sagittal line. Each is a large sac which extends from near the atlanto-axial joint to near the upper extremity of the posterior nares. The pouches meet one another on the middle line where their mucous linings come into apposition.

Various structures are related to their outer aspect, the stylomaxillaris, the digastricus (upper belly), the stylo-hyoid, and the occipitostyloid muscles lie over the pouch, which is crossed by the occipital and both the external and internal carotid arteries. Behind the styloid cornu of the hyoid bone, in addition to the foregoing, the pouch is crossed by 
the ninth, tenth, eleventh, and twelfth cranial nerves and also by the sympathetic cord.

In front of the cornu the pouch is related to the internal maxillary vessels and to the inferior maxillary division of the fifth cranial nerve.

Each pouch is lined by mucous membrane, which is continuous with the mucous lining of the eustachian tube. Since the latter opens into the pharynx there is thus a communication between the guttural pouches and the pharyngeal chamber, and this communication it is important to remember.

Plate XVIII. shows a transverse section through one of the pouches. On looking into the pouch from below we see a bulging inwards from its outer wall, which is caused by the styloid-cornu of the hyoid bone. On its inner wall is seen the eustachian tube. The probe is passed through the triangle of Virborg.

In the plate the pouch is in its normal condition, with its wall slightly fallen in on account of the pressure of the surrounding structures.

On palpating the interior it will be found that the membranous wall is very extensive and distensible, so that when the pouch becomes filled with some material such as purulent matter it easily admits of great enlargement, and consequently its floor approximates much more closely to the region of the angle of the inferior maxilla.

In Plate III., where a longitudinal section of the head is shown, the inner wall of the right pouch, which comes into apposition with the corresponding wall of the pouch of the other side, is seen.

Plate XIX. (facing page 80) shows this wall incised and its flaps reflected. One probe is passed from the pouch through the eustachian tube into the pharynx, and the method of communication between the latter and the puch is distinctly shown. In this same plate the other probe has been passed through the occipito-styloid muscle into the pouch, and it is seen between the styloid cornu of the hyoid 


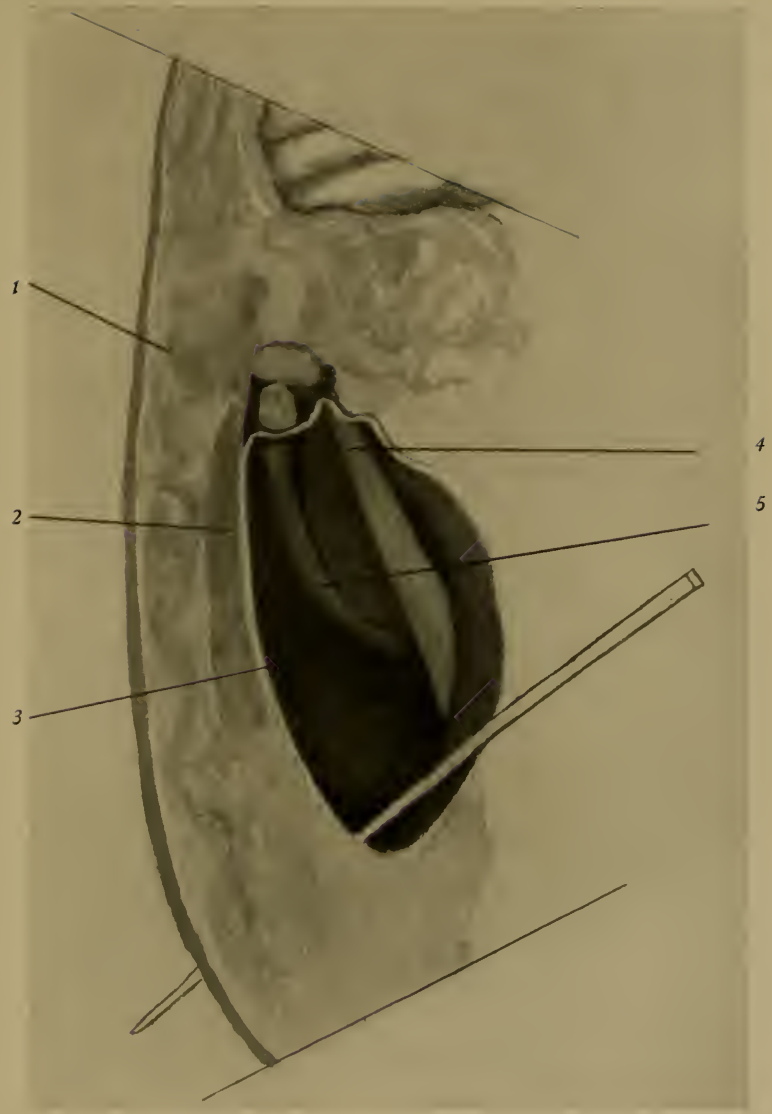

Plate XVili.-Transierse Vertical Section through Gutrural Pouch

I. The parotid gland. 2. Occipito-styloid muscle. 3. Interior of pouch. 4. Eustachian tube. 5. Styloid cornu of hyoid bone. 

bone in front, and the elevation which indicates the inferior extremity of the styloid process of the occipital bone, behind.

If a longitudinal section of the head be prepared and an incision made into the pouch through its inner wall, by the introduction of a finger into the cavity of the pouch, and by insinuating it in the forward direction, it will be found that the pouch becomes much narrowed down towards its anterior extremity. Here it forms a kind of diverticulum which comes into close relationship with the posterior wall of the pharynx. This diverticulum extends downwards and forwards in the direction of the long axis of the pouch. There is also a posterior diverticulum, which has already been referred to as extending downwards in the direction of the angle of the jaw.

These are points of considerable clinical importance; for in cases of accumulation of inflammatory or other products in the pouch, it will be evident that these products will gravitate downwards and forwards into the anterior diverticulum, and since there is little resistance to the pressure caused by the products the pouch is distended and bulges prominently into the pharynx, so prominently in fact that there is marked interference with the respirations of the animal, which become quite audible.

Again, since the floor of the pouch is in immediate relationship to the pharyngeal opening of the œsophagus, the pressure upon this opening renders the acts of deglutition much more difficult. There is also much soreness evinced when the region of the throat is pressed from without.

The products also gravitate into the posterior diverticulum, but in this direction their downward movement meets with considerable resistance, owing to the proximity of the ramus of the inferior maxillary bone. As the condition progresses therefore the accumulating matter becomes pressed in the direction of least resistance, and on this account a well-marked external distension ultimately makes its appearance, which is most apparent immediately in front of the wing of the atlas.

This swelling may be differentiated from an enlargement of the 
parotid gland, since in the case under consideration the gland itself may be detected apart from the swelling by carefully palpating its outline.

Owing to the natural difficulty which exists against the escape of such material formed within the pouch (the communication with the eustachian tube is in the form of a slit, and is situate at some distance above the lowest level of the pouch), the affection usually runs a chronic course, the liquid portion of the material is most frequently reabsorbed, and the accumulations take a more or less solid consistency. This consistency bears a close similarity to that of cartilage, and on this account the name "chondroids" has been given to the ball-like masses into which the inflammatory products so frequently resolve themselves.

In some cases, however, the pouch may be found tightly distended by material which retains the consistency of a thick liquid, and this is frequently mixed with a quantity of food material which has found its way into the pouch through the eustachian tube.

A normal pouch when opened does not appear at all capacious, but as an example of the great degree of distensibility possessed by the wall of the pouch, it may be mentioned that Schlampp found as much as twenty-seven ounces of food material accumulated in one pouch.

It usually happens that one pouch only is affected, since there is no direct communication between the two pouches.

The cause of the affection remains, to a certain degree, in obscurity, but cases of inflammation of the mucous lining of the pouch are generally accorded to be due to an extension of a similar condition affecting the mucous membrane of the pharynx.

When the contents of the pouch are of a fluid consistency there is present a discharge from one nostril, namely, that of the side corresponding to the pouch affected. This is due to the fact that the opening of the eustachian tube is so disposed, that the material, immediately on leaving the tube, readily passes into the posterior meatus of that side. The discharge, moreover, differs from most 


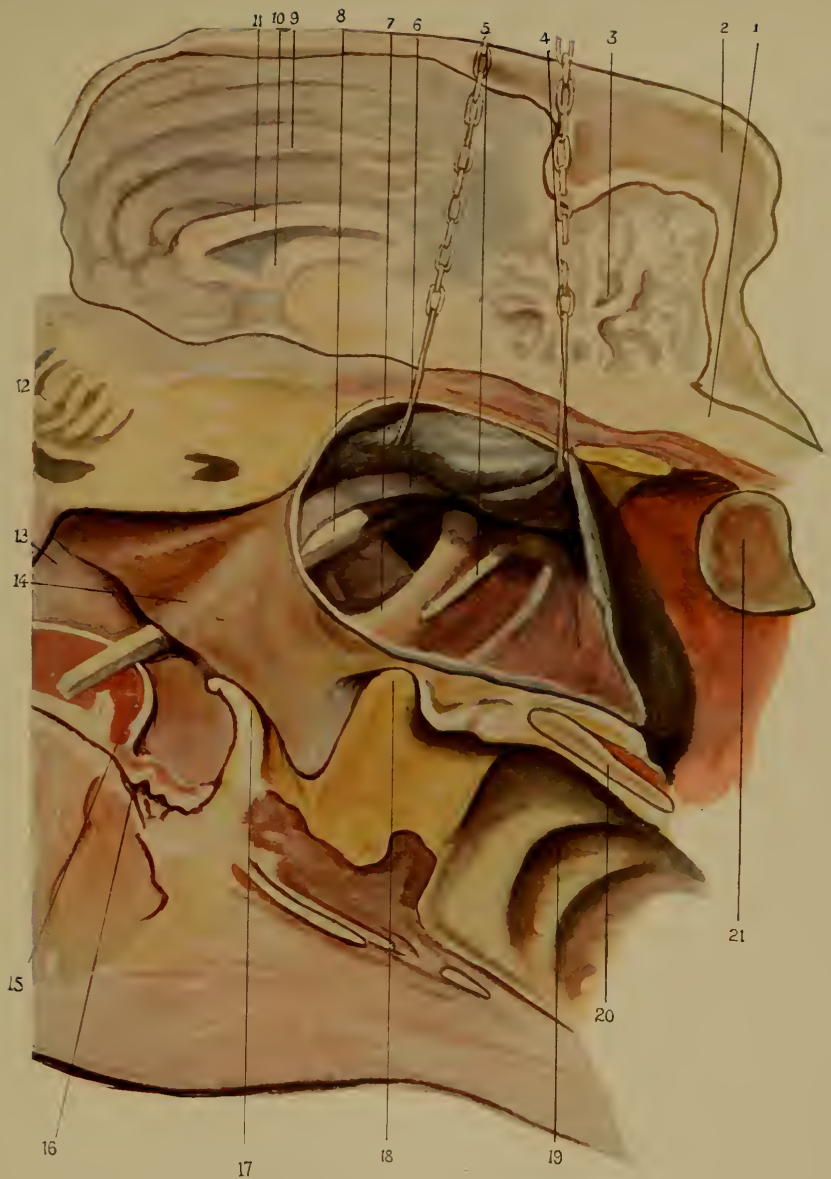

Plate NiX.-Longitudinal and Vertical Section, showing interior of right Guttural Pouch, THE RIght SIDE of THe LaRynx, Pharynx, \&c.

1. Spinal cord in foramen magnum. 2. Supra-accipital bone. 3. Cerebellum. 4. Posterior diverticulum. 5. Probe passed through occipito-styloid muscle. 6. Interior of right guttural pouch. 7. Styloid cornu of hyoid bone. 8. Probe in eustachian tube. 9. Inner surface of right cerebral hemisphere, 10. Fornix, 11. Corpus callosum, 12. Ethmoid bone. 13. Communication between nasal chamber and pharynx. I4. Right wall of pharynx. 15. Soft palate. 16. Isthmus of fauces. 17. Epiglottis. 18. Right arytenoid cartilage. I9. Interior of trachea. 20. Cricoid cartilage. 2r. Basi-occiput. 

chronic discharges of the kind, inasmuch as its odour is by no means offensive.

The two pouches, as already stated, are in close proximity to one another, and when one pouch is distended in a marked degree it bulges out laterally, exerts pressure upon the other pouch, and a swelling appears on the opposite side of the head, which might lead one astray by suggesting that both pouches are affected.

In extreme cases of impaction of a pouch the animal also inclines its head to the opposite side to relieve the pressure of the distended pouch upon the various and important anatomical structures which surround it.

Positive diagnosis may be frequently made by means of Gunther's catheter. This is a long brass tube, the extremity of which is rounded and closed in order that it may perform the function of the extremity of a sound. Communication between the bore of the tube and the exterior, however, is established through two apertures, placed opposite to one another just behind the rounded extremity. The tube is about two feet long, its point is slightly curved, and the other extremity is indexed in such a manner that the operator is enabled to ascertain when the end of the catheter arrives at the entrance to the eustachian tube. The free edge of the valve-like piece of cartilage guarding the entrance to the latter, it will be remembered, is directed towards the posterior meatus, and along this part of the nasal chamber the catheter must therefore be passed.

The opening into the eustachian tube and the temporal canthus are equidistant from the anterior nares, and thus the operator, by measuring the distance from this canthus to the nasal opening, is enabled to ascertain the length of tube which must be passed into the meatus before the eustachian orifice is reached, and to regulate the index on the catheter accordingly.*

* A further reference to Plate III., representing a longitudinal section of the head, will greatly assist in the operation of passing this instrument. 
The animal is now restrained by means of a twitch, and the occipito-atlantal joint is slightly extended by drawing the muzzle forwards. The catheter is then passed along the floor of the nasal chamber to a length which is slightly short of the required distance as indicated. The rounded end of the instrument is now turned outwards, and moved up and down in a vertical plane until the position of the edge of the valve guarding the eustachian orifice can be detected. Under this edge the point of the catheter will pass naturally without much pressure, and if in the eustachian tube, there will be no resistance to its inward passage.

The point of the tube must still be directed outwards, in order that it may pass readily into the pouch on arriving at the slit by which the latter communicates with the eustachian tube.

This instrument has been recommended as a means of evacuating the contents of the pouch when of a fluid consistency, but its utility for this purpose is not very effective, since the eustachian tube communicates with the pouch above the level of the floor of the latter.

\section{HYOVERTOBROTOMY.}

For the evacuation of material so accumulated in the pouch, the operation of hyovertobrotomy is performed. The contents are removed by making an incision into the pouch from without.

From the anatomical description given it will be understood that such an operation entails a considerable amount of care, on account of the various important structures related to the outer aspect of the pouch.

The operation was first performed in 1779 by Schabert, who gained entrance to the pouch by piercing the stylo-maxillaris muscle.

Virborg recommends the evacuation of the pouch by making a dependent orifice in the triangle which bears his name. This triangle is bounded by the border of the inferior maxillary bone, the tendon of the sterno-maxillaris, and the submaxillary vein. 


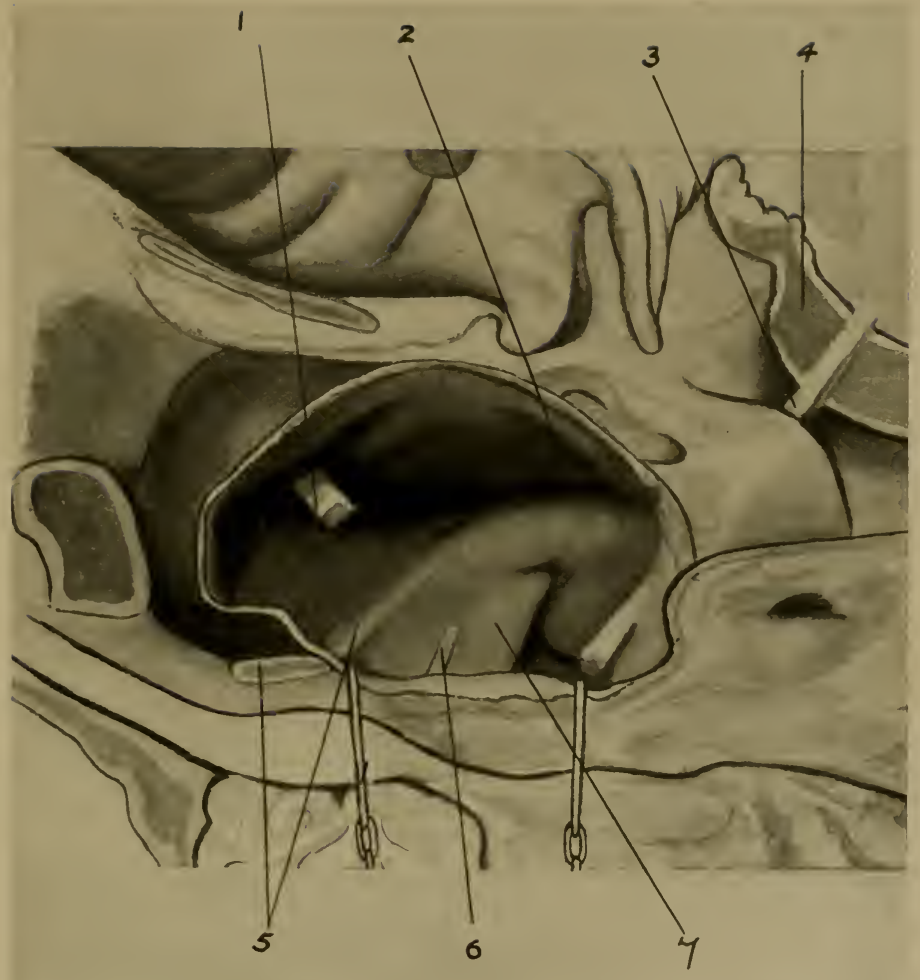

Plate XX.-Floor of left Guttural Pouch

I. Probe passed into posterior diverticulum to triangle of Virborg. 2. Anterior diverticulum. 3. Probe in eustachian tube. 4. Soft palate. 5. Styloid process of occipital bone. 6. Entrance of probe passed through occipito.styloid muscle. 7. Styloid cornu of byoid bone. 

The pouch is here simply covered by the skin, subcutaneous fascia, and the thin layer of the panniculus muscle, and this is the situation of the prominent swelling which appears near the angle of the inferior maxilla when the pouch is distended.

A cutaneous incision is made in the middle of the triangular area mapped out by the boundaries mentioned, the direction of the incision being parallel to that of the fibres of the sterno-maxillaris. The skin and panniculus muscle are carefully incised, and by separating the lips of the incision thus made, the wall of the pouch is exposed. To avoid injury to the surrounding structures, the wall is punctured by means of a trocar, and if it should be necessary to enlarge the opening, this is done by tearing the wall of the pouch with the fingers.

Fleming and Lecocq recommend the piercing of the stylo-hyoid muscle. Möller and Dollar pierce the occipito-styloid. The lastnamed muscle lies immediately over the pouch, and this is the seat which, when adopted, entails the least risk of injury to the important vessels and nerves in this region. Moreover, the landmarks by which the operator is guided to the seat of his incision into the pouch, are prominent and definite.

The first and perhaps the most important landmark is the wing of the atlas, the anterior edge of which should be most carefully located. A cutaneous incision should then be carried upwards and backwards, parallel to the edge of the wing, from about its middle, whilst from the same point an incision about an inch and a half in length should be carried upwards and forwards. We have thus a $\mathrm{V}$-shaped incision, with the apex directed downwards.

Reflect upwards the flap of skin incised, together with the thin subcutaneous layer, when the parotid gland, in addition to the edge of the wing of the atlas, will be exposed. The posterior auricular vein, which runs in a vertical direction, and the auricular branch of the second cervical nerve, which ascends obliquely upwards and forwards on the outer aspect of the gland, are clear of the operation area, since they are 
placed at a short distance anteriorly to the seat, as is also the cervical branch of the seventh cranial nerve, which descends obliquely downwards and lackwards to the jugular furrow. The last-mentioned nerve is also more deeply seated.

The gland will be found to be very loosely applied to the atlantal wing by means of a quantity of areolar tissue. This may be easily broken down with the finger, and the styloid process of the occipital bone will then be distinctly felt. By gently pushing the posterior edge of the gland forwards, the styloid-cornu of the hyoid bone may be felt as a flat plate, and running downwards and forwards to the cornu from the styloid process of the occipital bone is a small flat muscle. This is the occipito-styloid, which lies right over the pouch.

Having felt these various structures, an incision should be made in the occipito-styloid muscle, the incision being in the direction of the length of its fibres, care being taken to avoid the posterior auricular artery.

Through this incision a curved probe with a blunt "ball" extremity should be introduced, and so manipulated that the ball presses against the outer part of the floor of the pouch.

The position of the probe will then be evident on the exterior by a prominence appearing near the angle of the jaw in the triangle of Virborg. In this situation another incision should be carefully made, after the manner described in Virborg's method, down on to the probe, and through this lower opening the pouch may be emptied.

The openings should be kept patent by a seton tape passed through both, from above downwards, and the affection thereafter is treated as an ordinary abscess. 


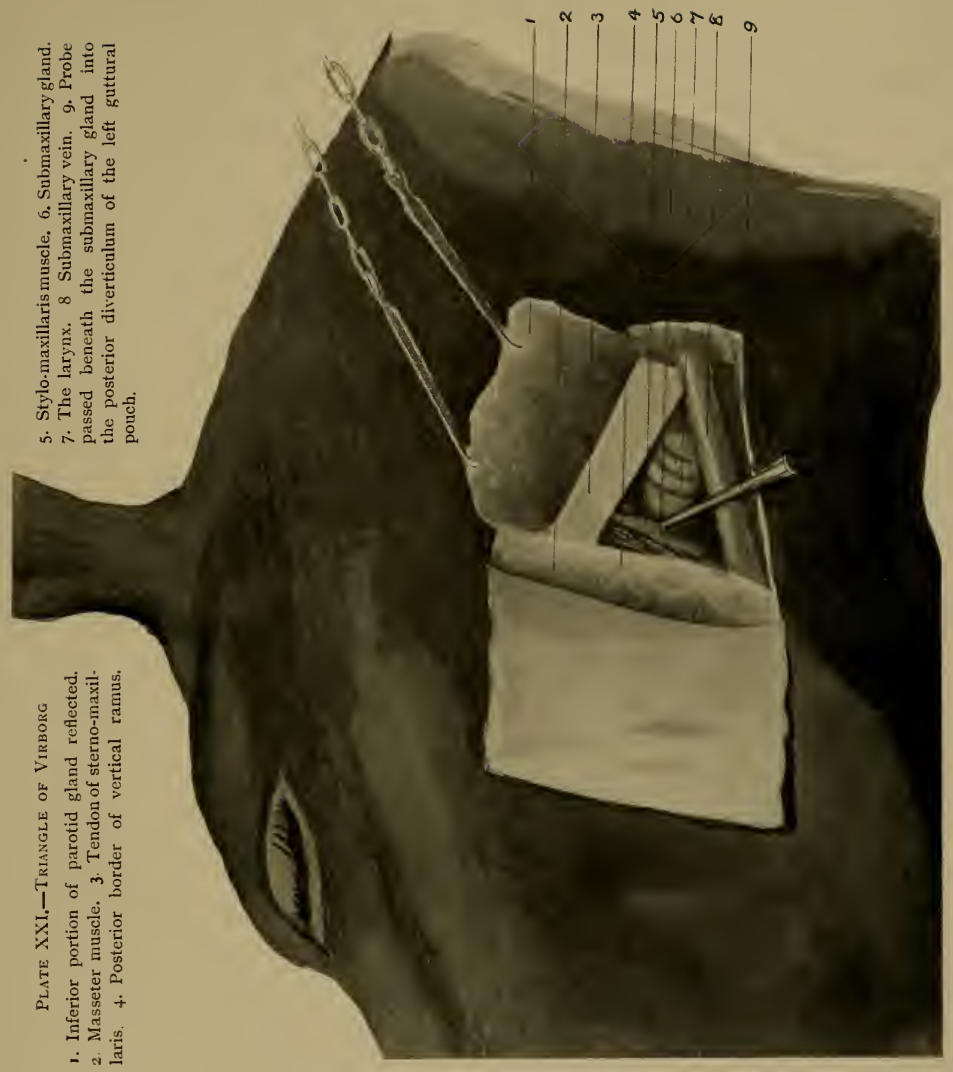





\section{CHAPTER VI \\ THE BONES-SINUSES OF THE SKULL}

\section{THE BONES-FRACTURES}

IT is unnecessary here to give a full description of the osteology of the skull, and for our purposes it will suffice to describe those parts which are the seats of the more common fractures.

In our superficial examination, the large subcutaneous area of bone extending from the divergent ridges formed by the splitting up of the sagittal crest above, to the nasal peak below, was described. The bones, which are here subcutaneous, namely, the frontal, nasal, and parts of the superior maxillary, malar and lachrymal bones, for the most part form the anterior boundaries of the frontal and maxillary sinuses, and the nasal fossæ.

Although these bones are of a very firm consistency, being made up mostly of compact tissue, their plate-like form and their position relative to the underlying cavities, render them very liable to fracture, as a result of blows and injuries received over the area named. Such fractures are very common in colliery ponies, owing to the head coming into contact with spars of timber, etc., which project from defective roofs into the colliery passages. In these cases the fractures usually occur in the inferior half of the area named, since the concussion of blows received over the region of the frontal bone is limited by the pad which these ponies usually wear suspended from the poll-strap of the bridle as a protection against "roofing" of the poll. The fractures frequently 
occur along the sutures in young animals, owing to the fact that they are not completely ossified.

Should there be no displacement of the bone, no treatment is necessary other than protecting the part from pressure from without. But such fractures are usually accompanied by a depression of the bones into the underlying cavities, and in these cases it becomes necessary to raise the depressed bones to their normal level. This is effected by trephining into the cavity, the trephined opening being made close to the area of bone depressed. Through this opening a curved probe with a blunt or "ball" extremity is introduced, and by utilising the instrument as a lever with the edge of the opening as a fulcrum, the ball is pressed against the displaced bone until the latter is sufficiently raised. It may be necessary to trephine at two or three seats. Any splintered pieces of bone or foreign material must be carefully removed.

The Nasal Peak.--This is the long tapering piece of bone which is formed by the inferior extremities of the two nasal bones. These in the young animal come into apposition with one another along the nasal suture, and in the old animal are ossified together.

The peak is flattened from before to behind, and in outline resembles an isosceles triangle, the base of which is directed upwards and is indicated by an imaginary line drawn transversely in the position where the peak is in continuity with the bodies of the nasal bones. The sides of the triangle are free, and are separated from the nasal processes of the pre-maxillary bones by an interval which progressively increases as we descend to the apex or point of the peak, which is also free.

The nasal peak is supported, therefore, only at its base, and it is commonly fractured, an injury which is due usually to the part coming into forcible contact with the ground when the animal falls. Displacement in the downward direction may readily occur. Diagnosis of such a fracture is not difficult, since the peak may be easily felt and manipulated.

To raise the depressed piece of bone a conical piece of wood, 


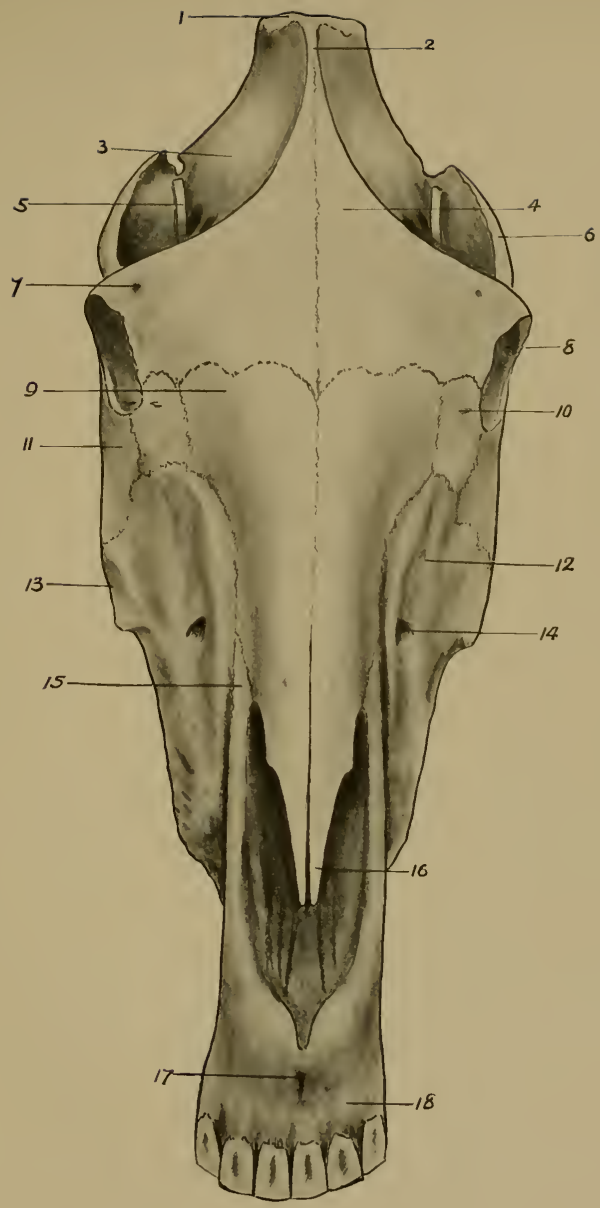

Plate XXII.-SKull of Horse (viewed from front)

I. Occipital crest, 2. Sagittal crest. 3. Temporal fossa. 4. Frontal bone. 5. Coronoid process. 6 Zygomatic process. 7. Supra-orbital foramen. 8. Orbital cavity. 9. Nasal bone. 10. Lachrymal bone. 11. Malar bone, 12. Superior maxilla. 13. Zygomatic ridge. If. Infra-orbital foramen. 15. Nasal process of pre-maxilla. 16. Nasal peak. 17. Incisor foramen. I8. Body of pre-maxilla. 

tapering gradually to the apex and wrapped in some soft material, such as chamois leather, in order not to injure the nasal mucous membrane, should be passed up one of the nostrils. Whilst this is being passed with one hand, the fingers of the other hand should be pressed against the apex of the peak, which should be steadily raised. A charge applied to the skin over the nasal bone, and extending for three or four inches above the line of fracture, will generally be found to be effective in maintaining the broken piece of bone in position, but if further assistance is necessary this may be rendered by plugging the nostril with a roll of tow or cotton wool.

The Pre-Maxillary Bone.-This bone consists of a body and two processes, namely, the nasal and palatine.

The body possesses three surfaces. The upper or labial surface is convex and smooth, and in the living animal is related to the upper lip. The inferior or buccal surface is concave and smooth, and in the recent state is covered by the buccal mucous membrane. The remaining surface is rough, and is that which is applied in the median line to the corresponding surface of the opposite pre-maxillary bone. Transversely across this surface runs a groove which, when the two pre-maxillary bones come into apposition, forms, with the corresponding groove of the opposite bone, the incisor foramen. Through this foramen the incisor or palato-labial artery passes to supply the upper lip.

The edge separating the labial and buccal surfaces carries alveoli for three incisor teeth.

The nasal process is an elongated rod, which extends upwards and backwards from the body. Its internal and external surfaces are convex and smooth, and blend with the greater part of the anterior surface, but superiorly the latter is articulated to the nasal bone. Posteriorly the process is articulated throughout its extent to the superior maxillary bone, and near its junction with the body is the alveolus for the canine tooth.

The palatine process or plate is flattened from before to behind. It extends upwards from the body and forms a small portion of the 
inferior part of the hard palate, whilst its anterior surface forms part of the floor of the nasal chamber. Its inner edge is opposed to the corresponding edge of the opposite plate. Its outer edge forms the inner boundary of the interval in the mascerated skull known as the nasopalatine cleft.

In the mature animal the inner surfaces of the bodies of the two pre-maxillary bones become firmly ossified to one another.

In the young animal fracture frequently occurs along the premaxillary suture due to the animal falling and striking the antero-lateral aspect of the muzzle, or both pre-maxillary bones may be displaced downwardly, and cause fracture of small portions of the nasal bones near the upper extremity of the nasal processes. In the adult animal from a similar cause both bones may be fractured transversely across the line of continuity between the nasal processes and the bodies. The walls of the incisor alveoli may be broken in. Frequently the body of the premaxilla is broken into a number of irregular pieces and we have a comminuted fracture.

Treatment depends upon the nature of the injury. Detached pieces of bone should be removed. In cases of fracture through the symphysis and downward displacement of one pre-maxilla only, the body of this bone may frequently be elevated to its proper position by the insertion of a mouth gag, which must be opened very gradually. The bone may be maintained in position by twisting wire round both premaxillary bodies, the wire being passed between the incisor teeth. Wire so applied may also be utilised to keep large fractured pieces of one pre-maxillary body in position after reduction.

Some operators, after reduction of the displaced bones, maintain them in position by the application of a padded, wooden or metal splint to the palate, upon which the splint is moulded. This splint is held in position by two straps carried round one on either side to near the peak of the nasal bones, where they are attached to a strap which descends the face from the brow-band. 
The Supra-Orbital Process.-This is a solid rod of bone which projects outwardly from the body of the frontal bone. It is convex and roughened superiorly and concave and smooth inferiorly, where it forms part of the roof of the orbit. Outwardly it is articulated to the zygomatic process of the squamous temporal bone. Near its root it is pierced by the supra-orbital foramen for the passage of the supra-orbital artery, etc.

The superior surface of the rod is immediately subcutaneous, and it forms a prominent projection in the living animal. Above the process is the temporal muscle.

Although the process is in an exposed position and forms one of the prominent parts of the body, it is not commonly fractured owing to its thickness and strength. Fracture of this bone only occurs in animals exposed to special risk, such as colliery ponies. When such a fracture occurs and the bone is displaced downwardly, it exerts pressure upon the eyeball, which must be relieved by raising the depressed piece of bone. This is effected by making an incision through the skin over the temporal muscle, behind the process. Through this incision a stout metal probe is introduced, and passed immediately behind the edge of the process. The probe should rest on the zygomatic process of the squamous temporal bone, and utilising the zygoma as the fulcrum, the depressed bone is elevated by a process of leverage.

The Inferior Maxilla.-This is made up of a body and two rami. The body is placed anteriorly, and from it the rami diverge. It possesses two surfaces, the inferior of which is convex and smooth, and in the living subject is related to the lower lip. The upper surface is depressed and smooth, and forms that part of the floor of the mouth upon which the tip of the tongue rests. These two surfaces are separated from one another by an edge which carries six alveoli for the incisor teeth. A short distance behind the alveolus for the corner incisor on each side is an alveolus for the canine tooth, which as a rule is only present in the male. 
Each ramus is a laterally compressed plate, which presents a wellmarked bend, dividing the plate into two portions, one of which is disposed vertically and the other horizontally. The width of the plate is greatest across the bend. For descriptive purposes the ramus may be said to possess two surfaces, two borders, and two extremities.

The outer surface of the horizontal portion is smooth and convex, but that of the vertical portion is depressed, and presents a number of rough markings for the attachment of the masseter muscle which clothes this part of the ramus. Near its junction with the body the ramus presents on this aspect the large mental foramen which communicates with the inferior dental canal, and through which the mental nerve and vessels pass.

The inner surface of the ramus is slightly depressed in its horizontal portion. The genio-hyoideus and genio-glossus muscles are attached to this surface of the bone close to its junction with the body, and the mylo-hyoid muscle is attached to a faint marking near the alveolar edge. On the vertical portion the surface is depressed and roughened for the attachment of the internal pterygoid muscle, and slightly behind its anterior border is a large foramen, which is the entrance to the inferior dental canal through which the inferior dental branch of the inferior maxillary division of the fifth nerve, with its accompanying artery, passes.

The superior or anterior border of the horizontal portion presents the alveoli for the six molar teeth, and where this border is continued in front of the vertical portion it is thin and sharp. To it, immediately below the coronoid process, the temporal muscle is attached.

The horizontal and vertical portions of the posterior or inferior border are sharp and well defined, but where these portions become continuous with one another the border becomes very much thickened and roughened, and this portion constitutes what is known as the angle of the jaw.

The upper extremity of the bone carries the coronoid process and the condyle, with the intervening sigmoid notch. 
The coronoid process is plate-like, being flattened from side to side, and its summit is rounded. It extends to a level of about one and a half to two inches above the condyle, and in the living animal is deeply seated to the zygomatic process of the squamous temporal bone.

The condyle presents an articular surface superiorly, which enters into the formation of the temporo-maxillary joint. Just below this surface it gives attachment outwardly to the external lateral ligament of the joint, and inwardly to the external pterygoid muscle.

The inferior extremity of the ramus is constricted and is attached to the body.

The inferior maxillary bone ossifies from two centres, one for each ramus and the corresponding half of the body. The two halves of the bone remain disrinct along the median suture for about three months after birth.

The inferior maxilla is very commonly fractured. Frequently the fracture is along the line fusion of the originally separate halves. Another common seat is across the constricted portion of the ramus just behind its attachment to the body. Pieces of bone may be splintered off the subcutaneous portion of the horizontal ramus (the vertical portion being protected by the masseter muscle), or the angle of the jaw, whilst the walls of the molar alveoli are commonly broken. Injury to, and occasionally a small fracture of, the inferior sharp edge of the horizontal portion is sometimes caused by the violent use of a curb.

Treatment of course varies with the seat and nature of the fracture. As usual, any splintered pieces should be removed.

When the fracture is along the symphysis the bones should be replaced and maintained in position by means of wire twisted round both halves of the body and passed in between the incisor teeth, as in the treatment of similar fractures of the upper jaw.

Fracture through the constricted portion of the ramus, when unilateral, may be similarly treated, and co-aptation in this case is 
assisted by the application of a charge along the lower border of the ramus. If such a fracture be comminuted, care must be taken in removing the loose pieces not to injure the structures issuing from the mental foramen.

Various kinds of apparatus have been designed for the treatment of fractured rami. Binz uses "a piece of wood, the shape of the inter-maxillary space, covered with cloth, and furnished with straps to suspend it behind the ear, and attach it round the forehead and face."

Walker designed a cradle " composed of two lateral portions fitting to the sides of the face, suspended from behind the ears by a padded strap, and kept in position by a brow-band, throat-strap, and jaw-straps, with a central portion of wood padded with leather to fit between the branches of the jaw, and two flanges to rest on the first molar on each side of it." For this cradle a considerable amount of success is claimed.

Solid food should be withheld, liquids only be given, and assistance in maintaining the condition of the animal may be derived from the frequent injection of nutritive enemata.

The Cervical Vertebre.-This series consists of seven bones. The last five approach most nearly the description of what is generally accepted as a typical vertebra, than do those of any other series. They are characterised by their long centra, the anterior extremity of which is markedly convex, and the posterior extremity correspondingly concave. Their superior and inferior spinous processes are poorly developed, excepting in the case of the seventh, which has a very prominent neural spine. Their oblique processes are large and present extensive articular areas for articulation with the processes of the bone with which they come into apposition. Their transverse processes are small, but they project out prominently and terminate abruptly, and excepting in the case of the seventh vertebra each is pierced by a vetebral foramen. Large intervertebral foramina are formed by the notches in the contiguous arches for the passage of the spinal nerves. 


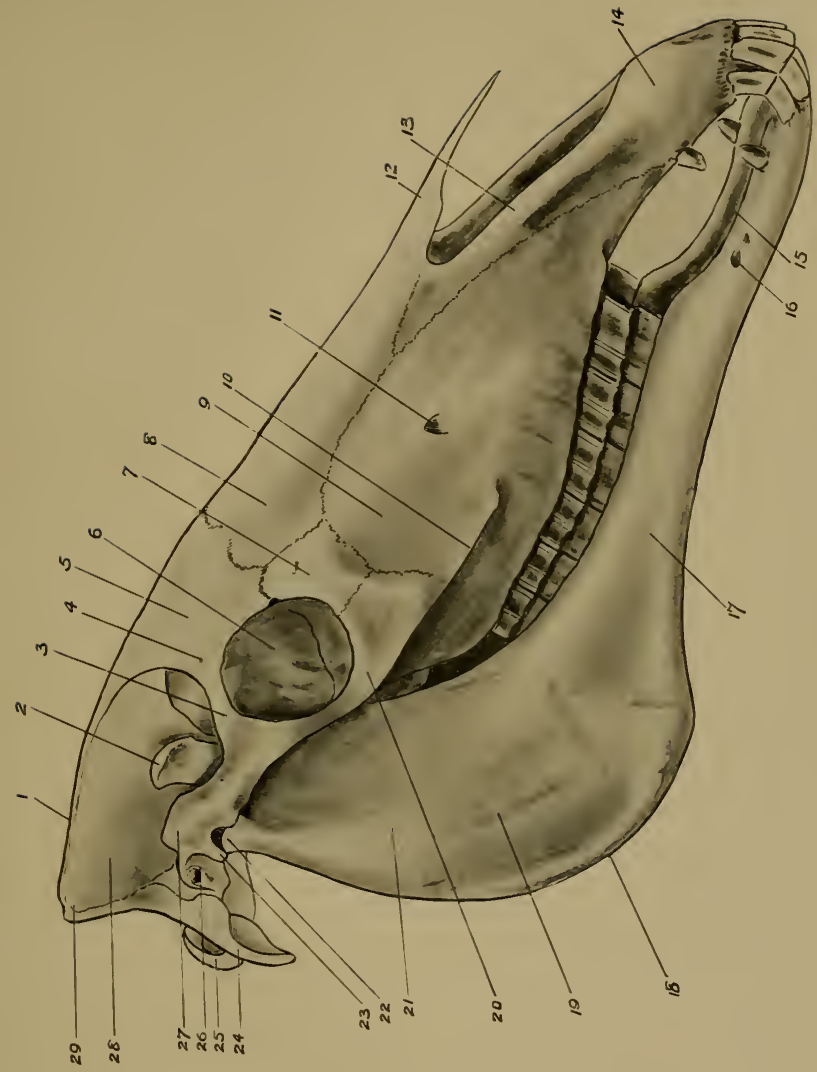

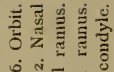

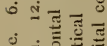

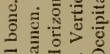
절

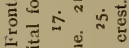

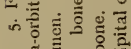

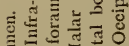
플

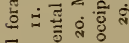

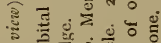
ป ङ

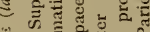
कै $\div$ के के क्ष

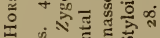
च

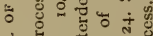
ป 岂

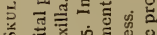

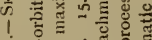

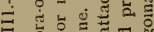
অ

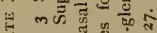

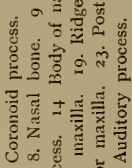
ن . 政茫范 롤

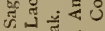
- $\therefore$ 迆 

A marked departure from the typical is seen in the first and second members of the series. The atlas is simply a ring of bone from which two plate-like wings project outwards. The edges of the wings project outwards and downwards, and as already remarked, they form a prominent landmark in the living animal. Posteriorly the wings present the posterior foramina for the passage of the retrograde arteries. Anteriorly four foramina are seen, two of which, namely, the antero-external, pierce the wings, and give passage to the occipital vessels and the inferior primary divisions of the first spinal nerves. The two remaining foramina, the antero-internal, pierce the ring, and give passage to the first spinal nerves and the cerebro-spinal arteries. Anteriorly the atlas presents two depressed facets for the accommodation of the occipital condyles. The posterior part of the floor of the ring is smooth, and articulates with the odontoid process of the axis.

The axis has an exceedingly long centrum, from which the odontoid process projects anteriorly. In the horse this process has a very stout base, which has not the marked constriction present in most other animals. The axis has an enormous neural spine, which is thick and powerful, and is bifid posteriorly, where each division terminates on the superior aspect of the posterior oblique process of its side. Its transverse processes are very small.

Fractures of the wings of the atlas frequently occur, as would naturally be expected from their exposed position. (See Poll-evil.) Fractures of the occipital condyles and the odontoid process are also reported, though the latter are extremely rare, on account of the strength of the process in the horse as already remarked.

A blow on the side of the neck may also fracture the tubercle-like extremity of the transverse process, and violent movement of head in a vertical plane may fracture the oblique processes on account of the great pressure thrown upon their articular surfaces. In cases of fracture of the transverse processes prognosis is favourable unless the fracture be across the base, in which case rupture of the vertebral artery 
and profuse hæmorrhage into the spinal canal with a fatal result, is a liable sequel.

Any fracture of the sixth or seventh vertebra is serious on account of the liability to injury of the phrenic nerve, in which case paralysis of the diaphragm would most probably result. This nerve derives its fibres from the inferior primary divisions of the fifth, sixth and seventh cervical nerves, though the contribution from the fifth is inconstant.

Fracture through the oblique processes of the third or fourth cervicals may be favourably treated when there is not much displacement. When such a fracture is suspected, a cradle should be applied to the neck, the head tied to the rack, and all precautions taken to prevent the animal moving its head.

\section{THE SINUSES OF THE SKULL}

These are large irregular spaces formed in the skull, the size of which they materially increase without providing any addition to its weight. The sinuses are placed chiefly in the region of the face, but some are deeply seated and extend towards the cranium.

Four pairs of sinuses are described, namely, the sphenoidal, frontal, superior maxillary, and inferior maxillary.

The Superior Maxillary Sinus.- This is much the most extensive and it is placed on the lateral aspect of the face, being bounded, as is gathered from its name, chiefly by the superior maxillary bone. Superiorly it communicates with the frontal sinus, the division between the two being a thin plate of bone, which stretches obliquely between the ethmoidal lateral mass and the osseous tube placed on the inner aspect of the superior maxilla through which the lachrymal duct passes. The communication between the frontal and superior maxillary sinuses is in this plate, and is in the form of a large elliptical foramen, the 
long axis of which is about two inches in extent and is directed vertically. This sinus may be said to have two compartments, which are incompletely separated from one another by a ridge of bone which bounds the superior dental canal; over this ridge there is free communication between the two divisions.

The inner compartment, which is the smaller of the two, extends beneath the floor of the orbit, and superiorly it is in communication with the sphenoidal sinus. This is the division which also communicates with the middle meatus of the nose, by a curved slit-like aperture near the upper part of the latter.

The outer division extends in the upward direction into the maxillary protuberance, at the upper extremity of the superior maxilla behind the maxillary hiatus. Its lower limit extends to a level which is situate from one and a half to two inches above the lower extremity of the zygomatic ridge. The lower extremity of this compartment is separated from the inferior maxillary sinus by an imperforate, horizontally placed, delicate, osseous septum. The position of this plate is extremely important, and will be again referred to in describing the operation of trephining into the sinus. The degree of development of the septum is also said to be variable. According to Lanfiletti, it attained a high degree of development in about 75 per cent. of a large number of cases examined.

The root of the sixth (and in part also that of the fifth) upper molar tooth projects into the posterior wall of this sinus, where it is covered by a thin plate of bone which forms part of the boundary of the alveolus. The bulgings formed by this plate of bone in the young animal almost entirely occupy the cavity of the outer compartment, but as the animal advances in age the teeth are pushed out from their sockets, the alveoli diminish in size, and a corresponding enlargement of the sinus takes place.

In addition to the superior maxilla this sinus is also bounded by part of the lachrymal bone, the malar, the posterior tubinated bone, and 
the lateral mass of the ethmoid. The boundaries of the outer wall of the sinus may be traced out on a skull as follows :

The superior border would be indicated by a line drawn transversely from the zygomatic ridge forwards to the nasal canthus. The anterior boundary may be similarly indicated by a line drawn obliquely downwards and forwards from the nasal canthus for a length of one and a half to two inches in the direction of the nasal peak. The posterior limit of the sinus may be likewise indicated by a line drawn along the zygomatic ridge, commencing at a point from one and a half to two inches above its lower extremity, and terminating superiorly where it intersects the line already drawn as indicating the superior limit of the sinus. A line connecting the inferior extremities of the lines indicating the anterior and posterior limits, would represent the position of the septum separating the superior and inferior maxillary sinuses.

The Frontal Sinus.-In size this sinus is the second largest, and it is placed towards the front of the face. It extends in the upward direction between the reflected plate and the body of the frontal bone, and this part of it is placed directly in front of the cranial cavity. On account of the disposition of the reflected plate and the body of the frontal bone to one another, it will be gathered that the size of the sinus from before backwards, diminishes as we ascend to the position where the reflected plate is united to the body. This point should be noted in connection with the operation of trephining into this sinus, for should the error be committed of adopting a seat too high up the forehead, there is an evident danger of opening into the cranial cavity, and causing serious injury to its contents.

The right and left frontal sinuses are separated from one another in the median line by a complete bony septum, and there is, therefore, no direct communication between them. This septum forms the greater part of the inner boundary of the sinus. It extends vertically for about four inches, and then takes a course which is slightly 


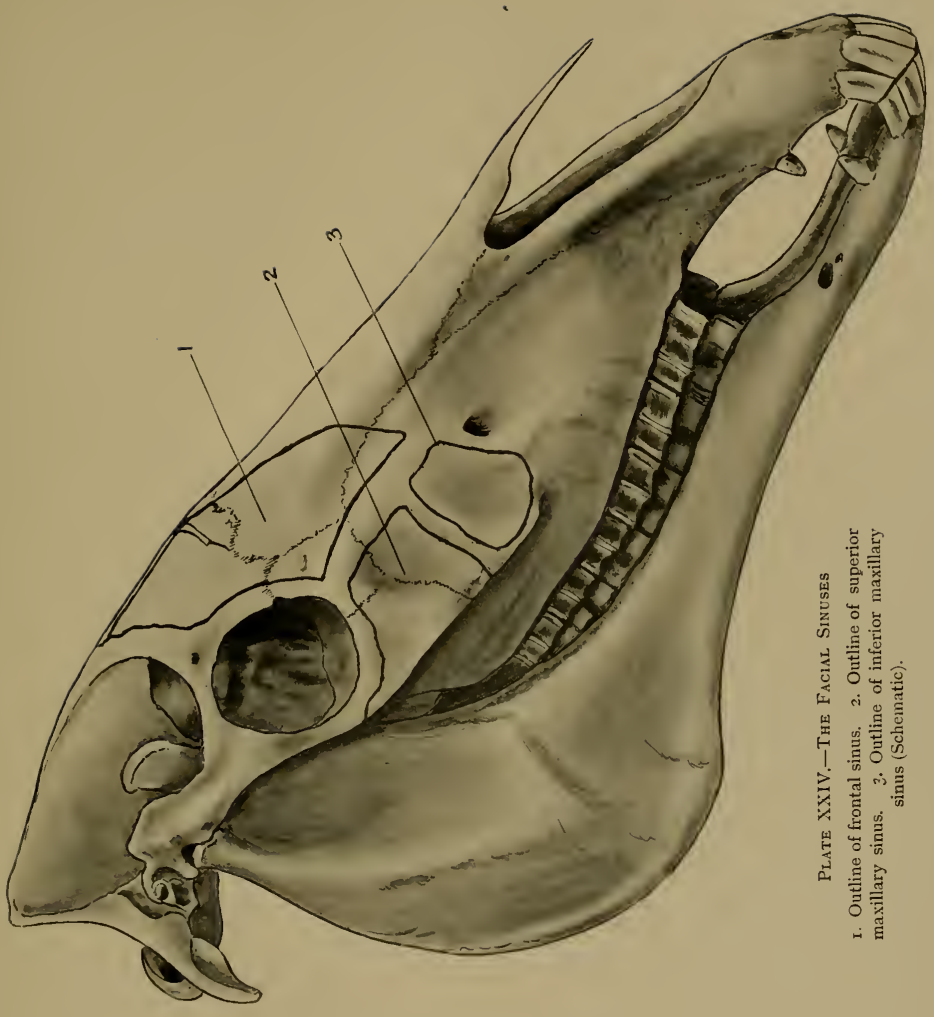



outwards. The upper portion of the anterior turbinated bone forms the remainder of the inner boundary of the sinus, and separates it from the cavity of the nose.

The lower limit of this sinus extends to a point which may be indicated by taking a line from the zygomatic ridge horizontally forwards, about three and a half to four inches in length, the anterior limit of which is about three inches from the nasal canthus.

The frontal sinus is bounded by the frontal, nasal, lachrymal, ethmoid, and anterior turbinated bones, and a point of considerable importance to remember is that it is direct communication with the superior maxillary sinus of its own side.

The outline of the sinus may be traced on the exterior of the skull as follows :

Its superior limit would be indicated by a transverse line drawn from the middle line at a distance of half an inch above the supraorbital process, to the level of which it extends in the outward direction.

The inner boundary in its upper portion is indicated by a straight line representing the position of the septum between the two frontal sinuses already referred to, and in its inferior portion by an oblique line drawn downwards and outwards from the lower extremity of the above, and which terminates on meeting the line, to be mentioned hereafter, indicating the course of the lachrymal duct.

The outer boundary of the sinus is very irregular. It takes at first a sinuous course downwards from the line indicating its upper limit, to the nasal canthus, and then takes a course obliquely downwards and forwards from this point in the direction of the nasal peak. The line indicating the latter portion of its course will also indicate the course of the osseous tube which accommodates the lachrymal duct, and where this line intersects the oblique portion of the line indicating the inner boundary of the sinus, we have its lowest limit.

The Inferior Maxillary Sinus.-The inferior maxillary sinus, like the 
superior, has two divisions, but these are in communication with one another over the osseous ridge which is the continuation of the superior dental canal. This sinus is placed in the superior maxillary bone. The inner division of the sinus is the smaller, and it communicates directly with the middle meatus of the nose. It is bounded inwardly by the posterior tubinated bone. The outer division is situate directly beneath the corresponding division of the superior maxillary sinus, from which, as already stated, it is completely separated by a thin and imperforate septum. The upper limit of this sinus therefore would be indicated by a line drawn horizontally in a position which is from one and a half to two inches above the lower extremity of the zygomatic ridge. The lower limit of the sinus may be likewise indicated by a line drawn horizontally about three-quarters of an inch below the inferior extremity of the zygomatic ridge. This line, however, takes a very irregular course, and on this account an opening made below the inferior extremity of the ridge may not necessarily lead into the sinus.

The tracing of this sinus on the exterior of the skull may be made as follows :

Its superior boundary would be represented by the line already drawn as indicating the inferior boundary of the superior maxillary sinus. Its anterior boundary is indicated by the inferior portion of the line representing the course of the lachrymal duct, its posterior boundary may be represented by a continuation of the line which indicates the posterior boundary of the superior maxillary sinus, and its inferior boundary by the irregular line already referred to.

The Sphenoidal Sinuses. - The sphenoidal sinuses are the smallest of the sinuses of the skull. They are also of least importance from a surgical point of view, since they are deeply seated, near the base of the cranium, and are consequently in an inoperable position. Each sinus is divided into two portions, namely, sphenoidal and palatine. The sphenoidal division is an excavation in the anterior or lower portion of the body of the pre-sphenoidal bone. This portion is divided up into a number of 


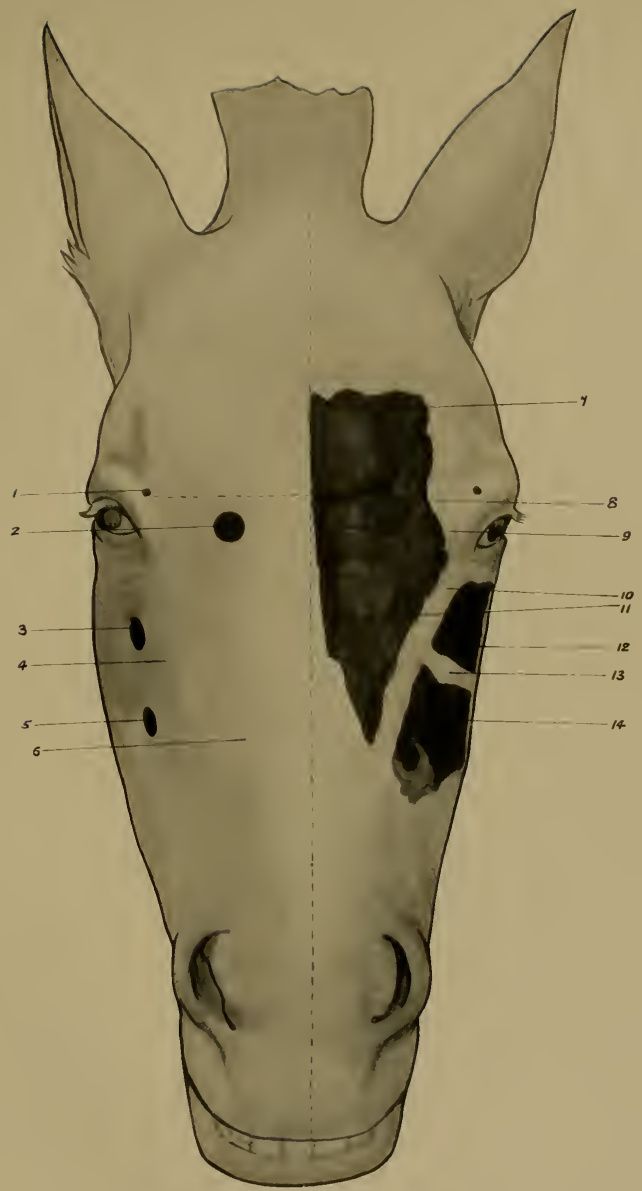

\section{Plate XXV.-interior of Facial Sinuses of Left Side}

1. Supra-orbital foramen. 2. Trephined opening into frontal sinus. 3. Trephined opening into superior maxillary sinus. 4. Elevation caused by levator labii superioris proprius muscle. 5. Trephined opening into inferior maxillary sinus. 6. Direction of fibres of levator labii superioris alaque nasi muscle. 7. Reflected plate of frontal bone. 8. Frontal sinus. 9. Lateral mass of ethmoid. ro. Course of osseous tube containing ductus ad nasum. Ir. Nasal turbinated bone. 12. Superior maxillary sinus. 13. Septum separating the maxillary sinuses. 14. Inferior maxillary sinus. 

irregular, and intercommunicating, loculi. Between it and the corresponding portion of the opposite sphenoidal sinus there is placed a vertical septum which, however, is perforated, and consequently the two sphenoidal sinuses are here placed in free communication with one another.

The other division of the sphenoidal sinus is the palatine, which is bounded by the vomer, the palatine, and the lateral mass of the ethmoid. This portion communicates above with the sphenoidal portion, and inferiorly it is in free communication with the inner division of the superior maxillary sinus.

From what has already been stated, it will be seen that all the sinuses communicate with the exterior. The superior maxillary sinus communicates directly with the middle meatus. The sphenoidal and frontal sinuses communicate with the superior maxillary, and the inferior maxillary sinus communicates directly with the middle meatus. Moreover, since the two sphenoidal sinuses communicate with one another through the perforations in the septum between them, the sinuses of one side of the head are therefore in communication with those of the other.

Operations on the Simuses. - The frontal, superior maxillary, and inferior maxillary sinuses are frequently opened into, which operation is known as "trephining." The operation is performed in the treatment of empyema of the facial sinuses, in cases of growths such as tumours in the cavities, or the presence of foreign bodies or fractured pieces of bone, and also, as already referred to, in the repulsion of certain molar teeth.

The superior maxillary sinus, otherwise the antrum of Highmore, was at one time trephined in the treatment of glanders, but for obvious reasons, in the present state of our knowledge of this disease, such a method of treatment is not now adopted.

On account of the communication which exists between the sinuses it will be understood that, as purulent matter is formed in the sphenoidal 
or frontal sinuses, it has a tendency to gravitate into the superior maxillary, and it is thus possible to drain all three sinuses by opening into the last named; but to facilitate the removal of the contents, and to remove any probable obstruction which there might be to the free communication between them it is always advisable to open both into the frontal and superior maxillary sinuses.

It will readily be gathered that inflammation of the mucous membrane lining the sinuses may be consequent upon a similar condition affecting the mucous membrane of the nasal chamber, and also, as already stated, that as the purulent exudate resulting from the process of inflammation accumulates in one or other of the sphenoidal or frontal sinuses, it has a tendency to gravitate into the superior maxillary sinus. In cases of empyema of the facial sinuses there will therefore be a chronic discharge of purulent material from the nostrils owing to the natural communication which exists between the superior maxillary sinus and the nasal chamber, and, moreover, this discharge would be augmented if the animal's head were held in the dependent position.

But from our examination of the nasal chamber it will be remembered that this communication is by no means a free one, being deeply seated between the two turbinated bones near the upper extremity of the middle meatus. Consequently, as a rule, the escape of the inflammatory exudate does not keep pace with its formation, and as a result we get, in advanced cases the frontal sinus, in addition to the superior maxillary, filled with purulent matter. Occasionally it happens that on account of great swelling of the Schneiderian membrane in the region of the orifice of communication with the nasal chamber, the escape of the material into the latter chamber is prevented, or the orifice itself may become occluded by the inflammatory products. In such cases therefore a purulent discharge from the nostrils would not be one of the symptoms of empyema of the sinuses.

Another symptom of empyema of the sinuses is the absence of the resonant sound which is normally heard upon percussing the areas 
already mapped out as indicating the position of the sinuses. In the place of this sound we now have a dull thud.

At times the area over the frontal bone loses its flattened appearance and becomes convex on account of the bulging forwards of the underlying bone. When the affection has reached an advanced stage, the bones become softened, and occasionally the finger, without utilising a great amount of force, may be pressed through the bone into the cavity of the sinus. Positive diagnosis may be made by exploration with a gimlet.

After diagnosis of the condition the operation of trephining into the sinuses becomes necessary in order that these cavities may be emptied of their purulent contents, and also in order that they may afterwards be injected out with antiseptic solutions.

In cases of tumours or foreign bodies, such as fractured pieces of bone in the sinuses, the seat of operation must be as nearly as possible over the area affected. In such cases it is advisable to revise the general superficial anatomy of the areas of the sinuses. (See Plate XIV., Superficial Dissection of Face.)

The following description refers to the performance of the operation in the treatment of empyema.

Trephining into the Superior Maxillary Sinus.-It is advisable in performing the operation of trephining into this sinus, to make the trephined opening in such a position that the lower portion of its circumference will be on as near as possible an exact level with the osseous septum separating the superior and inferior maxillary sinuses. The object in selecting this position is in order that the septum referred to shall form a natural floor for drainage, and also that there shall not be "pocketing" of purulent material behind the trephined opening.

The usual position of this septum in an average-sized animal is one inch and a half above the inferior extremity of the zygomatic ridge of the superior maxillary bone. The distance of the septum 
from the inferior extremity of the ridge, however, varies directly as the age and size of the animal, and as a rule the larger and older the animal, the further is the septum from the extremity of the ridge.

The position of the septum then, indicates the lower limit of the opening to be made. The centre of the trephine should also be placed at a spot which is situate one inch in front of the ridge. In young animals, however, it is advisable to select a spot still further forwards, namely, at a distance of an inch and a half to two inches from the ridge, in order that the walls of the molar alveoli may not be injured.

Upon examination of the area, the ridge of bone is easily felt and seen, and its inferior extremity readily located, since it terminates quite abruptly. In front of the ridge an elongated elevation is observed. This is the elevation which corresponds to the position of the levator labii superioris proprius muscle. This muscle is covered by the thin aponeurotic sheet of the levator labii superioris alæque nasi muscle, but the latter is here so thin that it does not materially affect the external conformation of the part.

The hair should now be removed from the surrounding area, and the seat thoroughly cleansed.

Several different kinds of cutaneous incisions are in use. Some operators make two crossed incisions. Others a T-shaped one, whilst others adopt two incisions meeting one another after the form of the letter $V$, the apex of which is directed downwards. This last is probably the best kind to be recommended, since the flap of skin is afterwards useful in obscuring from view for a few days the opening into the sinus, and at the same time admits of the free passage outwards of material from within the sinus.

Such an incision is carefully made, and the skin reflected upwards. There is usually no danger here of injuring either the angular artery or its accompanying vein, since these run obliquely upwards and 


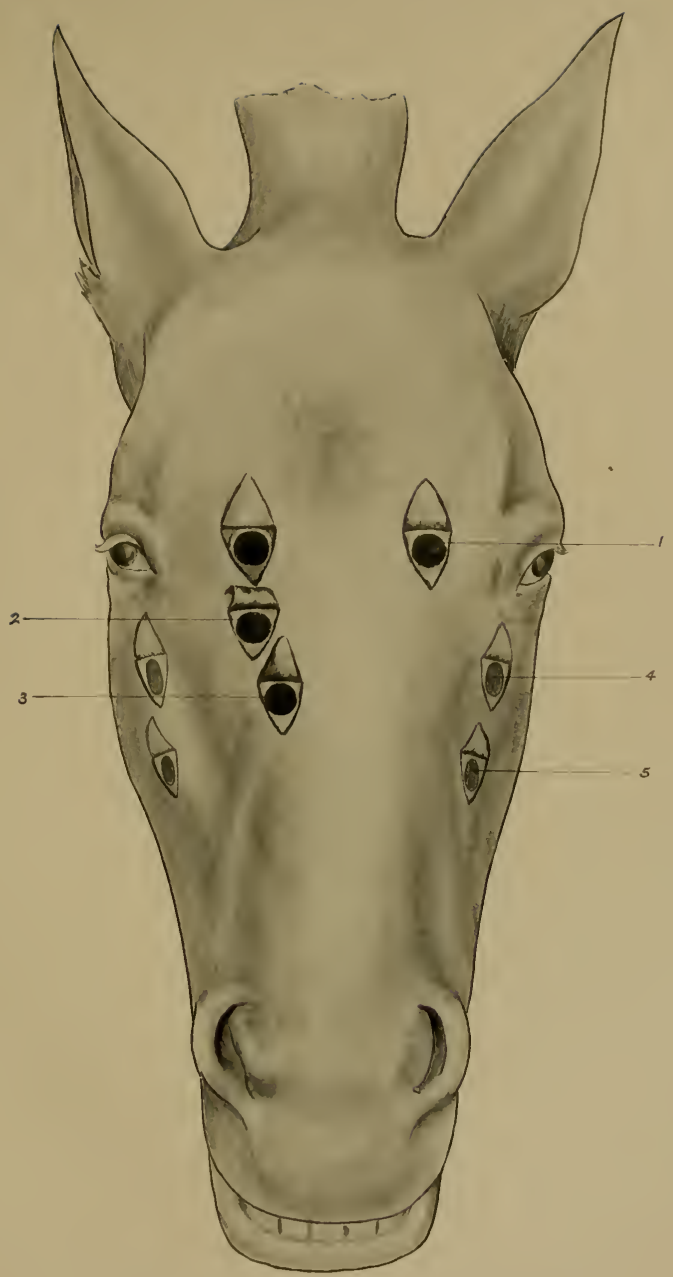

Plate xivi.-Trephined Openings into the Facial Sineses

1. Opening into frontal sinus. 2. Opening into frontal sinus (Siedamgrotzky's). 3. Opening into frontal sinus (Craig's). 4. Opening into superior maxillary sinus. 5 . Opening into inferior maxillary sinus. 

forwards a short distance in front of the seat. Greater care, however, is necessary when operating further forwards, as in the young animal.

A similar incision is next made through the levator labii superioris alæque nasi. Little if any hæmorrhage results from such an incision, since the aponeurosis is so thin. But no incision must be made into the proprius muscle. It is unnecessary to incise it, for since it is quite lonsely applied to the anterior aspect of the zygomatic ridge, it is easily displaced and pushed forwards out of the way of the operator. This should be done, and thus the considerable hæmorrhage which would necessarily follow an incision into the muscle is avoided.

The bone covered by its periosteum is now exposed, and the periosteal layer is removed by means of a periosteotomy knife.

With a gimlet a hole should now be bored in the centre of the exposed area. This hole is for the accommodation of the central spike of the trephine.

In removing the circular piece of bone, the saw should be worked at first to and fro towards the right and left alternately, until a hold is obtained, when the movement should be in one direction only. This part of the operation is facilitated by applying a greater amount of pressure to one side of the saw than to the other, and this side of the bone will therefore be pierced first. When this occurs the circular piece of bone may be usually broken off, and care must be taken that it does not fall into the sinus. This may be effectively done by snapping off the piece or bone to be removed by means of a rigid probe inserted into the central hole first made, just before section with the saw is complete.

Trephining into the Frontal Sinus.-This operation is not a painful one. It is usually unnecessary to cast the animal, and the only method of restraint required is the application of a twitch.

From the anatomical description given, and by a further reference 
to Plate III., we are reminded that the greatest antero-posterior dimension of the sinus is about its middle, and that this dimension progressively diminishes as we proceed from a transverse plane indicating the middle of the sinus, either in the upward or downward direction.

To adopt a seat too high up the forehead would render injury to the brain a liable complication, whilst to adopt a seat which is correspondingly too low down would bring about the liability to injury to the ethmoidal lateral mass. Again referring to the Plate we observe that if a horizontal line be drawn from one supra-orbital foramen to the other, it would indicate the upper limit of an area which from an operating point of view may be termed safe, since almost immediately below such a line the sinus presents its greatest depth, whilst above the line its antero-posterior dimension decreases somewhat rapidly.

The supra-orbital foramina should therefore be located, and an imaginary horizontal line drawn across from one to the other. (Some operators chalk out the line.) A short distance below this line then must be the upper limit of the opening to be made. The line thus drawn should now be bisected by a line which runs vertically, namely, at right angles to the first line. This second line gives us the median sagittal plane, and, as before remarked, it will indicate the position of a plate of bone which forms the partition between the two frontal sinuses. Care must therefore be taken to avoid this line in operating, in order not to open down on to the septum.

In order to effect this the method of procedure should be as follows :

To bisect each half of the originally bisected horizontal line, when we now arrive at a point of bisection exactly below which the centre of our trephined opening should be placed, and half an inch below which point the circumference of the circular opening should pass.

According to Möller, "the frontal sinus is trephined at a point 
on a level with the supra-orbital process of the frontal bone, and about one inch from the middle line." At this point the frontal sinus is opened just below its upper extremity. According to Fleming, "the opening may be safely made half an inch or so above this line, or as low as the horizontal line between the inner angle of each eye, though this involves the upper end of the nasal bone. The opening should be in the space between the frontal suture and the eye." The dangers of allowing much variation in the seat selected have already been pointed out.

The bone is here immediately subcutaneous. The area is shaved and cleansed, and the cutaneous incision, together with the removal of a piece of bone, is carried out in a manner exactly similar to that already described in connection with the preceding operation. The only difference is that in this case the operation is much more simple, since there are here no muscles to be removed or incised, neither are there any important vessels or nerves near the seat.

If for some reason the operation has been performed with the animal in the recumbent position it should now be allowed to rise in order that the sinuses may be irrigated through the opening which has been made in the frontal sinus. This will usually cause the purulent contents to be driven out through the opening which has been made into the superior maxillary sinus. Various kinds of irrigating solutions are subsequently used. MacQueen recommends a solution of boracic acid, followed by a weak solution of lysol. The patency of the openings into both the frontal and superior maxillary sinuses should be maintained until the discharge ceases, and any diseased pieces of bone should be removed by pinching off with the bone forceps.

In those cases where the communication between the frontal and superior maxillary sinuses is occluded, and when the process of flushing through the frontal sinus, and other methods are ineffective in restoring its patency, it becomes necessary to make a counter-opening 
into the frontal sinus in order that its contents may be evacuated. This latter opening should be made near the lower limit of the sinus.

With regard to this point it may be of utility to refer to the seats of operation recommended by Siedamgrotzky and Craig, in the performance of the operation generally. The former "opens the frontal sinus about one-half to three-quarters of an inch in front" (i.e., below if the head be held with its long axis disposed vertically) "of a horizontal line drawn between the two inner angles of the eye, and one and a quarter to one and a half inches from the middle line of the face. After washing out the sinus cavity, he effects a communication between it and that of the nose by thrusting a director downwards and inwards at the deepest spot, breaking through the thin plate of bone and the mucous membrane covering it, and enlarging the opening so made by excising with a tenatome an oval fragment three-quarters of an inch long, and three-eighths of an inch wide." The latter states that the "position in which trephining may be performed on the frontal sinus is near to its lower extremity. The point of operation is about two and a half inches below the nasal canthus, and one inch in front of a line drawn from that canthus to the side of the nasal peak."

Since both these seats are near the lower limit of the sinus, in such cases as have been referred to where the operator fails to obtain communication between the frontal and superior maxillary sinuses, the adoption of one or other of these seats as outlets through which the contents of the frontal sinus may be driven by irrigation through the higher opening described, will doubtless prove a very potent method of bringing about the desired effect.

Trephining into the Inferior Maxillary Sinus.-This operation is performed when the condition of empyema affects the inferior maxillary sinus in addition to those before mentioned. There is no natural direct communication between this and the other sinuses, 


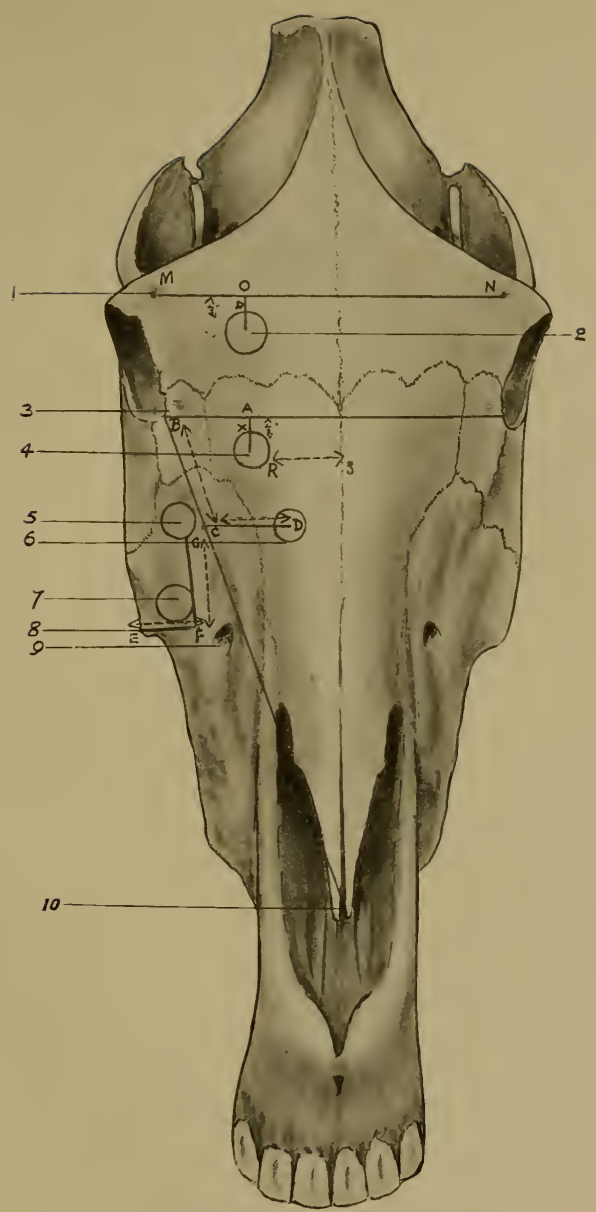

Plate XXVil.-Seats of Operations on Sinuses of Skull

1. Supra-orhital foramen. 2. Seat for opening into frontal sinus. 3. Nasal canthus. 4. Siedamgrotsky's seat of operation. 5. Seat of operation on superior maxillary sinus. 6. Opening into frontal sinus, recommended by Craig. 7. Seat of operation on inferior maxillary sinus. 8. Extremity of zygomatic ridge. 9. Infra-orbital foranen. 7. Seat of operation on inferior maxillary sinus. 8. Extremity
1o. Nasal peak.

$$
\mathrm{OP}=\frac{1}{2}^{\prime \prime} \quad \mathrm{AX}=\mathrm{l}^{\prime \prime} \quad \mathrm{MN}=4 \mathrm{M} \quad \mathrm{RS}=1 \frac{1}{2}^{\prime \prime} \quad \mathrm{BC}=2 \frac{1^{\prime \prime}}{2} \quad \mathrm{CD}=\mathrm{x}^{\prime \prime} \quad \mathrm{EF}=\mathrm{x}^{\prime \prime} \quad \mathrm{FG}=1 \frac{1}{2}-2^{\prime \prime}
$$



and it therefore always requires a separate opening for the evacuation of its contents.

Positive diagnosis of the affection in connection with this sinus should be made by exploration with a gimlet.

In describing the outline of this sinus it will be remembered that the line indicating its inferior boundary was most irregular, and that at some points it did not extend to a lower level than the inferior extremity of the zygomatic ridge, though the lowest limit of the sinus was about three-quarters of an inch inferiorly to this point.

The inferior limit of our trephined opening must therefore not come below the inferior extremity of the ridge, otherwise there would be a probability that our opening may not communicate with the cavity of the sinus. The area is shaved and cleansed as before. The flap of skin having been reflected, the bone is found to be subcutaneous. Care is necessary in this case to avoid the angular artery and vein, and particularly when operating on the young animal when a seat somewhat more anteriorly placed is selected as in the operation on the superior maxillary sinus, in order to avoid injury to the walls of the alveoli of the molar teeth. When the superior and inferior maxillary sinuses are affected the contents of both may be expelled through the opening just described, by breaking down the septum which separates the two sinuses. 'This is a method which is frequently adopted. 


\section{CHAPTER VII}

\section{THE TEMPORO-MAXILLARY JOINT- THE LIGAMENTUM NUCHÆ AND THE REGION OF THE ATLAS-POLL-EVIL}

\section{THE TEMPORO-MAXILLARY JOINT}

THERE are two of these joints, one between the condyle of each of the vertical rami of the inferior maxillary bone, and the glenoid cavity of the squamous temporal bone of the corresponding side of the skull.

The joints are of the diarthrodial variety, and they are the only joints of this kind in the skull.

The condyle is the process of bone which is placed posteriorly at the upper extremity of the vertical ramus. It is transversely elongated, and articular on its upper aspect. It is slightly convex in the transverse direction, and markedly so from before to behind.

The glenoid cavity is a transversely elongated depression. In front of it is the articular eminence, which is also elongated in the transverse direction, whilst behind it the "nipple-like" post-glenoid process projects. The anterior or inferior aspect of this latter process is also articular, whilst its posterior surface is roughened for ligamentous attachment.

Interposed between the articular surfaces of the bones is the fibro-cartilaginous meniscus, the inferior surface of which is moulded on to the superior aspect of the condyle. The superior surface 
conforms to the articular surface of the post-glenoid process and the glenoid cavity. The cartilage extends right across the joint, and to it the capsular ligament is firmly adherent on either side. This ligament is attached around the borders of the articular surfaces of the bones forming the joint.

Running from the roughened aspect of the post-glenoid process to be attached inferiorly to the back of the condyle just below the margin of its articular surface, is the posterior ligament, which is composed of yellow elastic fibres.

There is only one other ligament in connection with this joint in the horse, and this is placed on the external lateral aspect of the joint. It is a slender band of white fibrous tissue, which runs from the outer aspect of the condyle, where it is attached below the articular surface, forwards and upwards, to be attached superiorly to the inferior border of the zygomatic process of the squamous temporal bone.

This joint possesses two separate synovial membranes, one of which is placed between the condyle and the cartilage, and the other between the cartilage and the articular surface of the squamous temporal bone.

When the mouth is closed the cartilage and condyle are in position as described above. When the animal opens its mouth the two condyles are rotated on an imaginary horizontal axis passing through their centres. Whilst the condyle is being thus moved in the depression on the inferior aspect of the cartilage, the latter glides forwards along the articular eminence, so that when the mouth is fully opened the condyle and the articular eminence lie in the same vertical plane. During the closure of the mouth the cartilage glides backwards, and the condyle of the inferior maxilla is once more directly beneath the glenoid cavity. Lateral movement of the joint, such as is necessary when the molars triturate the food material, is permitted owing to the slight convexity of the condyle in the transverse direction. 
Dislocation of the Temporo-Maxillary Foint.-Dislocation of this joint is common in dogs. This is due to the fact that the articular eminence is absent in this animal, and consequently the condyle may be somewhat easily displaced in the forward direction from the glenoid cavity. Such a displacement in the horse however, otherwise than as sequel to a fracture of the bones themselves, is impossible, on account of the well-developed eminence which is present. Lateral displacement is prevented by the conformation of the articular surfaces, which restricts the lateral movements of the joint, and also by the capsular and external lateral ligaments, whilst displacement of the condyle in the posterior direction is prevented by the post-glenoid process.

Inflammation of the Temporo-Maxillary Foint.-Traumatic arthritis of this joint is somewhat common; this is due to the lack of protection to the joint, on its external lateral aspect. The outer extremity of the condyle is subcutaneous, and the only protection afforded the joint is by the external lateral and capsular ligaments, and, as already stated, the former is quite a thin band.

Wounds and other injuries in the neighbourhood of the joint must therefore be treated with the utmost care, and their closure brought about as quickly as possible, in order to avoid an extension into the joint.

Inflammation of this joint frequently occurs in animals remaining for a considerable length of time in the decumbent position, in which cases the outer extremity of the condyle is one of the prominent points of the body which come into contact with the ground.

As would naturally be expected, the animal refrains from opening its mouth, since this entails the movement of the condyle and the forward movement of the cartilage-movements which are necessarily accompanied by great pain. The result is that, unless promptly treated, the animal rapidly falls away in condition. The local treatment is as in traumatic arthritis of other joints, but it is logically deduced that only fluid nourishment must be given, and it is necessary to give 
this at frequent intervals in order that the animal may be as far as possible maintained in good condition. For this purpose nutritive enemata are also indicated. Some operators restrict the movement of the inferior maxilla by the application of a tight nose-trap.

Whilst dealing with this joint, the operator is here reminded of the close proximity of the seventh nerve, the branch of the fifth nerve, and the transverse facial artery and vein to the condyle.

\section{THE LIGAMENTUM NUCHÆ AND THE REGION OF}

\section{THE ATLAS-POLL-EVIL}

The ligamentum nuchæ is the largest ligament in the body, and in the horse it is particularly well developed. It is situate longitudinally in the median plane of the cervical region, superiorly to the vertebral column. In structure it is entirely composed of yellow elastic tissue, which renders it more effective in performing its function of assisting to suspend the head, and aiding the muscles to restore it to its elevated position after it has been depressed.

The ligament consists of two main divisions, termed respectively right and left, and each of these again comprises funicular and lamellar portions.

The funicular portion is in the form of a cord, which runs from the summit of the fourth dorsal spine, where it is continuous with the supra-spinous ligament, to the special tubercle on the upper aspect of the supra-occiput. In the middle line it is closely applied to the corresponding portion of the opposite division, and both cord-like portions are slightly curved with the concavity of the curve directed upwards.

The lamellar portion is in the form of a sheet which is triangular in shape, the apex of the triangle being directed forwards. It arises from the summits of the second and third dorsal spines and from the inferior surface of the funicular portion. Its fibres take an oblique 
direction downwards and forwards, and become collected into bundles which obtain insertion in the superior spines of the last six cervical vertebre. The lamellar portions are applied to one another and are connected by loose areolar tissue.

The distance of the funicular portion from the arches of the vertebra progressively increases from its origin to a point opposite the articulation between the last cervical and the first dorsal vertebra, and then it similarly decreases as we ascend the neck until we reach the atlas, immediately over the arch of which this portion of the ligament lies. This point is of considerable interest in dealing with poll-evil, which is frequently due to a blow received over the atlas or occiput, whereby a small portion of the bone is chipped off and remains in a position but slightly altered, and an incentive to the formation of a sinus. In the inflammatory fibrous growth which follows, it will be seen that the funicular portion of the ligament will usually be involved, and this by its compression of the diseased parts gives rise to intense pain during the movement of the head, particularly in the downward direction. Thus a horse with this affection will be observed to hold its head erect, with its nose poked forwards, the occipito-atlantal joint being fully extended, and the occipital bone brought as far backwards as possible to ease the tension on the ligament.

Cervical Desmotomy.-To relieve the pain in the condition thus described it becomes necessary to sever the funicular division of the ligament, and to this operation the name "cervical desmotomy" is given.

In connection with this operation it is to be noted that as we proceed down the neck, the amount of fatty tissue between the ligament and the skin carrying the mane increases. This is illustrated in the plates representing sections taken transversely across the neck. (Plates VII. and VIII.)

It becomes therefore more expedient to perform the operation near the occiput, where the ligament is most superficially placed, and in 
addition, this is the usual seat of the sinus. The ligament becomes more apparent if the occipito-atlantal joint be well flexed by pressing the muzzle towards the chest.

An incision is made longitudinally along the lateral border of the ligament, and through this incision a grooved director is introduced, which is insinuated beneath the ligament. Along the groove of the director a long, flat bistoury should be passed, with its cutting edge directed towards the ligament. The ligament is thus cut through during the introduction of the bistoury. It is advisable to separate the edges of the wound to such an extent that the severed ends of the ligament are plainly visible. These should then be examined and any diseased portion excised.

The cutaneous opening may be utilised for the removal of fractured spicules of bone, and if the condition has advanced to a considerable degree, so that a great quantity of inflammatory fibrous tissue has been formed, it will frequently become necessary to reflect two flaps of skin in order that the inflammatory tissue may be sliced away. This leaves a capacious gaping wound, which should be plugged with tow saturated with some antiseptic, such as a ro per cent. solution of zinc chloride. A drainage-tube is inserted at the lower extremity of the wound, and the flaps replaced by inserting a loose suture, in order that they may hold the tow in position. After two or three days the suture is cut and the flaps again reflected. The plug is removed and the wound examined. If it should present a healthy appearance the flaps should not again be sutured, but the wound treated in the usual manner by encouraging healing from the bottom.

Should the wound not present a favourable appearance upon the removal of the plug, it should be thoroughly probed and examined for fractured pieces of bone, diseased ligament, etc., and these should be removed, or it may be necessary to slice away more inflammatory fibrous tissue. The same process of plugging should be repeated, the flaps of skin being again utilised to keep the plug in position. 
On either side the median line the superior surface of the atlas presents three foramina; these are the antero-internal, antero-external and posterior. The first-named is nearest the median line, from which it is distant 1.25 inch in the average-sized animal, and its opening is placed one inch behind the anterior border of the atlas. It gives exit to the first spinal nerve, whilst through it the cerebro-spinal division of the occipital artery enters the spinal canal.

From the antero-internal foramen a furrow .75 of an inch long and .25 of an inch deep runs transversely outwards to the anteroexternal foramen. In this furrow the occipital artery splits up into its terminal branches, namely, the cerebro-spinal, which has already been referred to, and the occipito-muscular. The latter vessel again divides into a number of small branches for the supply of the muscles in the region of the poll. In the furrow, the first spinal nerve splits into its superior and inferior primary divisions.

The antero-external foramen pierces the atlantal wing, and it gives passage to the occipital artery, enabling this vessel to gain the before-mentioned furrow, and to the inferior primary division of the first spinal nerve.

The posterior foramen pierces the wing of the atlas obliquely, and it is placed two inches behind the antero-internal foramen, and .25 of an inch from the middle line. This foramen gives passage to the retrograde branch of the occipital artery which anastomoses with the vertebral.

From what has been said it will be gathered that when the seat of operation is near the front of the atlas, incisions may be made, with little danger of injuring the important structures referred to, within an area 2.5 inches in breadth, which is the distance between one antero-internal foramen and the other. The only structures within this area to be avoided are the small terminal branches of the occipito-muscular artery and the filaments of the superior primary division of the first spinal nerve. In the region of the 
furrow, however, although not an inoperable area, owing to the fact that the vessels and nerves lie within the depth of the furrow, considerable care is necessary on account of the serious consequences liable to attend injuries to these structures.

The auricular branch of the first spinal nerve passes forwards and upwards; and this nerve, as it leaves the atlas, is well protected by the tubercle-like anterior extremity of the ridge which forms the outer boundary of the atlantal wing.

The outer edge of the wing is easily located in the living animal, and it is distant .5 of an inch from the antero-external foramen, so that small fractured pieces of the anterior end of the edge of the wing may be removed with little danger of injury to the structures lying in the furrow.

When the operation area is situate in the posterior half of the atlas, less care is needed, the only situation to be avoided being the posterior foramen, since it gives passage to the retrograde artery. Between the two posterior foramina we have thus a safe area, fully five inches in breadth, and as the foramen is placed two inches from the outer border of the wing of the bone, a large fractured portion of the posterior half of the wing may be removed without any danger of injuring the artery.

In such an operation it is necessary to separate the parotid gland, which is loosely attached to the outer border of the wing, an incision into the substance of the gland being avoided, otherwise a fistula 1 of the gland is a liable consequence. 


\section{CHAPTER VIII \\ THE EYE AND EXTERNAL EAR}

\section{THE EYE AND ITS APPENDAGES}

The Eyelids.-The function of these structures is to protect the eyeball. It should be remembered that the upper lid has much the greater range of movement. Plate XXVIII. shows the structure of the lid, and on reference to the plate it is seen that the structures which form the lid from without inwards, or before backwards, are : Skin.

Orbicularis palpebrarum muscle.

Tarsal cartilage, palpebral ligament and the tendon of the levator muscle of the upper lid.

Meibomian glands.

Conjunctiva.

Normally, the inner aspect of the eyelid should be moulded perfectly on the anterior surface of the eyeball. Occasionally in horses, and very commonly in some of the larger breeds of dogs, e.g., Mastiffs, Bloodhounds and Newfoundlands, this conformation is departed from and we get either an incurving or outcurving of the lid. The former is the condition which is by far the more frequently met with. It constitutes the affection known as Entropion, and the incurved edge of the lid proves a constant source of irritation to the anterior surface of the cornea. 

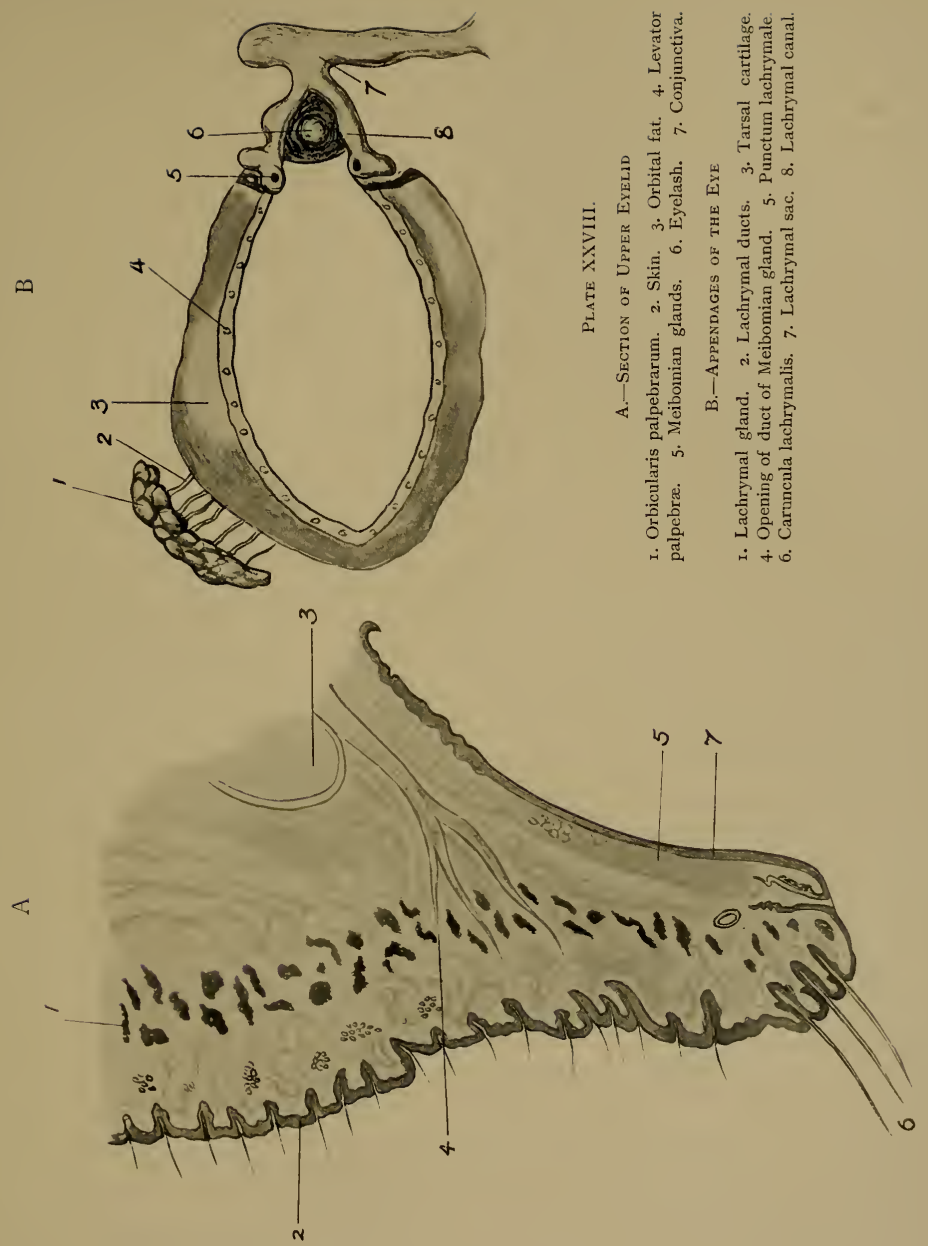

Operation for Relief of Entropion.-In performing this operation a long, narrow, elliptical piece of the cutaneous layer of the lid should be excised, and the free edges of the wound are then brought into apposition by the insertion of two or three small interrupted sutures.

Some operators do not suture, but maintain that the contraction of the cicatricial tissue which forms over the wound, provides sufficient traction to restore the inner aspect of the lid to its normal conformation. This is brought about by the shortening of the outer cutaneous layer, and the consequent pulling outwards of the lower or free edge of the lid.

Excessive outward curvature of the lid is known as Ectropion. In this case the conjunctiva becomes exposed and inflamed.

Operation for Relief of Ectropion.-The principle which underlies the treatment of this affection is similar to that upon which the treatment of Entropion is based. In this case an endeavour is made to pull the free edge of the lid inwards or towards the surface of the cornea, by causing a contraction of the layer of conjunctiva which lines the lid. To effect this a small elliptical portion of the conjunctiva is excised.

Trichiasis.-This term is applied to the condition when the eyelashes are incurved, and set up intense irritation of the conjunctiva covering the anterior face of the eyeball, which irritation leads to the production of symptoms of inflammation. The condition is relieved by the extraction of the incurved lashes with a pair of forceps.

Careful examination of the upper lid will reveal on its ocular aspect and near the temporal canthus the minute openings of the ducts of the lachrymal gland. These should be noted, for occasionally they become blocked, and it then becomes necessary to restore their patency by the passage of very delicate flexible probes. Failing probes of sufficient delicacy a firm bristle will suffice.

The Puncta Lachrymalia are near the opposite or nasal canthus. These are two in number, and they are placed one on either side the small, dark, rounded nodule which is known as the caruncula lachrymalis. 
The puncta are the openings of the lachrymal canals which convey the secretion of the gland to the lachrymal sac, after the secretion has performed its functions on the eyeball. They are slightly larger than the excretory ducts of the gland, and like the latter they should be carefully located, as mechanical blocking of them, which simply requires restoration of their patency, may lead one astray by suggesting some more serious affection on account of the great amount of lachrymation which is in evidence.

The Membrana Nictitans.-At the inner canthus is also seen the flexible piece of elastic cartilage called the membrana nictitans, commonly known as the "haw," and sometimes referred to as the third eyelid.

Although normally quite visible, the membrana nictitans only projects to a slight extent across the front of the eyeball. It passes to the inner side of the latter, and its posterior edge is connected with a pad of fat placed at the back of the orbit.

From the arrangement of the muscles of the eyeball and the disposition of the cartilage, it will be seen how in tetanus, when the retractor oculi muscle becomes contracted, the eyeball is drawn backwards into the orbit and presses on the pad of fat mentioned. The fat is thus pushed forwards along the inner aspect of the eyeball, thrusting the membrana nictitans before it. An almost completely exposed membrana nictitans is therefore one of the diagnostic symptoms of tetanus. In this disease it is unnecessary to treat the membrana nictitans. But other causes may lead to its being exposed to an abnormal extent, such as disease or defective conformation of the cartilage itself.

When so exposed the appearance presented is most unsightly, and is best remedied by excision of the cartilage.

Excision of the Membrana Nictitans.-For the performance of this operation local anæsthesia is sufficiently effective, and it is unnecessary therefore to place the animal under a general anæsthetic. Neither is it necessary to cast the patient. 


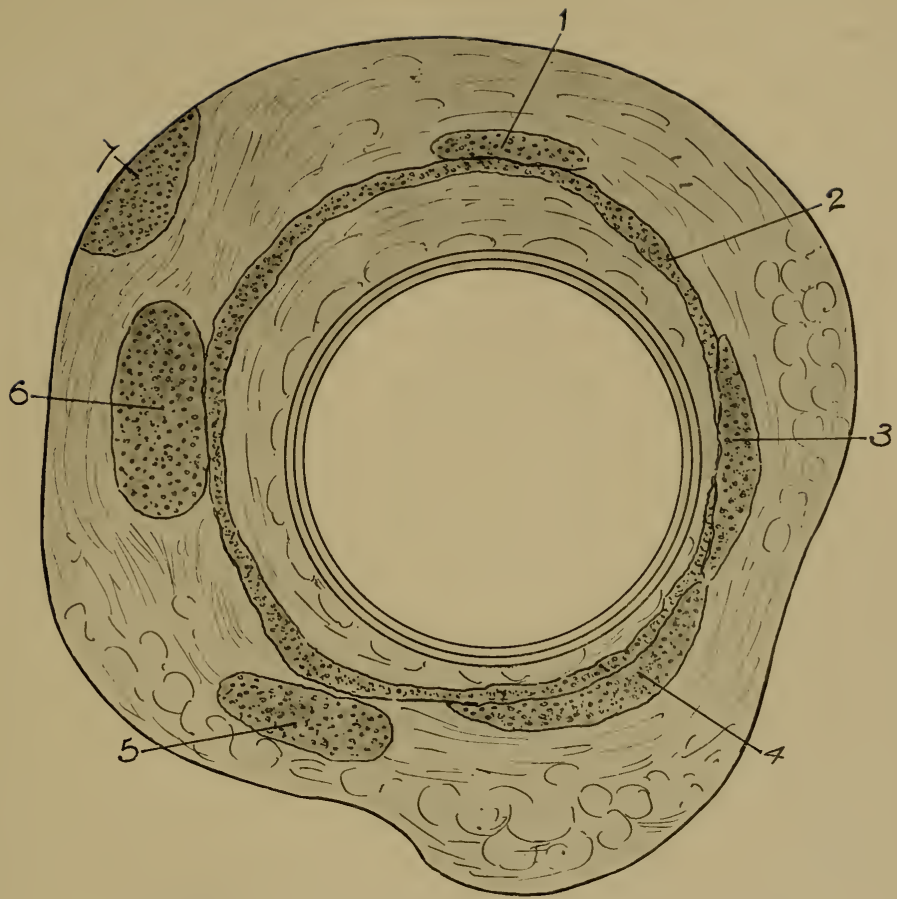

Plate Nixi. - Transierse Vertical Section across Muscles of Eyeball

I. Superior rectus. 2. Retractor oculi. 3. External rectus. 4. Inferior oblique. 5. Inferior rectus. 6. Internal rectus. 7. Superior oblique. 

The cartilage should first be manipulated to ascertain whether there are any abnormal adhesions. Having done this, the head of the patient should be held as still as possible whilst the operator passes a curved, threaded needle through the cartilage. The needle should be held with its convexity directed towards the eyeball, and it should be passed through the cartilage from within outwards. Having thus secured the cartilage it is then drawn out as far as possible, and with a curved pair of scissors, its posterior extremity should be severed from its attachment.

The Lachrymal Canals. - These are found in the eyelids themselves, and they are lined by a continuation of the conjunctiva.

They open separately into a membranous receptacle called the lachrymal sac, which is placed in the lachrymal fossa on the floor of the orbit. The sac in turn discharges its contents into the ductus ad nasum or lachrymal duct. The latter is a long membranous tube which runs at first along the osseous canal on the inner aspect of the lachrymal and superior maxillary bones, to open on the floor of the nasal cavity. The inferior opening is easily seen in the living animal by separating the alæ of the nostril. It appears as though a small circular piece of skin had been punched out. Its position is in the skin immediately in front of the line of division between the skin and mucous membrane. To reach this spot from the osseous canal mentioned the duct passes beneath the mucous membrane lining the middle meatus of the nasal chamber.

Epiphora.-This is the name technically given to the condition resulting from an obstruction of the ductus ad nasum.

It will be easily understood that the first symptom will be an overflow of the lachrymal fluid. The obstruction may be placed anywhere along the course of the duct, and the first step necessary is to discover as near as possible its position. This may be done by means of injections into the duct, and it is stated that if the injection escapes chiefly through the upper opening, the obstruction is not far 
distant from the orbit, and vice versa should the liquid escape by the nasal opening.

Injections will usually prove sufficient to relieve the obstruction, but, failing these, the duct should be probed with a fine bouge, the thickness of which should not exceed that of a goose-quill.

An inflammatory swelling of the wall of the duct may cause an obstruction of the lumen, in which case an astringent injection should be utilised. Failing relief by injection, an artificial opening may be made into the duct by trephining the superior maxillary bone along the line represented in Plate XXV., which indicates the course of the duct.

\section{The Eyeball}

Upon looking at the exposed portion of the eyeball in situ, we see that the cormea is somewhat elliptical. Close observation, however, will reveal the fact that it is not regularly so, since the inner end of the ellipse would form an arc of a greater circle than would the outer end. Surrounding the cornea is the visible white zone of the sclerotic.

Looking through the cornea in a dim light, where the direct rays are cut off by shading the eye, the pupil is seen to be also elliptical, with its long axis directed transversely as in the case of the cornea. Surrounding the pupil is the iris, and hanging into the pupil are two or three dark-coloured bodies. These are the peculiar corpora nigra, which are nothing more nor less than ball-like masses of uvea, the material forming the pigmented layer on the posterior aspect of the iris. Apart from the presence of the easily visible corpora nigra, the whole of the elliptical area forming the pupil should be quite clear. This is a point of great importance in the examination of horses as to soundness.

Sagittal Section of the Eyeball.-From the study of such a section we find that covering the front of the cornea is the layer of conjunctiva which is continuous with that lining the inner aspect of the eyelid. 


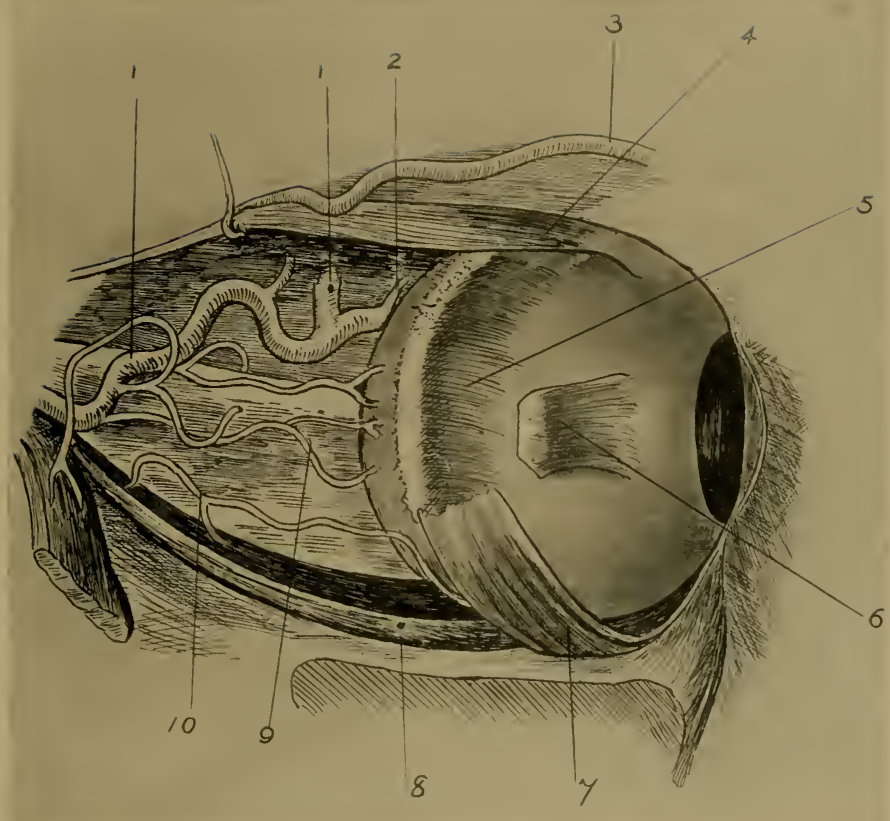

Plate XXX.-Outer Aspect of Orbit, showing Arteries and Muscles

1. Ophthalmic artery. 2. Its lachrymal branch. 3. Supra-orbital artery. 4. Superior rectus muscle. 5. Retractor oculi. 6. Part of external rectus. 7. Inferior oblique muscle, 8. Inferior rectus. 9 and 10. Branches of oph thalmic to muscles. 

The posterior layer of the cornea is an elastic lamina (Membrane of Descemet), on which is a layer of polygonal cells. This should be noted because this is the layer which replenishes the anterior chamber of the eyeball with aqueous humour when the latter escapes through the chamber being perforated by injury. Behind the cornea is the anterior chamber into which the iris is seen to project. Posteriorly to the iris again is the Crystalline Lens, which is more convex on its posterior than on its anterior aspect, whilst the lens is accommodated posteriorly in a depression of the vitreous humour-the material which fills the large posterior chamber of the ball.

The entrance of the optic nerve with the central artery of the retina is placed in the inferior half of the ball.

Excision of the Eyeball.-This is an operation which is rather frequently necessary in the horse, particularly in colliery ponies, owing to the injuries to which the latter are liable.

If the ball has not burst, it is advisable to preserve it intact, as this facilitates the operation of removal.

A thread should be passed with a fine needle through the conjunctiva and superficial portion of the cornea, a sufficient thickness of the cornea only being included as to enable the operator to obtain a firm hold with the thread; but, for the reason stated, namely, that of preserving the ball intact, care should be taken not to pierce the cornea completely.

The thread should be utilised to draw the ball outwards towards the operator.

A puncture should then be made in the conjunctiva, and the latter should be slit all round with a curved pair of scissors, thus severing the connection between the ball and the eyelids. This will enable the ball to be drawn further out of the bony socket.

The next step is to cut through each of the straight and oblique muscles of the eyeball separately, and lastly, the retractor oculi with its contained optic nerve should be severed. 
Particular care should be taken in dealing with the inferior and posterior aspects of the ball on account of the numerous vessels placed on the floor and back of the orbit, among which may be mentioned the ophthalmic artery and its branches, and the orbital branch of the superior dental artery.

Subsequent treatment depends upon whether it is intended to insert an artificial eye or not. If such a procedure is not intended the cavity should be packed with absorbent material saturated with antiseptic solution, which should be kept in position by suturing the eyelids-a single suture being quite sufficient. This packing should be left in position for two or three days, when a fresh one is introduced, and this process should be repeated until there is no trace of discharge visible on the plug. The eyelashes should now be clipped off, and the edges of the eyelids scraped until raw. The lids are then sutured together by means of a number of closely inserted interrupted sutures.

\section{THE EXTERNAL EAR}

The parts of the external ear are the conchal, annular, and scutiform cartilages, the tube-like auditory process of the petrous temporal bone, the muscles which move the cartilages, or attach them to the head or to one another, and the nerves and vessels which supply these structures.

The Cartilages.-The conchal cartilage is usually referred to as resembling a trumpet in shape. The tube-like portion is dilated near its upper extremity, but inferiorly it becomes much narrower and embraces the annular cartilage.

The opening of the trumpet approaches the elliptical in outline, and presents superior and inferior commissures where its edges meet one another. This cartilage is attached to the guttural pouch by a fibrous prolongation over the outer aspect of the scutiform. 
The annular cartilage is a ring which encircles the auditory process, and, as already stated, it is itself telescoped within the base of the conchal cartilage. The lining membrane of the ear is continued over the inner aspect of the annular cartilage on to that of the concha. In addition to the continuity of this membrane, the cartilages are maintained in connection by elastic fibres which pass from one to the other.

The scutiform cartilage is a thin somewhat triangular plate, which lies on the outer aspect of the temporal muscle, in front of the conchal base. It is attached to the concha by muscles.

The Muscles. - Numerous little muscles are attached to the conchal cartilage, and by their contraction these muscles enable the animal to direct the opening of the trumpet forwards, outwards or backwards at will.

The parotido-auricularis runs from the cartilage to the outer surface of the parotid gland and enables the animal to incline the ear downwards and outwards.

The three cervico-auriculares muscles run from the poll to the cartilage, and these during contraction direct the opening first outwards, and then backwards, meanwhile drawing the ear toward the poll.

The parieto-auriculares (externus and internus) connect the cartilage with the parietal or sagittal crest, and enable the animal to prick the ear, and restore it to its erect position after its having been depressed by the parotido-auricularis.

The zygomatico-auricularis muscle runs from the zygomatic process to the scutiform and the concha, and assists in pricking the ear.

The scuto-auriculares (externus and internus) connect the outer and inner surfaces of the scutiform cartilage with the base of the concha.

The mastoido-auricularis is a short muscle running from the auditory process to the base of the concha. It assists in telescoping the latter on the annular cartilage. 
The Blood-Supply.-The superficial temporal artery divides beneath the parotid gland and just below the condyle of the inferior maxilla, into the transverse facial and anterior auricular arteries.

The antirior auricular artery takes an upward course behind the temporo-maxillary joint upon the capsular ligament of which it lies. It is distributed to the muscles and skin at the base of the concha, and terminates in the temporal muscle.

The posterior auricular artery is given off as a collateral branch of the external carotid. It commences under the parotid gland on the outer aspect of the styloid cornu of the hyoid bone. After a short course, during which it passes on to the occipito-styloid muscle, it splits up into anterior and posterior divisions. The former takes a course upwards, and is distributed to the concha behind the entrance to the ear. It also gives off branches to the base of the ear, and a long slender branch which is distributed on the inner aspect of the concha.

The anterior auricular vein is slightly larger than the artery which it accompanies, and it assists in the formation of the superficial temporal vein. The veins which accompany the divisions of the posterior auricular artery unite to form two vessels. These again unite to form the posterior auricular vein, which descends at first on the outer aspect of the parotid gland, and then dips into the gland within which it empties itself into the jugular.

The Nerve-Supply. - The anterior auricular nerve is a branch of the seventh cranial nerve, from which it is given off beneath the parotid gland. This nerve runs over the zygomatic process and down the anterior aspect of the body of the frontal bone, to terminate near the nasal canthus, where it pierces the levator labii superioris alreque nasi muscle. During its course it distributes filaments to the parietoauriculares muscles.

The middle auricular nerve is another branch of the seventh. It passes upwards behind the downwardly projecting piece of the conchal 


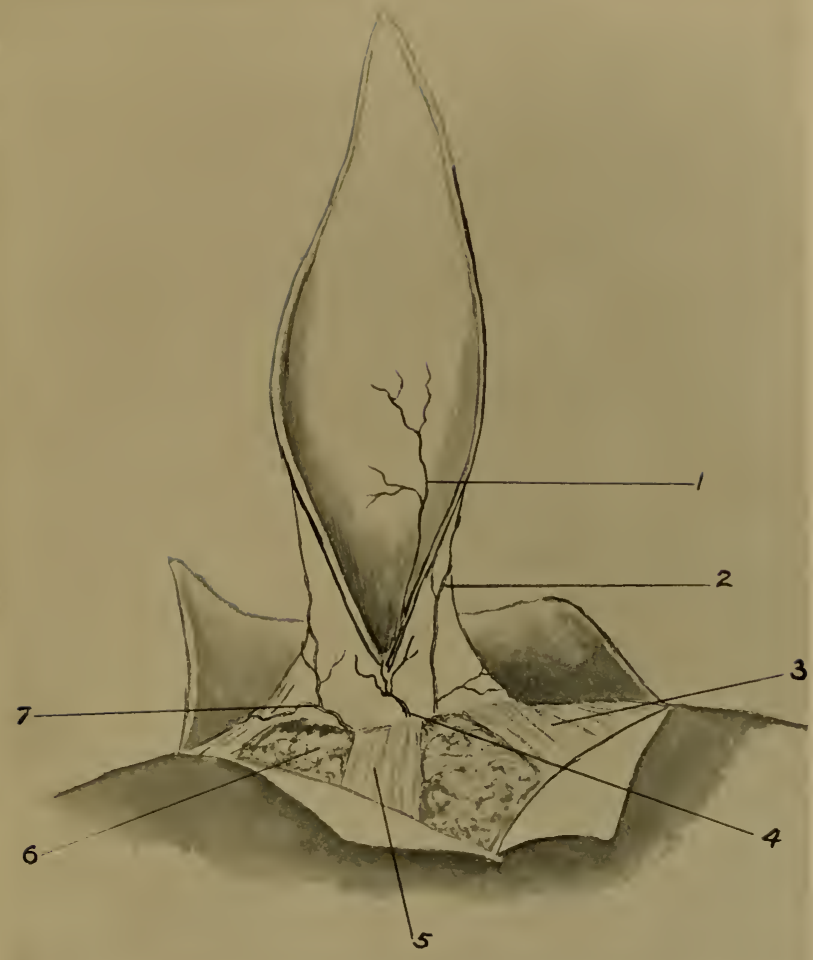

Plate XXXi.-Arteries of External Ear

I. Long branch of anterior division of posterior auricular artery 2 Posterior division of posterior auricular artery. 3. Cervico-auriculares muscles. 4. Anterior division of posterior auricular artery. 5. Parotido auricularis muscle. 6. Parotid gland. 7. Anterior auricular artery. 

cartilage, across the annular cartilage. It passes through the inferior commissure of the concha to be distributed to the interior of the latter.

The posterior auricular nerve is also given off by the seventh nerve. It follows the course of the posterior auricular artery upwards to the back of the concha to supply the cervico-auriculares muscles.

Branches of the first cervical nerve are distributed to the inner side of the base of the ear, as are branches of the second cervical nerve, which are also continued to supply the inner aspect.

Diseases of the External Ear.-Wounds and other injuries of the external ear are extremely common in dogs, but are not commonly met with in horses. This is due mainly to the difference in conformation and disposition of the conchal cartilage, which in the former animal cause the flap of the ear to be pendulous, and consequently much more exposed to risk of injury.

When such injuries affect the base of the ear profuse hæmorrhage results, on account of the number of small vessels which ramify on this part, and to arrest this it is advisable to secure and ligature the anterior auricular artery and the vertical branch of the posterior auricular, which may be found by dissecting between the superior border of the parotid gland and the base of the cartilage.

In cases where the cartilage has been exposed it should be pared, and the cartilage should then be pressed back between the two layers of skin, the edges of which are brought into apposition and secured by the insertion of numerous fine interrupted sutures. These will prevent corrugation of the part during the healing process.

Tumours in the external ear are by no means uncommon, and they frequently give rise to much trouble and annoyance. They are usually fibromata or papillomata, and they are commonly associated with a most offensive odour.

They are most frequently situate near the base of the concha, 
which, it will be readily understood, renders their excision much more troublesome, owing to the profuse hxmorrhage which will inevitably occur.

In removing such growths, the ear is first plugged with cotton wool to absorb blood, etc., and prevent its inward passage. An incision is then made through the skin on both sides of the concha around the base of the growth. The skin is next pressed slightly away from the tumour and the cartilage is incised, the incision passing through the zone of healthy cartilage surrounding the tumour. (This will admit of the flaps of skin being brought into apposition more readily when the edges are sutured to enclose the cartilage.) The largest vessels are ligatured, and it may be necessary to apply the actual cautery to arrest the hæmorrhage from the smaller ones, when the flaps of skin may be sutured as directed. The plug of wool is now removed, and a clean one inserted, completely filling up the interior of the concha. Dry dressing should then be dusted over the part, or the wound may be covered with iodoform and collodion.

Dentigerous Cysts.-Occasionally there is found on the anterior aspect of the base of the ear an opening from which a serous discharge is ejected if the surrounding parts be compressed. This is the external opening of a sinus, which, if probed, will usually be found to take a direction downwards, extending to the zygomatic process of the squamous temporal bone and sometimes even to the malar. In the latter cases the sinus is from two to three inches in length. Further exploration will reveal the presence at the bottom of the sinus of a hard body, and this body will be subsequently found to be of the nature of a tooth. In this situation it acts as a foreign body to the surrounding structures, and leads to the development of a sinus.

As in the case of the presence of other foreign bodies, rormation of a considerable amount of fibrous tissue may result, and an abscess 
may be formed. In such cases the treatment should be that usually adopted in treating sinuses, namely, to open at its lowest point, to which the operator is guided by the point of the probe in the sinus. The tooth is then removed, the walls of the sinus curetted, and the parts treated antiseptically. 


\section{CHAPTER IX}

\section{THE SUPERIOR MAXILLARY DIVISION OF THE FIFTH NERVE. THE BLOOD AND LYMPH VESSELS}

\section{THE SUPERIOR MAXILLARY DIVISION OF THE FIFTH CRANIAL NERVE}

THIs is one of the sensory divisions of the fifth nerve. It leaves the gasserian ganglion and passes out of the cranial cavity by the foramen rotundum, which in the mascerated skull is easily recognised as the most posterior of the foramina forming the orbital hiatus. The foramen rotundum is in close proximity to the inferior opening of the subsphenoidal canal, and since the internal maxillary division of the external carotid artery passes through the latter, it will be seen how this artery comes to run in close proximity to this branch of the fifth nerve.

The nerve crosses the lower and posterior part of the orbit, and gains the maxillary hiatus. Having given off a number of branches, the main portion of the nerve now passes into the superior dental canal and gives off a large branch, which appears on the face through the infra-orbital foramen and under cover of the levator labii superioris proprius muscle. It then divides into superior, middle, and inferior branches, which form intricate piexuses with branches of the seventh nerve (which is motor), and are distributed to the true and false nostrils, upper lip, and to the muscles and skin of the face. 


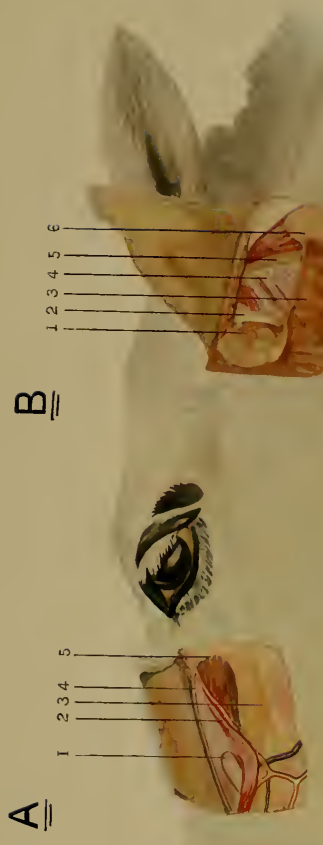

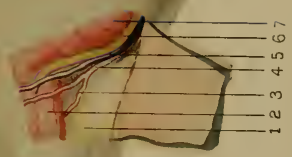

U॥ $\sqrt{11}$

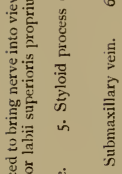

कुँ

造的总产

सहैं के

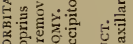

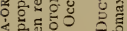

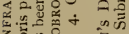

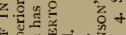

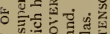

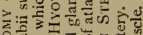

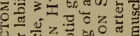

论记

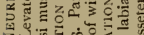

可可的实

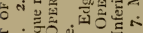

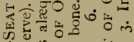

का

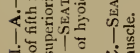

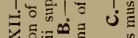

请:

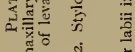

芩

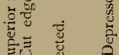

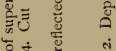

氠产

हैं का

है है है

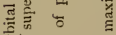

눈 능

递总

E. 

Neurectomy of the Fifth Nerve.-Neurectomy of this nerve has been practised by Williams, of Cornell University, and others in the treatmen of "Involuntary shaking of the head." The animal should be placed under a general anæsthetic, and it is necessary to remove the bridle, halter or head-collar, in order to clear the operation area.

By careful manipulation of the levator labii superioris proprius muscle, the infra-orbital foramen may be located. An incision in the direction of the length of the muscle should be made about an inch long, downwards and forwards from the superior border of the foramen, which is placed two inches forwards from the inferior extremity of the zygomatic ridge. The incision is carried through the subcutaneous fascia and the tendinous portion of the levator labii superioris alæque nasi muscle. Through this opening a finger should be introduced, and the proprius muscle, together with the angular branches of the submaxillary artery and vein which lie on its superficial aspect, may be pushed aside, since, as already stated, this muscle is very loosely attached to the subjacent bones.

The nerve is thus brought into view, and it should be clearly exposed by carefully dissecting away all the surrounding connective tissue. The nerve is then divided as it is leaving the infra-orbital foramen, and the distal end seized with a pair of artery forceps, care being taken to include between the jaws of the forceps all the branches of the nerve. About an inch of the nerve is thus excised.

Particular attention should be directed to asepsis, since a not uncommon sequel is said to be a severe neuritis of the proximal end of the nerve due to septic infection.

\section{THE ARTERIES}

Synopsis of Origin, Distribution and Anastomoses

The Common Aorta.-This is the enormous arterial trunk which extends upwards from the conus arteriosus of the left ventricle. It is 
only about three inches in length, and it divides into two parts, namely, anterior and posterior.

The Anterior Aorta is the smaller of the two divisions of the common aorta. It curves forwards between the first pair of ribs, and like the common aorta it has a length of only about three inches, when it splits up into the left axillary and innominate arteries.

The Left Axillary Artery.-This artery is placed at a higher level than the innominate, and passes forwards between the two first ribs. It is related on its right side to the trachea and touches at its highest point the asophagus. It curves round the anterior border of the first rib below the insertion of the scalenus muscle, and is then continued across the axilla. The intra-thoracic branches of the left axillary artery are :

(1) The Dorsal Artery, which passes across the asophagus and longus colli muscle, to gain the second intercostal space, where it splits up into branches which are distributed to the parts beneath the scapula. An important branch of this artery is the subcostal, which runs backwards along the under aspect of the ribs, and which gives off the second, third, and fourth intercostal arteries.

(2) The Superior Cervical Artery is given off by the axillary before the latter leaves the chest. It also ascends across the œsophagus and longus colli muscle to reach the first intercostal space. This vessel gives off the first intercostal artery, and ultimately splits up into a great number of branches which are distributed to the muscles of the upper portion of the neck. It anastomoses freely with the twigs of the dorsal artery.

(3) The Vertebral Artery. - This branch is given off between the first pair of ribs. It passes forwards under the transverse process of the seventh cervical vertebra, and then through the series of vertebral foramina to the back of the atlas, where it anastomoses with the retrograde branch of the occipital artery. As it passes up the neck the vertebral artery gives 
off twigs, which enter the spinal canal through the intervertebral foramina to assist in supplying the structures therein.

From the extra-thoracic portion of the left axillary artery one branch is given off which concerns us here :

The Inferior Cervical Artery.-This leaves the axillary artery as the latter turns round the first rib. After a course of from one and a half to two inches it divides into two branches, one of which passes into the groove between the mastoido-humeralis and subscapulo-hyoideus muscles, and the other runs downwards between the mastoido-humeralis and the anterior superficial pectoral, where it is placed alongside the cephalic vein.

The Innominate Artery.-This vessel gives off a trunk which is common to the superior cervical and dorsal arteries, and the innominate then splits up into the right axillary and cephalic vessels. As already mentioned, the innominate artery is at a lower level than the left axillary.

The right axillary artery gives off the vertebral, the course and distribution of which resemble those of the corresponding artery of the left side.

(1) The Dorso-Cervical Artery takes a short upward course and splits up into the dorsal and superior cervical arteries, which are also distributed as on the left side. Round the dorsocervical artery, the right recurrent laryngeal nerve curves to take its course up the neck after leaving the vagus.

(2) The Cephalic Trunk.-This passes forwards on the inferior aspect of the trachea. It is only about two inches long, and it divides into the two common carotid arteries.

The Common Carotid Artery.-This is the vessel which carries the blood to the head. It is at first placed on the inferior aspect of the trachea, and is related to the scalenus, longus colli, and rectus 


\section{I32 THE SURGICAL ANATOMY OF THE HORSE}

capitis anticus major muscles. The left common carotid is also related to the esophagus. The artery is accompanied by the jugular vein, above and slightly internal to which it is placed, but as it passes up the neck the subscapulo-hyoideus muscle passes between the artery and vein. Above the artery and closely related to it is the nerve cord, which is common to the vagus and the cervical portion of the sympathetic, whilst below the artery is the inferior (recurrent) laryngeal nerve.

During its course the vessel crosses the trachea obliquely to gain the superior aspect of the cricoid cartilage of the larynx, where it divides into the occipital, external carotid and internal carotid arteries. The common carotid gives off a number of branches to the osophagus, the trachea, and the muscles which are placed along its course, and towards the upper end of the neck it gives off the thyroid artery, which runs to the thyroid body, the posterior extremity of which it pierces. A little in advance of the origin of the thyroid artery the carotid gives off the thyro-laryngeal artery. This vessel passes to the inner side of the thyroid body, and then splits up into two portions, one of which takes a retrograde direction to enter the anterior face of the body, and the other passes forwards to supply the larynx.

The Occipital Artery.-This vessel ascends from the cricoid cartilage to the inferior edge of the wing of the atlas. It then passes through the antero-external foramen of the wing, and in the groove connecting the two anterior foramina it splits up into the occipito-muscular and cerebro-spinal arteries. During its course the occipital artery gives off the following collateral branches:

(1) The pre-vertebral artery, which is distributed to the muscles in front of the vertebræ (longus colli, anterior straight muscles of head, etc.).

(2) The mastoid artery, which passes across the styloid process and runs forwards to dip under the edge of the pyramidal process 
of the squamous temporal bone. Passing through the mastoid foramen into the parieto-temporal canal, it there anastomoses with the great meningeal or spheno-spinous artery.

(3) The retrograde branch, or ramus anastomoticus, passes backwards through the posterior foramen of the wing of the atlas to anastomose with the vertebral artery.

Terminal Branches of the Occipital Artery.

(1) The occipito-muscular artery.-This takes a course upwards towards the occipital crest, and it is distributed to the muscles in the region of the poll.

(2) The cerebro-spinal artery.-This division of the occipital enters the spinal canal through the antero-internal foramen of the atlas. It then divides into two parts, one of which runs forwards and the other backwards.

The anterior division joins its fellow of the opposite side and forms the basilar artery, which enters the cranial cavity through the foramen magnum. It passes along the inferior aspect of the medulla oblongata to the pons variolii, where it divides into the posterior cerebral arteries, which enter into the formation of the Circle of Willis.

The posterior division of the cerebro-spinal artery inosculates with its fellow of the opposite side to form the median spinal artery.

The External Carotid Artery.-This vessel passes along the wall of the guttural pouch, where it is covered by the stylo-maxillaris, the upper belly of the digastricus and the stylo-hyoid muscles. It emerges from between the anterior border of the last-named muscle and the posterior border of the long cornu of the hyoid bone. It then traverses the outer surface of the cornu for a short distance, and divides into the superficial, temporal, and internal maxillary arteries. 
The Collateral Branches of the External Carotid are :

A. The submaxillary artery, which is a very large branch running downwards across the subscapulo-hyoideus muscle. It next places itself in company with the submaxillary vein and Stenson's Duct, and these three structures run forwards along the intermaxillary space. They curve round the inferior border of the horizontal ramus, and the subsequent course of the artery has already been seen in our description of the Duct of Stenson. After leaving the duct, the artery continues its course across the buccinator muscle, passes under the zygomaticus, and ultimately divides into the angular and nasal arteries.

Collateral Branches of the Submaxillary Artery.

(1) The pharyngeal artery, which is distributed to the pharynx, from whence it is continued as a long slender vessel to assist in the supply of the soft palate.

(2) The lingual artery. - This branch passes under the great hyo-glossus muscle and across the small cornu of the hyoid bone. It then runs downwards beneath the middle hyo-glossus and palatoglossus muscles to enter the tongue. In the tongue it has a very tortuous disposition, and it runs forwards to the tip where it anastomoses with the corresponding artery of the opposite side.

(3) The submental artery.-This is a much smaller vessel, and it takes a course along the inferior belly of the digastricus muscle to gain the superior face of the mylo-hyoid. It subsequently pierces this latter muscle and is distributed to the parts beneath it.

(4) The inferior labial artery.-This branch passes along the outer surface of the inferior maxillary bone, and it takes a course beneath the depressor labii inferioris muscle, to be distributed to the lower lip. It anastomoses with the mental branch of the inferior dental artery, which comes out through the mental foramen.

(5) The superior labial artery passes forwards across the buccinator 
and under the zygomaticus to gain the deep face of the levator labii superioris alæque nasi muscle. It is distributed to the upper lip, and it anastomoses with the incisor trunk of the palato-labial arteries, which comes forwards to the upper lip through the incisor foramen.

Terminal Branches of the Submaxillary Artery.

(I) The angular artery runs upwards on the levator labii superioris proprius muscle and is distributed to the region below the orbit. It contracts an anastomosis with the orbital branch of the superior dental artery.

(2) The nasal branch runs obliquely downwards and forwards to be distributed to the nostril.

B. The maxillo-muscular artery.-This branch of the external carotid runs downwards and forwards and splits into two divisions, which pass one on either side of the vertical ramus. The outer division pierces the masseter muscle and is distributed to it, whilst the inner division is distributed to the internal pterygoid muscle.

C. The posterior auricular artery.-This vessel takes a course upwards beneath the parotid gland, and it passes on to the occipitostyloid muscle, where it splits up into two divisions, one of which is distributed to the base of the concha and the other runs up the back of the conchal cartilage to terminate near the tip of the ear.

\section{Terminal Branches of the External Carotid Artery.}

A. The superficial temporal artery.-This is a very short vessel, which takes an upward course on the styloid cornu and splits up into the transverse facial and anterior auricular arteries.

(I) The transverse facial artery.-This vessel curves round the posterior border of the vertical ramus just below the condyle. After a very short course it dips into the masseter muscle, to which it is distributed. 
(2) The anterior auricular artery runs upwards on the capsular ligament of the temporo-maxillary joint to reach the anterior aspect of the base of the external ear, to which it is distributed.

B. The Internal Maxillary Artery passes to the inner side of the condyle of the lower jaw, and crosses the guttural pouch obliquely. Whilst crossing the pouch it forms an S-shaped curve, the first convexity of which is directed downwards. The artery now enters the subsphenoidal canal above the root of the subsphenoidal process. It passes through the whole length of the canal, and leaving it by the foramen rotundum, it takes its course to the maxillary hiatus, where it is continued as the palato-labial artery. The branches given off by the internal maxillary artery are as follows:

(1) The inferior dental artery.-This is a vessel of considerable calibre, which is given off from the first convexity of the S-shaped curve. It passes between the two pterygoid muscles, and then between the internal pterygoid and the surface of the inferior maxilla. It next enters the inferior dental canal, and is distributed to the molar and incisor teeth of the lower jaw. Whilst in the canal it gives off a small mental branch, which passes out through the mental foramen to anastomose with the inferior labial artery as already stated.

(2) The tympanic artery comes off from the opposite side of the internal maxillary artery. It follows the course of the chorda tympani nerve, and passes into the petrous temporal bone to supply the tympanum or middle ear.

(3) The great meningeal artery.-This branch passes into the cranial cavity through the outermost notch in the superior border of the wing of the post-sphenoid bone, to anastomose in the parieto-temporal canal with the mastoid artery. 
(4) Two or three branches are given off to the pterygoid muscles.

(5) The posterior iep temporal artery.-This vessel is also given off before the iniernal maxillary artery enters the subsphenoidal canal. It ascends to supply the temporal muscle.

(6) The anterior deep temporal branch is given off in the subsphenoidal canal, which it leaves by passing through the temporal foramen to the temporal muscle, which it supplies.

(7) The ophthalmic artery also leaves the internal maxillary whilst the latter is in the canal. It passes out through the foramen rotundum with the internal maxillary. The ophthalmic artery then crosses the back of the orbit, and passes between the superior rectus and retractor oculi muscles to enter the cranial cavity by the internal orbital foramen. In the cranial cavity it divides into meningeal and nasal branches.

Collateral Branches of the Ophthalmic Artery.

(a) The supra-orbital, which passes out through the supraorbital foramen, and supplies the upper eyelid and the region of the nasal canthus.

(b) The lachrymal branch, which is distributed to the lachrymal gland.

(c) Numerous muscular branches to the muscles of the eyeball.

(d) The ciliary branches.

(e) The central artery of the retina which pierces the sclerotic coat with the optic nerve in the axis of which the artery is placed.

Terminal Branches of the Ophthalmic Artery.

(a) The meningeal branch gives off branches to the dura 
mater, and then unites with the corresponding branch of the opposite side to form a single trunk, which joins the middle cerebral artery.

(b) The nasal branch passes into the nasal chamber through the cribriform plate of the ethmoid, and to the upper part of this chamber it is distributed.

(8) The buccal artery. - This is the first branch given off after the internal maxillary leaves the subsphenoidal canal. As its name implies it is distributed to the buccal region.

(9) The staphyline artery is a long and slender branch, which courses along the staphyline groove to reach the soft palate, to which it is distributed.

(Io) The spheno-palatine artery passes through the foramen of the same name to enter the nasal chamber. It is distributed chiefly to the posterior meatus.

(I I) The superior dental artery passes into the superior dental canal, and is distributed to the molar and incisor teeth of the upper jaw. Before entering the canal this vessel gives off a long orbital branch, which passes over the floor of the orbit to reach the face where it anastomoses with the angular artery. Within the canal the superior dental artery gives off an infra-orbital branch, which reaches the face by passing through the infra-orbital foramen.

(12) The palato-labial artery is the direct continuation of the internal maxillary. It passes through the superior palatine foramen into the palatine canal. Leaving the canal by the inferior palatine foramen it runs along the palatine groove. As it approaches the body of the pre-maxilla it curves inwards towards the middle line, passing under the small bar of cartilage which is here situate. In the middle of the palate the vessel meets, and inosculates with the corresponding vessel of the opposite side, and the resulting artery passes forwards through the incisor foramen to supply the 
upper lip, where its terminal branches anastomose with those of the superior labial branch of the submaxillary artery.

The Internal Carotid Artery.-This vessel takes a course upwards from the cricoid cartilage across the guttural pouch, in a fold of which it is enveloped. It reaches the upper border of the wing of the post-sphenoid bone, and passing through the innermost of the three notches in this wing it gains the cranial cavity. It next pierces the cavernous sinus and concurs in the formation of the Circle of Willis.

\section{THE JUGULAR VEIN}

This vein commences below the temporo-maxillary joint by the union of the superficial temporal and internal maxillary veins, the two veins which correspond to the terminal branches of the external carotid artery.

Passing downwards and backwards, the vein is lodged at first in the substance of the parotid gland, and then takes its course down the neck in the jugular furrow. Near the entrance to the chest the two jugulars unite with one another. The confluence occurs between the two first ribs, and on the inferior aspect of the trachea. It is surrounded by the prepectoral lymphatic glands. Fibrous bands fix the confluent to the first ribs and surrounding parts, so that its walls do not collapse when it is emptied of its contents. This point is of considerable surgical importance in connection with the operations on the vessel to be hereafter described.

The upper extremity of the vein is surrounded by the glandular tissue of the parotid, and forming its external covering throughout the remainder of its course is a thin sheet of muscle which is the cervical portion of the panniculus. Inwardly it is related in the upper part of the neck to the subscapulo-hyoideus muscle, which separates the vein from the carotid artery, and the vagus and recurrent laryngeal nerves. In the inferior cervical region it is in direct relationship to the carotid, 
which is placed at a higher level, and, also to the trachea. On the left side in the lower part of the neck it is also related to the axsophagus.

The jugular receives the submaxillary or glosso-facial vein, which helps to drain the blood from the face, and the course of which has already been seen in the description of Stenson's Duct.

\section{INTRAVENOUS INJECTION}

This is one of the methods of administering drugs, in fact it is the method of administration which is adopted when it is most desirable that the drugs should take effect quickly. The first step in performing the operation is to carefully locate the position of the jugular vein, which is the vessel most commonly selected for this operation.

To effect this purpose the vein is raised by arresting the current of blood in it. This is done by applying pressure to the vessel with the thumb or fingers below the seat at which it is the intention to operate.

It is usual to stand on the right side of the animal and to raise the vein with the left hand, leaving the right hand free to manipulate the needle. Left-handed operators however will adopt the left side for operating, and raise the vessel with the right hand. Having done this, the seat of operation decided upon should be cleansed and the hair removed. The hypodermic needle should now be taken between the index and medius fingers of the right hand, its point should be directed obliquely forwards and upwards, and firm pressure should be applied to its base with the thumb-thus passing the needle through the skin, the thin layer of the panniculus carnosus muscle, and the wall of the vein into the lumen of the latter.

That the needle has passed into the vein may be proved by removing the thumb, when a little blood will escape through the opening in the needle. The barrel of the syringe, having been filled 


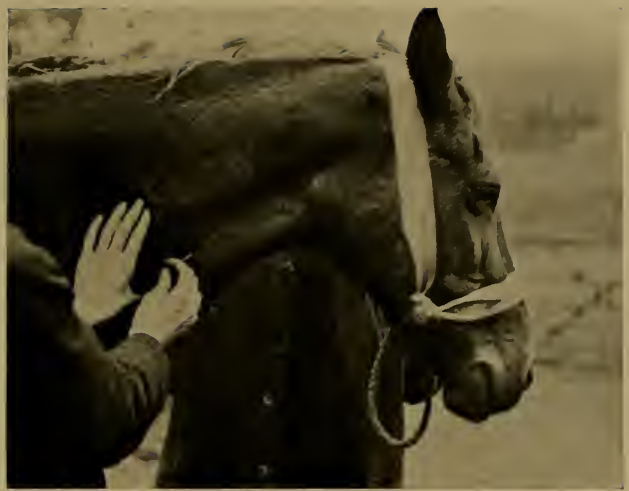

Plate XXXilia.-Intravenous Injection

Raising vein with thumb of left hand and inserting needle of syringe with right hand.

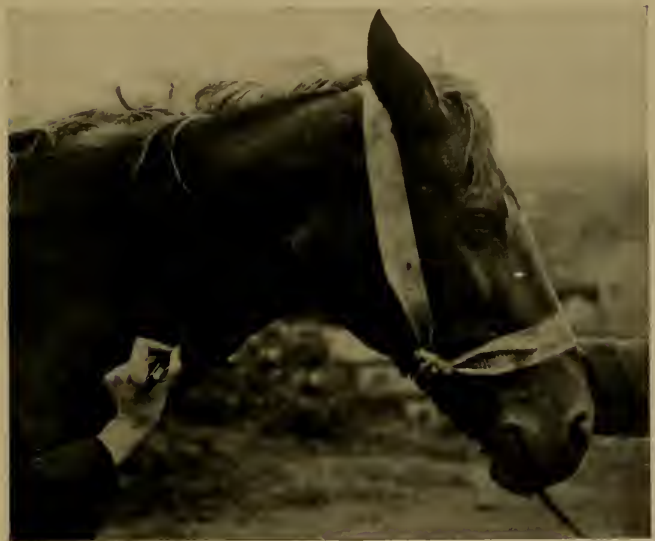

Plate Xxxilib,-Phlebotomy with Fleams

Method of holding fleam between thumb and index finger of left hand, the vein being raised by the remaining fingers. 

by an assistant with the material to be injected, may now be applied to the needle, and pressure gently placed upon the piston of the syringe by the operator's thumb, as in the case of inserting the needle, but in the present case the pressure should be applied very much more gradually.

The needle should now be withdrawn, care being taken while so doing to apply pressure to the skin near the seat of injection, to prevent the escape of blood from the vein into the subcutaneous tissue.

\section{Phlebotomy, Bleeding, or Blood-letting}

This operation was very commonly practised a few years ago in this country, but although it has lost favour with our modern practitioners, it is still very frequently performed on the continent.

The jugular vein is again usually the vessel selected, and there are several methods of performing the operation.

(I) A trocar and canula with a fine bore may be used after the manner described in the previous operation of intravenous injection, and blood thus extracted.

(2) An incision may be made into the vein with an ordinary scalpel or lancet, which should be held with about half an inch of the blade exposed, between the thumb and forefinger of the right hand. The vein should be raised after the manner already described, when the exposed portion of the blade should be pushed into the vessel, the scalpel being held at right angles to the direction of the vein.

(3) A third method, and perhaps the one most commonly adopted, is phlebotomy by means of the ordinary fleam. In this case the fleam should be held between the thumb and index finger of the left hand, whilst the remaining fingers of the hand are utilised to raise the vein by the application of pressure. Having raised the vein and thus clearly made out its course, and 
being careful to so hold the instrument that its point is directed towards that part of the vessel which presents the greatest degree of distension, the edge of the blade being in the direction of the long axis of the vein, a mallet should be taken in the right hand and a firm rap given to the back of the fleam. The whole of the blade should be driven in, since the structure of the instrument is such that the length of the blade indicates the required depth of the incision.

The size of the fleam selected varies with the size of the animal, the thickness of the skin, and of the muscle at the seat of operation.

The tleam should be removed before the pressure which caused the vein to be raised is relaxed by removing the fingers. When the latter is done, the pressure should be continued by placing the edge of the receptacle into which the blood is to be drawn, against the vein at the spot where the fingers were at first applied.

As blood is withdrawn, there is an alteration in the respirations, and the animal frequently sighs. There is dilation of the pupils, and the pulse is increased in rapidity. When these symptoms appear they are evidence of a sufficient quantity of blood having been withdrawn. If the process of withdrawal of blood be continued the animal will collapse and fall.

The next step is the closure of the wound. It is unnecessary to suture or otherwise treat the slit in the vessel wall. It usually happens that blood ceases to escape from the vessel as soon as the pressure upon the latter is removed. The cutaneous wound, however, should be closed by inserting a pin-suture. Care should be taken, whilst manipulating the skin for this purpose, not to separate the skin from the wall of the vein by applying too much traction. This would permit of blood escaping from the vein into the space between it and the panniculus muscle and 
skin, and the subsequent formation of a blood tumour or hæmatoma.

Septic inflammation of the vein, or Septic Phlebitis, may follow as a complication due to infection at the time of operating, or subsequently. This leads to the formation of a thrombus, which at first causes partial, but later complete obstruction of the lumen of the vessel. It is indicated externally by a swelling, which extends up the jugular furrow from the seat of operation. Systemic disturbances arise, the temperature running up to $104^{\circ}-105^{\circ} \mathrm{F}$, the animal shows no inclination to move the neck, and is the subject of anorexia. The method of treatment is to cast the animal and apply two ligatures to the vein, one just below the seat of operation, and the other above the superior limit of the elongated swelling. The intermediate part of the vein, with its contained thrombus, should then be carefully excised.

Febrifuges and antiseptics should be given internally, and food requiring little mastication, in order that the movements of the jaw may be restricted as much as possible.

\section{LYMPHATICS OF THE HEAD AND NECK}

All the lymph from the head and neck passes through the prepectoral lymphatic glands, and towards these glands therefore all the lymphatic vessels of this region are directed.

The Prepectoral Glands.-The prepectoral glands are found at the entrance to the chest on the deep face of the scalenus muscle, being therefore quite close to the jugular confluent. They are related also to the inner surface of the first rib.

The efferent vessels from the submaxillary, pharyngeal, the prescapular glands, and also from the chain of glands running along the carotid artery, discharge their contents into the prepectoral glands. 
The efferent vessels from the prepectoral glands of the right side help to form the accessory lymphatic duct (sometimes called the great lymphatic vein), whilst those from the left side empty themselves into the thoracic duct.

The Submaxillary Glands.-These are placed in the submaxillary space, in the grooves which are bounded externally by the inferior belly of the digastricus muscle and internally by the mylo-hyoid and subscapulo-hyoideus muscles.

A careful examination of the position, size, and relations of these glands is of extreme clinical importance, since their efferent vessels drain the lymph from the nasal cavities, the nostrils, the tongue, lips and cheeks; and enlargement of these glands is one of the first symptoms of infection of these important areas.

The Pharyngeal Glands. - These run across the side of the pharynx, below the guttural pouches. They frequently extend as far backwards as the thyroid bodies, and are deeply seated to the parotid glands.

The afferent vessels of the submaxillary group empty themselves into the pharyngeal glands. In fact all the lymph of the head passes through these latter glands, including that derived from a small gland embedded in the substance of the parotid. Four or five large afferent vessels are given off from these glands on either side, and these vessels follow the course of the carotid arteries. These lymphatic vessels present several small glands in their course, forming what is known as the "carotid chain" of glands. The vessels ultimately empty themselves into the prepectoral glands.

\section{Diseases of the Lymphatic Glands}

The pharyngeal lymphatic glands are frequently diseased. Enlargement and abscess formation in them is of common occurrence during the course of strangles, and may follow as a sequel any infection of 
the region of the pharynx, from whence the infection is easily spread to the glands.

There is great swelling of the glands, which causes much interference with the respirations and with deglutition, owing to pressure upon the pharyngeal wall. Evidences of enlargement of the glands make their appearance just below the ear, where they cause the thin, upper portion of the parotid to bulge outwardly, and also, and more frequently, near the postero-inferior end of the parotid, where the condition has advanced to those glands which extend towards the thyroid body. As infection progresses the chain of lymphatics along the course of the carotid artery becomes affected, and a long diffuse swelling makes its appearance in the jugular furrow.

The condition is easily distinguished from a swelling of the parotid gland, since the swelling in the case under consideration is much more ill-defined. The parotid gland is pushed outwardly, and careful manipulation will reveal the fact that its outline is better marked.

As in the case of abscess formation in the parotid the condition here quickly progresses, fluctuation may be readily detected; and unless a surgical outlet is made for the escape of the purulent contents, the abscess bursts.

From the relationship of the glands to the pharynx it will be readily understood that there is very little resistance to the pointing and bursting of the abscess towards the pharynx, and to the consequent discharge of its inflammatory contents into that chamber, with the result that pneumonia arises as a serious complication.

The surgical opening of the abscess is thus indicated at the earliest possible opportunity, and of the methods recommended probably that of Virborg is the one which is attended by least risk. The principle of this method is that, after the cutaneous incision has been made, the use of a sharp instrument is discarded, and the underlying structures broken down or separated by the operator's finger, 
which is insinuated in the direction or the abscess wall. When this is reached the wall is torn. The contents are usually discharged through such an opening made below the inferior border of the parotid gland, and thus quite clear of the large vessels. 


\section{MUSCLES OF THE HEAD AND NECK}

\begin{tabular}{|c|c|c|c|c|}
\hline MUSCLE & ORIGIN & INSERTION & ACTION & $\begin{array}{l}\text { NERVE- } \\
\text { SUPPLY }\end{array}$ \\
\hline $\begin{array}{l}\text { Aryteno-pharyn- } \\
\text { geus }\end{array}$ & $\begin{array}{l}\text { Arytenoid carti- } \\
\text { lage }\end{array}$ & Wall of pharynx & $\begin{array}{c}\text { Constrictor of } \\
\text { pharynx }\end{array}$ & $\begin{array}{c}\text { Pharyngeal } \\
\text { plexus }\end{array}$ \\
\hline Azygos uvulx & $\begin{array}{c}\text { Aponeurosis of } \\
\text { soft palate }\end{array}$ & $\begin{array}{l}\text { Free edge of soft } \\
\text { palate }\end{array}$ & $\begin{array}{l}\text { Raises free edge } \\
\text { of velum }\end{array}$ & $\begin{array}{l}\text { Spheno-palatine } \\
\text { ganglion ( } 7 \text { th } \\
\text { nerve) }\end{array}$ \\
\hline $\begin{array}{l}\text { Buccinator (su- } \\
\text { perficial divi- } \\
\text { sion) } \\
\text { Deep division }\end{array}$ & $\begin{array}{l}\text { Median raphe } \\
\text { Sup. \& inf. max- } \\
\text { illx }\end{array}$ & $\begin{array}{l}\text { Sup. \& inf. max- } \\
\text { illae } \\
\text { Angle of mouth }\end{array}$ & $\begin{array}{l}\text { In mastication } \\
\text { com presses } \\
\text { cheek against } \\
\text { teeth, or re- } \\
\text { tracts angle of } \\
\text { mouth }\end{array}$ & $7^{\text {th }}$ nerve \\
\hline $\begin{array}{l}\text { Cervico-auricu- } \\
\text { lares-Externus } \\
\text { Internus } \\
\text { Medius }\end{array}$ & $\begin{array}{l}\text { Ligamentum } \\
\text { nuchæ }\end{array}$ & $\begin{array}{l}\text { Conchal cartilage } \\
\text {-inner side } \\
\text { Conchal cartilage } \\
\text {-outer aspect } \\
\text { of base } \\
\text { Conchal cartilage } \\
\text { - posterior as- } \\
\text { pect of base }\end{array}$ & $\begin{array}{l}\text { In moderate con- } \\
\text { traction, give } \\
\text { openingof con- } \\
\text { cha an out- } \\
\text { ward direction. } \\
\text { In forcible con- } \\
\text { tractionincline } \\
\text { ear towards } \\
\text { poll }\end{array}$ & 7 th nerve \\
\hline Complexus & $\begin{array}{l}\text { Dorsal vertebrx, } \\
2 \text { nd, } 3 \text { rd \& } 4 \text { th } \\
\text { spines, trans- } \\
\text { verse processes } \\
\text { of first } 6 \text { or } 7 \text {, } \\
\text { cervical verte- } \\
\text { bra, articular } \\
\text { processes of } \\
\text { last six }\end{array}$ & Occipital bone & $\begin{array}{l}\text { Both muscles ex- } \\
\text { tend occipito- } \\
\text { atlantal joint. } \\
\text { Muscle of one } \\
\text { side will ele- } \\
\text { vate head and } \\
\text { turn to one } \\
\text { side }\end{array}$ & $\begin{array}{l}\text { Cervical and } \\
\text { dorsal nerves }\end{array}$ \\
\hline
\end{tabular}




\begin{tabular}{|c|c|c|c|c|}
\hline MUSCLE & ORIGIN & INSERTION & ACTION & $\begin{array}{l}\text { NERVE- } \\
\text { SUPPLY }\end{array}$ \\
\hline Crico-pharyngeus & Cricoid cartilage & Wall of pharynx & $\begin{array}{l}\text { Constrictor of } \\
\text { pharynx }\end{array}$ & $\begin{array}{l}\text { Sup. laryngeal } \\
\text { nerve }\end{array}$ \\
\hline $\begin{array}{l}\text { Depressor labii } \\
\text { inferioris }\end{array}$ & Inferior maxilla & Lower lip & $\begin{array}{l}\text { Depresses the } \\
\text { lower lip }\end{array}$ & 7 th nerve \\
\hline $\begin{array}{l}\text { Depressor labii } \\
\text { superioris }\end{array}$ & Pre-maxilla & Upper lip & $\begin{array}{l}\text { Assists orbicularis } \\
\text { oris by depress- } \\
\text { ing upper lip }\end{array}$ & 7 th nerve \\
\hline Disgastricus & $\begin{array}{l}\text { Styloid process of } \\
\text { occiput }\end{array}$ & Inf. maxilla & $\begin{array}{l}\text { Depresses the } \\
\text { lower jaw and } \\
\text { opens mouth }\end{array}$ & 7 th nerve \\
\hline $\begin{array}{l}\text { Dilatator naris } \\
\text { inferioris }\end{array}$ & $\begin{array}{l}\text { Pre-maxilla and } \\
\text { sup. maxilla }\end{array}$ & $\begin{array}{c}\text { False nostril and } \\
\text { maxillary tur- } \\
\text { binated bone }\end{array}$ & $\begin{array}{l}\text { Dilates the false } \\
\text { nostril }\end{array}$ & 7th nerve \\
\hline $\begin{array}{l}\text { Dilatator uaris } \\
\text { lateralis }\end{array}$ & Sup. maxilla & $\begin{array}{l}\text { Outer wing of } \\
\text { nostril }\end{array}$ & Dilates nostril & 7 th nerve \\
\hline $\begin{array}{l}\text { Dilatator naris } \\
\text { superioris }\end{array}$ & Septum nasi & $\begin{array}{c}\text { False nostril and } \\
\text { ethmoidal tur- } \\
\text { binated bone }\end{array}$ & $\begin{array}{l}\text { Dilates false nos- } \\
\text { tril }\end{array}$ & 7 th nerve \\
\hline $\begin{array}{l}\text { Dilatator naris } \\
\text { transversalis }\end{array}$ & $\begin{array}{l}\text { Cartilage of nos- } \\
\text { tril }\end{array}$ & $\begin{array}{l}\text { Corresponding } \\
\text { cartilage of } \\
\text { opposite side }\end{array}$ & Dilates nostril & $7_{\text {th nerve }}$ \\
\hline Dilatator pupillæ & $\begin{array}{l}\text { Attached edge of } \\
\text { curtain }\end{array}$ & Sphincter & Dilates pupil & Ciliary nerves \\
\hline Genio-glossus & $\begin{array}{l}\text { Inf. maxilla, near } \\
\text { symphysis }\end{array}$ & Tongue & $\begin{array}{l}\text { Upper fibres pro- } \\
\text { trude tongue } \\
\text { Lower fibres re- } \\
\text { tract tongue } \\
\text { Interm e diate } \\
\text { fibres depress } \\
\text { tongue }\end{array}$ & 12 th nerve \\
\hline
\end{tabular}




\begin{tabular}{|c|c|c|c|c|}
\hline MUSCLE & ORIGIN & INSERTION & ACTION & $\begin{array}{l}\text { NERVE- } \\
\text { SUPPLY }\end{array}$ \\
\hline Genio-hyoideus & $\begin{array}{l}\text { Inf. maxilla, near } \\
\text { symphysis }\end{array}$ & $\begin{array}{l}\text { Hyoid bone, glos. } \\
\text { sal process }\end{array}$ & $\begin{array}{l}\text { Pulls forwards the } \\
\text { hyoid bone }\end{array}$ & 12th nerve \\
\hline Hyo-glossus, great & $\begin{array}{l}\text { Glossal process, } \\
\text { body and thy- } \\
\text { roid cornu of } \\
\text { hyoid }\end{array}$ & Tongue & $\begin{array}{l}\text { Retracts and de- } \\
\text { presses tongue }\end{array}$ & 12th nerve \\
\hline $\begin{array}{c}\text { Hyo-glossus, } \\
\text { middle }\end{array}$ & $\begin{array}{l}\text { Hyoid, intercor- } \\
\text { nual joint }\end{array}$ & Tongue & $\begin{array}{l}\text { Feeble retractor } \\
\text { of tongue }\end{array}$ & 12th nerve \\
\hline Hyo-glossus, small & $\begin{array}{l}\text { Hyoid, small } \\
\text { cornu and body }\end{array}$ & Tongue & $\begin{array}{l}\text { Aids in retracting } \\
\text { the tongue }\end{array}$ & 1 2 th nerve \\
\hline Hyo-pharyngeus & $\begin{array}{l}\text { Hyoid, thyroid } \\
\text { cornu }\end{array}$ & Wall of pharynx & $\begin{array}{l}\text { Constricts the } \\
\text { pharynx }\end{array}$ & $\begin{array}{l}\text { Pharyngeal } \\
\text { plexus }\end{array}$ \\
\hline $\begin{array}{l}\text { Inter - transver- } \\
\text { sales colli }\end{array}$ & $\begin{array}{l}\text { Vertebrre, last five } \\
\text { cervical and ist } \\
\text { dorsal articular } \\
\text { processes }\end{array}$ & $\begin{array}{l}\text { Last six cervical } \\
\text { transverse pro- } \\
\text { cesses }\end{array}$ & $\begin{array}{l}\text { Bend the neck } \\
\text { laterally }\end{array}$ & Cervical nerves \\
\hline $\begin{array}{c}\text { Levator labii sup. } \\
\text { alæque nasi }\end{array}$ & $\begin{array}{l}\text { Frontal and nasal } \\
\text { bones }\end{array}$ & $\begin{array}{l}\text { Outer wing of } \\
\text { nostril, upper } \\
\text { lip, angle of } \\
\text { mouth (2 divs.) }\end{array}$ & $\begin{array}{l}\text { Dilates nostril } \\
\text { and elevates } \\
\text { upper lip by } \\
\text { anterior divi- } \\
\text { sion,raisesangle } \\
\text { of mouth by } \\
\text { posterior divi- } \\
\text { sion }\end{array}$ & $7^{\text {th }}$ nerve \\
\hline $\begin{array}{l}\text { Levator labii sup. } \\
\text { proprius }\end{array}$ & $\begin{array}{l}\text { Malar and suf. } \\
\text { max. bones }\end{array}$ & Upper lip & $\begin{array}{l}\text { Acting together } \\
\text { elevate upper } \\
\text { lip vertically }\end{array}$ & $7^{\text {th }}$ nerve \\
\hline Levator menti & Inf. maxilla & $\begin{array}{l}\text { Prominence of } \\
\text { chin }\end{array}$ & Elevates lower lip & $7^{\text {th }}$ nerve \\
\hline
\end{tabular}




\begin{tabular}{|c|c|c|c|c|}
\hline MUSCLE & ORIGIN & INSERTION & ACTION & $\begin{array}{l}\text { NERVE- } \\
\text { SUPPLY }\end{array}$ \\
\hline Levator palati & $\begin{array}{l}\text { Petrous temporal, } \\
\text { styloid process } \\
\text { and eustachian } \\
\text { tube }\end{array}$ & Soft palate & $\begin{array}{l}\text { Raises velum to- } \\
\text { wards roof of } \\
\text { pharynx and } \\
\text { shuts off com- } \\
\text { munication be- } \\
\text { tween pharynx } \\
\text { and nose }\end{array}$ & $\begin{array}{l}\text { Spheno - palatine } \\
\text { ganglion ( } 7 \text { th } \\
\text { nerve) }\end{array}$ \\
\hline $\begin{array}{l}\text { Levator palpe- } \\
\text { bræ super!oris }\end{array}$ & $\begin{array}{c}\text { Sphenoid above } \\
\text { optic foramen }\end{array}$ & Upper eyelid & $\begin{array}{l}\text { Opens eye by } \\
\text { raising upper } \\
\text { lid }\end{array}$ & $3^{\text {rd }}$ nerve \\
\hline Masseter & $\begin{array}{c}\text { Malar and sup. } \\
\text { m axill a ry } \\
\text { bones, zygo- } \\
\text { matic ridge }\end{array}$ & $\begin{array}{l}\text { Inf.maxill } d \text {, outer } \\
\text { surface of ver- } \\
\text { tical ramus }\end{array}$ & $\begin{array}{l}\text { Elevates lower } \\
\text { jaw and aids } \\
\text { mastication hy } \\
\text { bringing lower } \\
\text { teeth against } \\
\text { upper }\end{array}$ & $\begin{array}{l}\text { Sup. maxillary } \\
\text { division of } 5 \text { th } \\
\text { nerve }\end{array}$ \\
\hline $\begin{array}{l}\text { Mastoido-auricu- } \\
\text { laris }\end{array}$ & Auditory process & Conchal cartilage & $\begin{array}{l}\text { Telescopes con- } \\
\text { chal on annular } \\
\text { cartilage }\end{array}$ & 7 th nerve \\
\hline $\begin{array}{l}\text { Mastoido-hume- } \\
\text { ralis }\end{array}$ & $\begin{array}{c}\text { Mastoid process } \\
\text { and crest ; cer- } \\
\text { vical vertebræ, } \\
\text { Ist four trans- } \\
\text { verse processes }\end{array}$ & $\begin{array}{l}\text { Humerus, anterior } \\
\text { lip of musculo- } \\
\text { spiral groove }\end{array}$ & $\begin{array}{l}\text { Inward rotator of } \\
\text { shoulder. Ex- } \\
\text { tensor of shoul- } \\
\text { der }\end{array}$ & $\begin{array}{l}\text { Cervical nerves } \\
\text { and circumflex }\end{array}$ \\
\hline Mylo-hyoideus & $\begin{array}{l}\text { Inf. maxilla, hori- } \\
\text { zontal ramus }\end{array}$ & $\begin{array}{l}\text { Hyoid, body and } \\
\text { glossal process, } \\
\text { and median } \\
\text { raphe }\end{array}$ & $\begin{array}{l}\text { Raises the body } \\
\text { of tongue to } \\
\text { roof of mouth } \\
\text { and thus assists } \\
\text { in mastication } \\
\text { and deglutition }\end{array}$ & $\begin{array}{l}\text { Sup. maxillary } \\
\text { division of } 5 \text { th } \\
\text { nerve }\end{array}$ \\
\hline $\begin{array}{l}\text { Obliquus capitis } \\
\text { inferioris }\end{array}$ & Axis, spine & Atlas, wing & $\begin{array}{l}\text { Rotates the atlas } \\
\text { and head round } \\
\text { odontoid pro- } \\
\text { cess of axis }\end{array}$ & Cervical nerves \\
\hline
\end{tabular}


MUSCLES OF THE HEAD AND NECK

\begin{tabular}{|c|c|c|c|c|}
\hline MUSCLE & ORIGIN & INSERTION & ACTION & $\begin{array}{l}\text { NERVE- } \\
\text { SUPPLY }\end{array}$ \\
\hline $\begin{array}{l}\text { Obliquus capitis } \\
\text { superioris }\end{array}$ & Atlas, wing & $\begin{array}{r}\text { Occipital bone } \\
\text { mastoid crest } \\
\text { styloid proces: }\end{array}$ & $\begin{array}{l}\text { Inclines the head } \\
\text { on the atlas } \\
\text { and slightly } \\
\text { extends it }\end{array}$ & Cervical nerves \\
\hline $\begin{array}{c}\text { Obliquus oculı } \\
\text { inferioris }\end{array}$ & $\begin{array}{l}\text { Fossa of lachry- } \\
\text { mal bone }\end{array}$ & Sclerotic coat & $\begin{array}{l}\text { Pivots the eyeball } \\
\text { downwardsand } \\
\text { outwards }\end{array}$ & $3^{\text {rd }}$ nerve \\
\hline $\begin{array}{l}\text { Obliquus oculi } \\
\text { superioris }\end{array}$ & $\begin{array}{l}\text { Sphenoid, near } \\
\text { optic foramen }\end{array}$ & Sclerotic coat & $\begin{array}{l}\text { Pivots the eyeball } \\
\text { inwards and } \\
\text { upwards }\end{array}$ & $4^{\text {th }}$ nerve \\
\hline Occipito-styloid & $\begin{array}{l}\text { Occipital, styloid } \\
\text { process }\end{array}$ & $\begin{array}{l}\text { Hyoid, styloid } \\
\text { cornu }\end{array}$ & $\begin{array}{l}\text { Flexes temporo- } \\
\text { hyoideal joint } \\
\text { and carries hy- } \\
\text { oid bone and } \\
\text { parts attached } \\
\text { backwards }\end{array}$ & $7^{\text {th }}$ nerve \\
\hline Orbicularis oris & Surrounds mouth & & $\begin{array}{l}\text { Approximates the } \\
\text { lips }\end{array}$ & $7^{\text {th }}$ nerve \\
\hline $\begin{array}{c}\text { Orbicularis pal- } \\
\text { pebrarum }\end{array}$ & $\begin{array}{l}\text { Lachrymal bone, } \\
\text { tubercle }\end{array}$ & $\begin{array}{l}\text { Surrounds palpe- } \\
\text { bral fissure }\end{array}$ & $\begin{array}{l}\text { Closes eye by } \\
\text { approximating } \\
\text { free edge of } \\
\text { eyelids }\end{array}$ & $7^{\text {th }}$ nerve \\
\hline Palato-glossus & Soft palate & Ends in tongue & $\begin{array}{l}\text { Narrows the } \\
\text { fauces }\end{array}$ & $\begin{array}{l}\text { Spheno-palatine } \\
\text { ganglion ( } 7 \text { th } \\
\text { nerve) }\end{array}$ \\
\hline Panniculus & $\begin{array}{l}\text { At lower part of } \\
\text { neck, carini- } \\
\text { form cartilage }\end{array}$ & $\begin{array}{l}\text { Fibrous raphe to } \\
\text { muscle of op- } \\
\text { posite side }\end{array}$ & $\begin{array}{l}\text { Braces the mus- } \\
\text { cles over which } \\
\text { it is spread and } \\
\text { may help in } \\
\text { depressing the } \\
\text { n eck with } \\
\text { mastoido - hu- } \\
\text { meralis }\end{array}$ & $\begin{array}{l}\text { Cervical branch } \\
\text { of } 7 \text { th cranial } \\
\text { nerve }\end{array}$ \\
\hline
\end{tabular}




\begin{tabular}{|c|c|c|c|c|}
\hline MUSCLE & ORIGIN & INSERTION & ACTION & $\begin{array}{l}\text { NERVE- } \\
\text { SUPPLY }\end{array}$ \\
\hline $\begin{array}{r}\begin{array}{l}\text { Palato-pharyn- } \\
\text { geus }\end{array}\end{array}$ & Soft palate & Wall of pharyux & $\begin{array}{l}\text { Tenses the velum } \\
\text { and carries free } \\
\text { edge up to- } \\
\text { wards pharynx }\end{array}$ & Pharyngeal plexus \\
\hline $\begin{array}{l}\text { Paricto - auricu- } \\
\text { laris externus }\end{array}$ & $\begin{array}{l}\text { Crest of parietal } \\
\text { bone }\end{array}$ & $\begin{array}{l}\text { Conchal and scu- } \\
\text { tiform carti- } \\
\text { lages }\end{array}$ & Pricks the ear & ith nerve \\
\hline $\begin{array}{l}\text { Parieto - auricu- } \\
\text { laris internus }\end{array}$ & $\begin{array}{l}\text { Crest of parietal } \\
\text { bone }\end{array}$ & Conchal cartilage & $\begin{array}{l}\text { Brings ear into } \\
\text { erect position }\end{array}$ & $7^{\text {th }}$ nerve \\
\hline $\begin{array}{l}\text { Parotido - auricu- } \\
\quad \text { laris }\end{array}$ & Parotid gland & $\begin{array}{l}\text { Conchal cartilage } \\
\text { (base) }\end{array}$ & $\begin{array}{l}\text { Depresses the ear } \\
\text { outwards }\end{array}$ & 7 th nerve \\
\hline $\begin{array}{l}\text { Pterygoideus in- } \\
\text { ternus }\end{array}$ & $\begin{array}{l}\text { Sphenoid and pa- } \\
\text { latine bones }\end{array}$ & $\begin{array}{l}\text { Inf. maxilla, inner } \\
\text { surface of ver- } \\
\text { tical ramus }\end{array}$ & $\begin{array}{c}\text { Elevates lower } \\
\text { ja w. One } \\
\text { muscle acting } \\
\text { alone produces } \\
\text { lateral move- } \\
\text { ment }\end{array}$ & $\begin{array}{l}\text { Sup. maxillary di- } \\
\text { vision of } 5^{\text {th }} \\
\text { nerve }\end{array}$ \\
\hline $\begin{array}{l}\text { Pterygoideus ex- } \\
\text { ternus }\end{array}$ & Sphenoid bone & $\begin{array}{l}\text { Inf. maxilla } \\
\qquad \text { (neck) }\end{array}$ & $\begin{array}{l}\text { Right and left } \\
\text { muscles acting } \\
\text { simultaneously } \\
\text { cause lower in- } \\
\text { cisors to pro- } \\
\text { trude in front } \\
\text { of upper. } \\
\text { Muscle of one } \\
\text { side a ting } \\
\text { alone throws } \\
\text { enti re inf. } \\
\text { maxilla to op- } \\
\text { posite side }\end{array}$ & $\begin{array}{l}\text { Inf. maxillary di- } \\
\text { vision of } 5^{\text {th }} \\
\text { nerve }\end{array}$ \\
\hline $\begin{array}{l}\text { Pterygo -pharyn- } \\
\text { geus }\end{array}$ & Pterygoid process & Wall of pharynx & $\begin{array}{c}\text { Constrictor of } \\
\text { pharynx }\end{array}$ & Pharyngeal plexus \\
\hline
\end{tabular}




\begin{tabular}{|c|c|c|c|c|}
\hline MUSCLE & ORIGIN & INSERTION & ACTION & $\begin{array}{l}\text { NERVE- } \\
\text { SUPPLY }\end{array}$ \\
\hline $\begin{array}{l}\text { Rectus capitis an- } \\
\text { ticus major }\end{array}$ & $\begin{array}{l}\text { Cervical verte- } \\
\text { brr, } 3 \text { rd, } 4 \text { th, } \\
5^{\text {th }} \text { transverse } \\
\text { processes }\end{array}$ & $\begin{array}{l}\text { Occipital (basilar } \\
\text { process) and } \\
\text { body of sphe- } \\
\text { noid }\end{array}$ & $\begin{array}{l}\text { Right and left } \\
\text { muscles acting } \\
\text { together, flex } \\
\text { the head. One } \\
\text { muscle acting } \\
\text { alone inclines } \\
\text { head to same } \\
\text { side. }\end{array}$ & Cervical nerves \\
\hline $\begin{array}{l}\text { Rectus capitis } \\
\text { posticus major }\end{array}$ & Axis (spine) & Occipital & $\begin{array}{l}\text { Extends head on } \\
\text { atlas }\end{array}$ & Cervical nerves \\
\hline $\begin{array}{l}\text { Rectus capitis } \\
\text { posticus minor }\end{array}$ & Atlas (ring) & Back of occipital & $\begin{array}{l}\text { Extends head on } \\
\text { atlas }\end{array}$ & Cervical nerves \\
\hline $\begin{array}{l}\text { Rectus capitis } \\
\text { lateralis }\end{array}$ & Atlas & $\begin{array}{c}\text { Styloid process of } \\
\text { occipital }\end{array}$ & $\begin{array}{l}\text { Flexor of occipito- } \\
\text { atlantal joint }\end{array}$ & Cervical nerves \\
\hline $\begin{array}{l}\text { Rectus oculi ex- } \\
\text { ternus }\end{array}$ & $\begin{array}{l}\text { Sphenoid, near } \\
\text { optic foramen }\end{array}$ & Sclerotic coat & $\begin{array}{l}\text { Rolls eyeball out- } \\
\text { wards round } \\
\text { vertical axis }\end{array}$ & 6th nerve \\
\hline $\begin{array}{l}\text { Rectus oculi in- } \\
\text { ternus }\end{array}$ & $\begin{array}{l}\text { Sphenoid, near } \\
\text { optic foramen }\end{array}$ & Sclerotic coat & $\begin{array}{l}\text { Rolls eyeball in- } \\
\text { wards round } \\
\text { vertical axis }\end{array}$ & $3^{\text {rd }}$ nerve \\
\hline Rectus oculi inf. & $\begin{array}{l}\text { Sphenoid, near } \\
\text { optic foramen }\end{array}$ & Sclerotic coat & $\begin{array}{l}\text { Rolls e yeball } \\
\text { dow nwards } \\
\text { round horizon- } \\
\text { tal transverse } \\
\text { axis }\end{array}$ & $3^{\text {rd }}$ nerve \\
\hline Rectus oculi sup. & $\begin{array}{c}\text { Sphenoid, near } \\
\text { optic foramen }\end{array}$ & Sclerotic coat & $\begin{array}{r}\text { Rolls eyeball up- } \\
\text { wards round } \\
\text { hor } \mathrm{iz} \text { on } \mathrm{tal} \\
\text { transverse axis }\end{array}$ & $3^{\text {rd nerve }}$ \\
\hline
\end{tabular}




\begin{tabular}{|c|c|c|c|c|}
\hline MUSCLE & ORIGIN & INSERTION & ACTION & $\begin{array}{l}\text { NERVE- } \\
\text { SUPPLY }\end{array}$ \\
\hline Retractor oculi & $\begin{array}{l}\text { Margin of optic } \\
\text { foramen }\end{array}$ & Sclerotic & $\begin{array}{l}\text { Pulls e y e ball } \\
\text { directly back- } \\
\text { wards into or- } \\
\text { bital cavity and } \\
\text { thus protrudes } \\
\text { t he me m- } \\
\text { brana nectitans }\end{array}$ & $\begin{array}{l}3^{\text {rd, }} 4^{\text {th }} \text {, and } 6 \text { th } \\
\text { nerves }\end{array}$ \\
\hline Scalenus & $\begin{array}{l}\text { Cervical verte- } \\
\text { brat, last four } \\
\text { transverse pro- } \\
\text { cesses }\end{array}$ & $\begin{array}{l}\text { First rib (two } \\
\text { insertions) }\end{array}$ & $\begin{array}{l}\text { Pulls forwards or } \\
\text { fixes first rib } \\
\text { and thus aids } \\
\text { in inspiration. } \\
\text { When rib is } \\
\text { fixed point } \\
\text { muscles flex } \\
\text { neck or if one } \\
\text { only acis, in- } \\
\text { clines neck to } \\
\text { same side }\end{array}$ & Cervicals \\
\hline $\begin{array}{l}\text { Scuto-auricularis } \\
\text { externus }\end{array}$ & $\begin{array}{l}\text { Scutiform carti- } \\
\text { lage (outer sur- } \\
\text { face) } \\
i\end{array}$ & Conchal cartilage & $\begin{array}{l}\text { Assists parieto- } \\
\text { auricularis ex- } \\
\text { ternusiuprick- } \\
\text { ing ear }\end{array}$ & 7 th nerve \\
\hline $\begin{array}{l}\text { Scuto-auricularis } \\
\text { internus }\end{array}$ & $\begin{array}{l}\text { Scutiform carti- } \\
\text { lage (inner sur- } \\
\text { face) }\end{array}$ & Conchal cartilage & $\begin{array}{l}\text { Opposes scuto- } \\
\text { auricularis ex- } \\
\text { ternus and } \\
\text { assists retahen- } \\
\text { tes in rotating } \\
\text { concha to turn } \\
\text { opening out- } \\
\text { wards and } \\
\text { backwards }\end{array}$ & 7 th nerve \\
\hline Semispinales colli & $\begin{array}{l}\text { Cervicalvertebra } \\
3 \text { rd to } 7 \text { th arti- } \\
\text { cular processes }\end{array}$ & $\begin{array}{l}\text { Cervical vertebra } \\
\text { 2nd to } 6 \text { th } \\
\text { spines }\end{array}$ & $\begin{array}{l}\text { Both musclesact- } \\
\text { ing together } \\
\text { extend or ele- } \\
\text { vate cervical } \\
\text { part of spinal } \\
\text { column. One } \\
\text { muscle acting } \\
\text { singly, rotates } \\
\text { and inclines } \\
\text { spinal column } \\
\text { toopposite side }\end{array}$ & Cervicals \\
\hline
\end{tabular}




\begin{tabular}{|c|c|c|c|c|}
\hline MUSCLE & ORIGIN & INSERTION & ACTION & $\begin{array}{l}\text { NERVE- } \\
\text { SUPPLY }\end{array}$ \\
\hline $\begin{array}{l}\text { Small stylo- } \\
\text { pharyngeus }\end{array}$ & $\begin{array}{l}\text { Hyoid, styloid } \\
\text { (great) cornu }\end{array}$ & IVall of pharynx & $\begin{array}{l}\text { Constrictor of } \\
\text { pharynx }\end{array}$ & Pharyngeal plexus \\
\hline Sphincter pupillæ & A narrow band a & round pupil, and & close to posterior & surface of curtain \\
\hline Splenius & $\begin{array}{l}\text { Dorsal vertebrx, } \\
2 \text { nd, } 3 \text { rd, and } \\
4 \text { th spines and } \\
\text { tunicular part } \\
\text { of ligamentum } \\
\text { nuch }\end{array}$ & $\begin{array}{l}\text { Mastoid crest, } \\
\text { wing of atlas } \\
\text { and transverse } \\
\text { processes of } \\
\text { 2nd to } 5 \text { th cer- } \\
\text { vical vertebrx }\end{array}$ & $\begin{array}{l}\text { Both musclesact- } \\
\text { ing together, } \\
\text { elevateheadand } \\
\text { neck. Acting } \\
\text { singly incline } \\
\text { head and neck } \\
\text { to side of act- } \\
\text { ing muscle }\end{array}$ & $\begin{array}{l}\text { Cervical and dor- } \\
\text { sal nerves }\end{array}$ \\
\hline Stapedius & $\begin{array}{l}\text { Within the pyra- } \\
\text { mid (small pro- } \\
\text { cess of bone at } \\
\text { back of tym- } \\
\text { panum) }\end{array}$ & $\begin{array}{l}\text { Into the neck of } \\
\text { stapes, tendon } \\
\text { of insertion } \\
\text { c on t a ins a } \\
\text { small nucleus } \\
\text { of bone }\end{array}$ & $\begin{array}{l}\text { Regulates move- } \\
\text { ments of stapes }\end{array}$ & Branch of 7 th \\
\hline Sterno-maxillaris & $\begin{array}{l}\text { Sternum, carini- } \\
\text { form cartilage }\end{array}$ & $\begin{array}{l}\text { Inf. maxilla } \\
\text { (angle) }\end{array}$ & $\begin{array}{c}\text { Depresses head or } \\
\text { gives it lateral } \\
\text { inclination }\end{array}$ & It th nerve \\
\hline $\begin{array}{l}\text { Sterno-thyro- } \\
\text { hyoideus }\end{array}$ & $\begin{array}{l}\text { Sternum, carini- } \\
\text { form cartilage }\end{array}$ & $\begin{array}{l}\text { Thyroid cartilage } \\
\text { and body of } \\
\text { hyoid bone }\end{array}$ & $\begin{array}{r}\text { Depresses hyoid } \\
\text { bone and larynx }\end{array}$ & 1st cervical \\
\hline Stylo-glossus & $\begin{array}{l}\text { Great cornu of } \\
\text { hyoid }\end{array}$ & Ends in tongue & $\begin{array}{l}\text { Retracts tongue } \\
\text { (both), acting } \\
\text { singly draws } \\
\text { tongue to one } \\
\text { side }\end{array}$ & I 2 th nerve \\
\hline Stylo-hyoid & $\begin{array}{l}\text { Creat cornu of } \\
\text { hyoid }\end{array}$ & Thyroid cornu & $\begin{array}{l}\text { Carries base of } \\
\mathrm{t} \cap \mathrm{ng} \mathrm{g} \text { e a } 11 \mathrm{~d} \\
\text { larynxupward. } \\
\text { and backwards }\end{array}$ & 7 th nerve \\
\hline
\end{tabular}




\section{THE SURGICAL ANATOMY OF THE HORSE}

\begin{tabular}{|c|c|c|c|c|}
\hline MUSCLE & ORIGIN & INSERTION & ACTION & $\begin{array}{l}\text { NERVE- } \\
\text { SUPPLY }\end{array}$ \\
\hline Stylo-maxillaris & $\begin{array}{l}\text { Occipital styloid } \\
\text { process }\end{array}$ & $\begin{array}{l}\text { Inf. maxilla } \\
\text { (angle) }\end{array}$ & $\begin{array}{l}\text { Depresses lower } \\
\text { jaw and assists } \\
\text { in opening } \\
\text { mouth }\end{array}$ & 7 th nerve \\
\hline Stylo-pharyngeus & $\begin{array}{l}\text { Styloid cornu of } \\
\text { hyoid }\end{array}$ & Wall of pharynx & $\begin{array}{l}\text { Dilates anterior } \\
\text { part of pharynx }\end{array}$ & 9th nerve \\
\hline $\begin{array}{l}\text { Subscapulo- } \\
\text { hyoideus }\end{array}$ & Subscapular fascia & Body of hyoid & $\begin{array}{l}\text { Depresses hyoid } \\
\text { bone }\end{array}$ & Ist cervical \\
\hline Temporalis & $\begin{array}{l}\text { Parictal, frontal, } \\
\text { squamous tem- } \\
\text { poral and sphe- } \\
\text { noid bones }\end{array}$ & $\begin{array}{l}\text { Inf. maxillary, co- } \\
\text { ronoid process } \\
\text { and ant. border }\end{array}$ & $\begin{array}{l}\text { Elevates lower } \\
\text { jaw acting } \\
\text { with masseter } \\
\text { and external } \\
\text { pterygoid, also } \\
\text { opposes action } \\
\text { of int. ptery- } \\
\text { goid }\end{array}$ & $\begin{array}{l}\text { Inf. maxillary di- } \\
\text { vision of } 5 \text { th } \\
\text { nerve }\end{array}$ \\
\hline Tensor palati & $\begin{array}{l}\text { Styloid process of } \\
\text { petrous tempo- } \\
\text { ral and eusta- } \\
\text { chian tube }\end{array}$ & $\begin{array}{l}\text { Hamular process, } \\
\text { and fibrous apo- } \\
\text { neurosis of pa- } \\
\text { late }\end{array}$ & $\begin{array}{l}\text { Makes tense an- } \\
\text { terior half of } \\
\text { palate }\end{array}$ & $\begin{array}{l}\text { Otic ganglion } \\
5^{\text {th nerve }}\end{array}$ \\
\hline Tensor tympani & $\begin{array}{l}\text { Petrous temporal, } \\
\text { near eustachian } \\
\text { orifice }\end{array}$ & $\begin{array}{l}\text { Handle of mal- } \\
\text { leus, near its } \\
\text { root }\end{array}$ & $\begin{array}{l}\text { Makes tense mem- } \\
\text { brana tympani }\end{array}$ & $\begin{array}{l}\text { From 5th nerve } \\
\text { through otic } \\
\text { ganglion }\end{array}$ \\
\hline $\begin{array}{l}\text { Thyro- } \\
\text { arytenoideus }\end{array}$ & $\begin{array}{l}\text { Inrer surface of } \\
\text { thyroid wing, } \\
\text { near junction } \\
\text { with body, and } \\
\text { crico - thyroid } \\
\text { membrane }\end{array}$ & $\begin{array}{l}\text { Lower fibres are } \\
\text { inserted into } \\
\text { outer surface of } \\
\text { arytenoid car- } \\
\text { tilage }\end{array}$ & $\begin{array}{l}\text { Diminishes ten- } \\
\text { sion of vocal } \\
\text { chord, by act- } \\
\text { ing on crico- } \\
\text { thyroid joint }\end{array}$ & $\begin{array}{l}\text { Inf. laryngeal (re- } \\
\text { current) nerve }\end{array}$ \\
\hline
\end{tabular}




\begin{tabular}{|c|c|c|c|c|}
\hline MUSCLE & ORIGIN & INSERTION & ACTION & $\begin{array}{l}\text { NERVE- } \\
\text { SUPPLY }\end{array}$ \\
\hline Thyro-hyoideus & $\begin{array}{l}\text { Thyroid cornu } \\
\text { of hyoid }\end{array}$ & $\begin{array}{l}\text { Oblique line on } \\
\text { outer surface of } \\
\text { thyroid wing }\end{array}$ & $\begin{array}{l}\text { Acting alone, } \\
\text { elevate larynx } \\
\text { between thy- } \\
\text { roid cornu. } \\
\text { When acting } \\
\text { with sterno- } \\
\text { thyroid, thy- } \\
\text { roid cartilage } \\
\text { is steadied and } \\
\text { acts as fixed } \\
\text { point for crico- } \\
\text { thyroid and } \\
\text { thyroid-aryte- } \\
\text { noid muscles }\end{array}$ & Recurrent nerve \\
\hline $\begin{array}{r}\text { Thyro-pharyn- } \\
\text { geus }\end{array}$ & Thyroid cartilage & Roof of pharynx & $\begin{array}{l}\text { Constrictor of } \\
\text { pharynx }\end{array}$ & Pharyngeal plexus \\
\hline $\begin{array}{l}\text { Trachelo-mas- } \\
\text { toideus }\end{array}$ & $\begin{array}{c}\text { Dorsal vertebra, } \\
\text { Ist and 2nd } \\
\text { transverse pro- } \\
\text { cesses. Cervi- } \\
\text { cal vertebrx, } \\
\text { last six articu- } \\
\text { lar processes }\end{array}$ & $\begin{array}{l}\text { Mastoid crest and } \\
\text { wing of atlas }\end{array}$ & $\begin{array}{l}\text { Acting singly, } \\
\text { bends neck la- } \\
\text { rerally. Both } \\
\text { acting, extend } \\
\text { occipito-atlan- } \\
\text { tal articulation } \\
\text { (elevatethehead) }\end{array}$ & $\begin{array}{l}\text { Cervical and dor- } \\
\text { sal nerves }\end{array}$ \\
\hline $\begin{array}{l}\text { Trapesius } \\
\text { 1.-Cervical }\end{array}$ & $\begin{array}{l}\text { Funicular part of } \\
\text { lig. nuchæ }\end{array}$ & $\begin{array}{l}\text { Scapula, tubercle } \\
\text { of spine, and } \\
\text { aponeurosis on } \\
\text { outer scapular } \\
\text { muscles }\end{array}$ & $\begin{array}{l}\text { Cervical trapesius, } \\
\text { draws scapula } \\
\text { upwards and } \\
\text { furwards }\end{array}$ & Spinal accessory \\
\hline 2.-Dorsal & $\begin{array}{l}\text { Ant. dorsal spines } \\
\text { or s u Pra - } \\
\text { spinous liga- } \\
\text { ments }\end{array}$ & $\begin{array}{l}\text { Scapula, tubercle } \\
\text { of spine }\end{array}$ & $\begin{array}{l}\text { Dorsal trapesius } \\
\text { draws scapula } \\
\text { backwards and } \\
\text { upwards }\end{array}$ & Spinal accessory \\
\hline $\begin{array}{l}\text { Zygomatico-auri- } \\
\text { cularis }\end{array}$ & $\begin{array}{l}\text { Squamous tem- } \\
\text { poral bone, zy- } \\
\text { gomatic crest }\end{array}$ & $\begin{array}{l}\text { Scutiform and } \\
\text { conchal carti- } \\
\text { lages }\end{array}$ & To prick the ear & 7 th nerve \\
\hline Zygomaticus & $\begin{array}{l}\text { Surface of masse- } \\
\text { ter muscle }\end{array}$ & $\begin{array}{l}\text { B uccinator } \\
\text { muscle above } \\
\text { angle of mouth }\end{array}$ & $\begin{array}{c}\text { To raise the angle } \\
\text { of the mouth }\end{array}$ & $7^{\text {th }}$ nerve \\
\hline
\end{tabular}




\section{TABLE OF NERVES OF HEAD AND NECK}

I.-Crariat.

A.-Camplex.

Glosso-pharyngeal, gth.

Glossal branch (special sense)

Pharyngeal.

Pnumogastric, toth.

Communicating branches

Superior laryngeal / pharyngeal

Superior laryngeal / motor

Inferior laryngeal or recurrent

Branches to thoracic plexus

" " " ganglia

Esophageal fgastric branches

(sup. and inf.) (branch to solar plexus.

Pars trigemini, 5th.

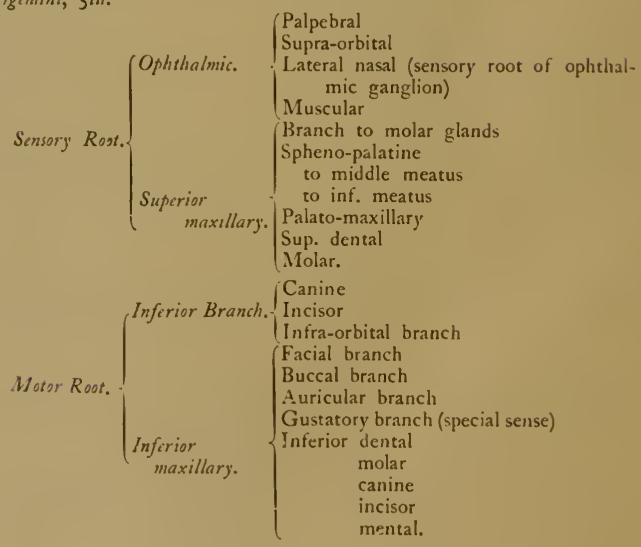


B.-Special Sense.

Olfactory, Ist

Optic, 2nd

Portio mollis, 8th.

C. - Motor.

Motor oculi, 3rd muscular motor root to ophthalmic ganglion

Pathetic or trochlear, $4^{\text {th }}$

Abducens, 6th

Spinal accessory, I Ith

Lingual, 12th.

D.-Sensory.

Portio dura, 7 th

Tympanic

Petrosal

Facial

Chorda tympani.

II.-Cervical.

\section{Chorda cympani.}

Ist, Sub- - lauriches to sup. cervical ganglion

occipital branches to neighbouring nerves muscular branches, \&c.

2nd, muscular branches, \&ic.

$3^{\text {rd, }} 4^{\text {th }}$, and 5 th, muscular and phrenic branches

6 th, 7 th, and 8 th, muscular branches and axillary tranches and communicating branches to inferior cervical ganglion. 






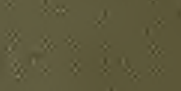

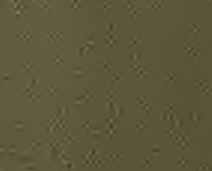

$3 x=8$
$x^{4}=0=8$

$\overline{8}$

83

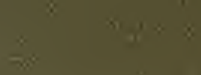

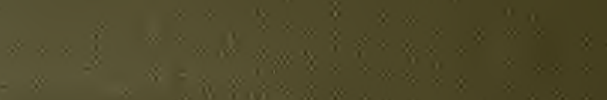

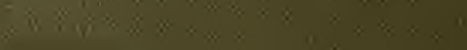

